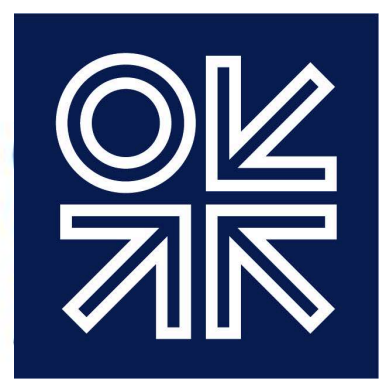

THE OXFORD

INSTITUTE

FOR ENERGY

STUDIES

July 2019

\title{
Gas Production from the UK Continental Shelf:
}

\section{An Assessment of Resources, Economics and Regulatory Reform}

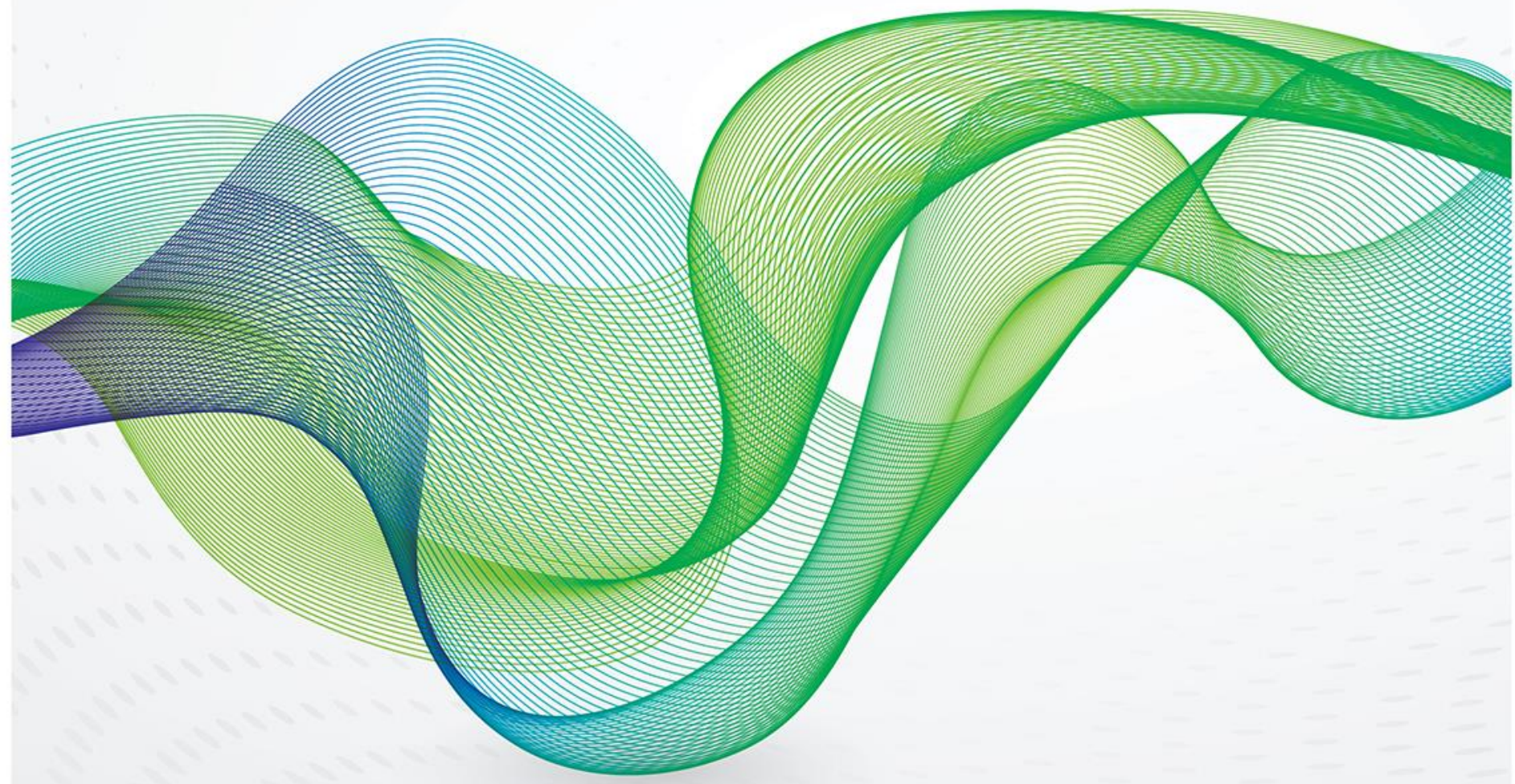



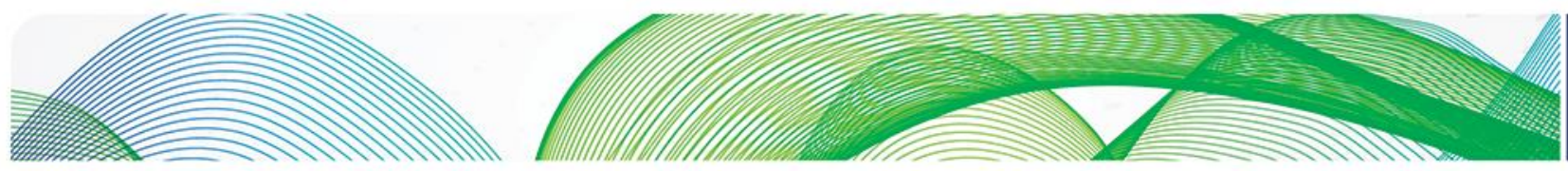

\section{잊조}

The contents of this paper are the author's sole responsibility. They do not necessarily represent the views of the Oxford Institute for Energy Studies or any of its members.

Copyright $\odot 2019$

Oxford Institute for Energy Studies

(Registered Charity, No. 286084)

This publication may be reproduced in part for educational or non-profit purposes without special permission from the copyright holder, provided acknowledgment of the source is made. No use of this publication may be made for resale or for any other commercial purpose whatsoever without prior permission in writing from the Oxford Institute for Energy Studies.

ISBN: 978-1-78467-141-9

DOI: https://doi.org/10.26889/9781784671419 

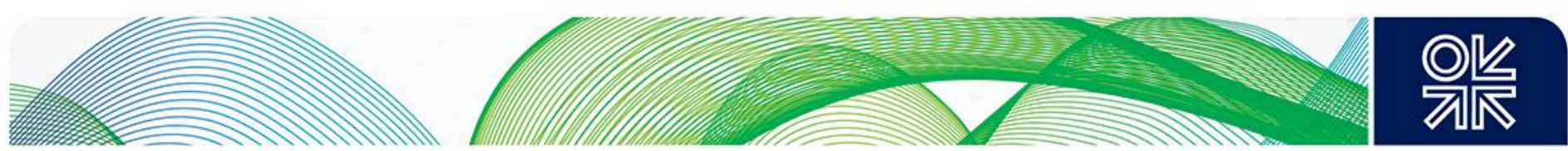

\begin{abstract}
The outlook for oil and gas production on the UKCS has improved dramatically since 2015 due to the industry's successful commissioning of large-scale projects, its efforts to reduce costs and to improve its operational performance, the bold reduction in tax rates in 2016 and the adoption in law of a new statutory objective to achieve the maximum economic recovery of UKCS resources (MER UK). The new regulator, the Oil and Gas Authority (OGA), has so far acted mainly as a behavioural regulator, without using its formal regulatory powers, but it has signalled its willingness to intervene more actively to overcome the obstacles to MER UK. The hard economics of UKCS investment (costs, prices and taxes) are likely to be the main determinants of future investment and resource recovery since the UKCS will remain a relatively high-cost producing province. Maintaining a competitive, stable tax regime and rigorous industry cost control will be essential for MER UK. The OGA may be able to influence the course of future oil and gas production through prudent use of its powers, especially in less mature regions such as West of Shetland, but preventing 'premature' decommissioning of gas infrastructure in mature areas and the 'stranding' of known resources will be a constant challenge. Promoting a sustained recovery in exploration activity from recent lamentable levels is perhaps the most urgent task facing the OGA.
\end{abstract}

An estimated 10-20 billion boe of oil and gas remains to be produced from the UKCS. The improved industry outlook has led to upward revisions in the last four years of estimates of both future production and ultimately recoverable resources (URR). However, future production and URR remain highly sensitive to the course of oil prices, the development of unsanctioned, marginal discoveries and future exploration in the 2020s. The prospects for UKCS gas production are intimately linked to those of oil since two-thirds of UKCS gas production is now associated gas. In recent years, UKCS gas production (41 bcm in 2018) has exceeded short-term projections by the OGA. Following the start-up of the Culzean field in 2019 and the recent discovery of Glendronach and Glengorm, output is expected to remain at about $40 \mathrm{bcm}$ per year until 2021 before resuming its long-term decline. Gross production is expected to fall to about $33 \mathrm{bcm}$ in 2024. The current range of published estimates of output in $2035(8-20 \mathrm{bcm})$ reflects the geological and economic uncertainties over future exploration and investment rather than conventional cost-based competition with imported gas. MER UK is compatible with the UK's 'net zero emissions' target in 2050 providing the UKCS does not in future incur policy-related emissions costs not faced by imported supplies. 

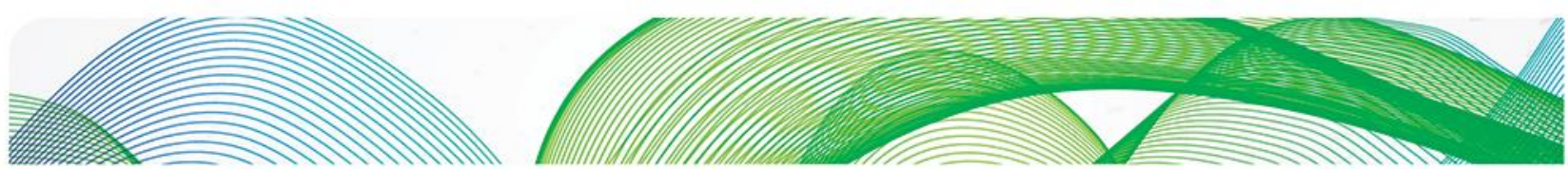

\section{O败}

\section{Units of Measurement}

$\mathrm{mcm} \quad$ million cubic metres

mcm pa million cubic metres per annum

bcm billion cubic metres

bcm pa billion cubic metres per annum

bbl barrel ( 1 cubic metre $=6.29$ barrels)

mboe million barrels oil equivalent

mboe/d million barrels oil equivalent per day

bn boe billion barrels oil equivalent

bcf billion cubic feet

\$/mBTU US dollars per million British Thermal Units

$\mathrm{MJ} / \mathrm{m}^{3} \quad$ megajoules per cubic metre 


\section{Contents}

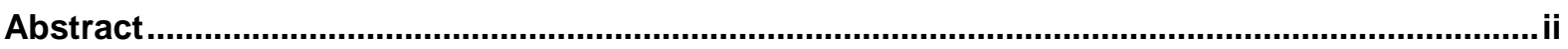

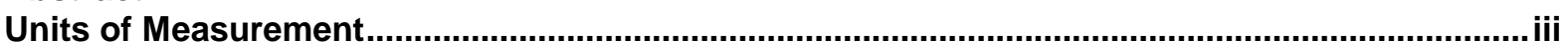

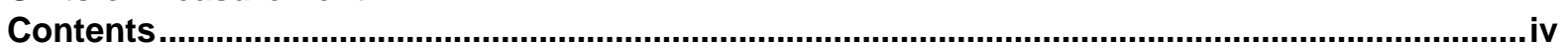

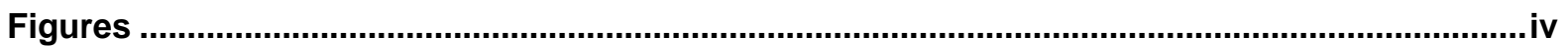

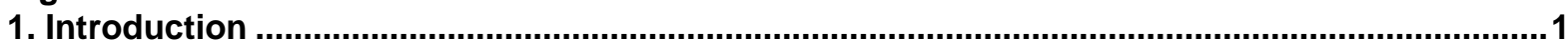

2. Background: A Short History of UKCS Gas Development …...............................................

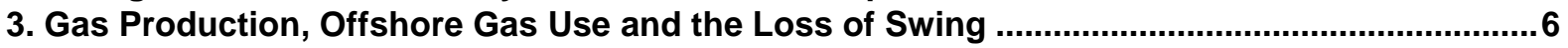

4. Economics of UKCS Production: Profitability, Costs and Taxation..........................................8

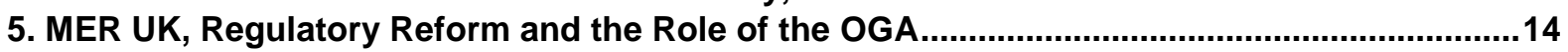

6. Projections of Future UK Gas Production..........................................................................18

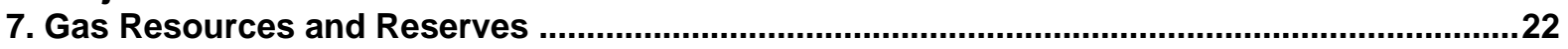

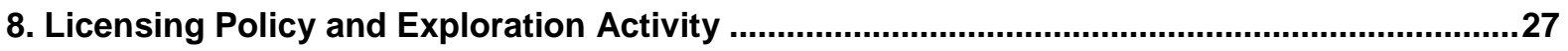

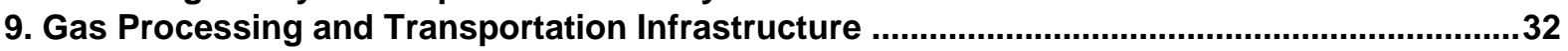

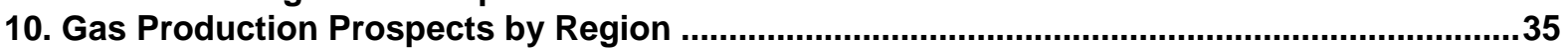

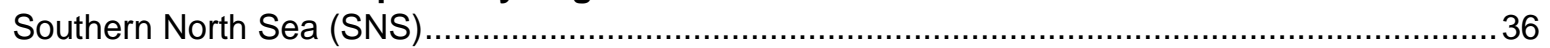

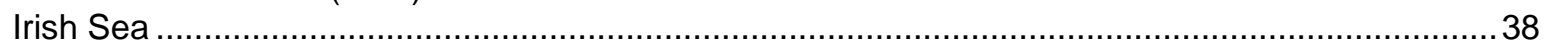

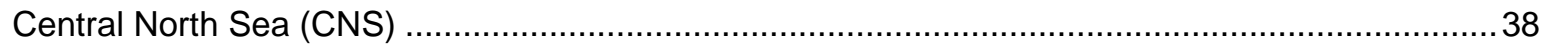

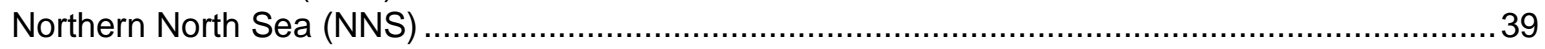

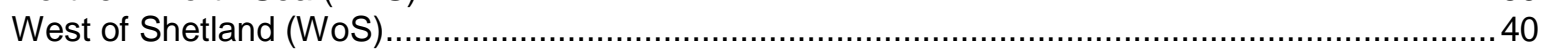

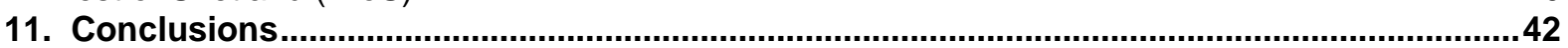

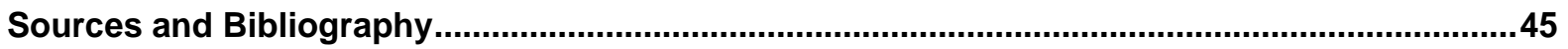

\section{Figures}

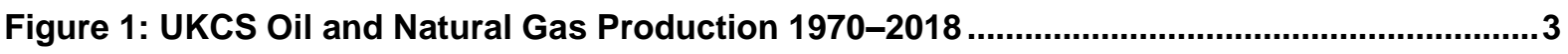

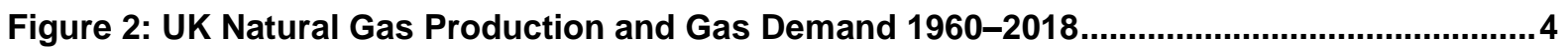

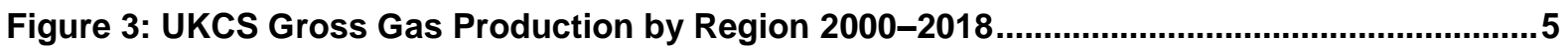

Figure 4: Monthly Production of Associated and Dry Gas Jan 2010-Dec 2018 ..........................8

Figure 5: Indicative Profitability of UKCS Industry 1Q 2000-4Q 2018.......................................

Figure 6: UKCS Unit Operating Costs (UOC) and Brent Oil Price 2005-18 .................................10

Figure 7: Government Tax Revenues from the UKCS 2004-2018............................................12

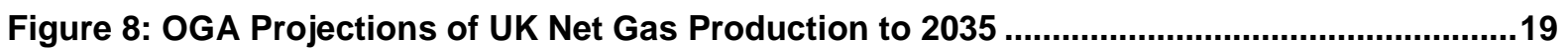

Figure 9: National Grid's UKCS Gas Supply Projections (FES 2018) .......................................20

Figure 10: Projections of UKCS Oil and Gas Production 2015-2050 ......................................21

Figure 11: Projections of Cumulative UKCS Production to 2050 .............................................22

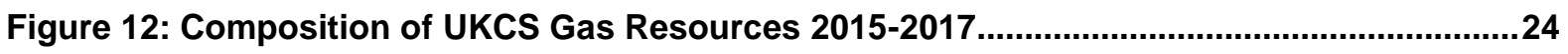

Figure 13: Cumulative UKCS Gas Production and Remaining Reserves 1973-2017 .................24

Figure 14: Distribution of UK Gas Reserves and Resources at End of 2017 ............................25

Figure 15: Gas Reserves and Resources by Field Type at End of 2017 ...................................26

Figure 16: UKCS Exploration and Appraisal Wells Drilled 1965-2018 .......................................29

Figure 17: Exploration and Appraisal Wells Drilled by Region 2000-18 ...................................29

Figure 18: Discovered Resource Additions through Exploration 2005-18.................................30

Figure 19: Main UK Offshore and Onshore Gas Infrastructure .............................................31

Figure 20: UKCS Gross Gas Production Projections by Region 2010-2024 ..............................35

Figure 21: Central North Sea Gross Gas Production 2010-2024 ............................................39

Figure 22: West of Shetland Oil and Gas Resources ............................................................. 41 

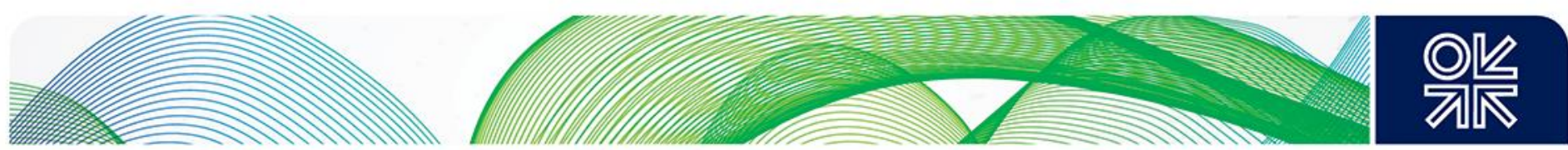

\section{Introduction}

The UK offshore industry has recently been through an exceptional period of legal and regulatory reform following the publication in 2014 of the Wood Review on maximising economic recovery (MER UK) of oil and gas resources on the UK Continental Shelf (UKCS). These reforms established MER UK as a statutory objective for all UKCS operations and created a new regulator, the Oil and Gas Authority (OGA), to implement the reforms and to achieve the new statutory objective. They were accompanied in 2016 by fiscal reforms which reduced tax rates to ensure the UKCS remains attractive for new investment. The regulatory and fiscal reforms coincided with a period of lower oil and gas prices which caused severe financial pressure on UKCS producers and supply companies alike and forced operators to urgently address their cost base. The sharp contraction in discretionary expenditure in 2015-16 and forecasts of persistently low oil prices led some commentators to anticipate the imminent end of North Sea oil and gas production, the early decommissioning of producing fields and the likely failure to recover the 10-20 million barrels oil equivalent (mboe) of oil and gas estimated to remain on the UKCS. Since then, the outlook has improved significantly. Between 2014 and 2018, the UKCS industry reduced its unit operating costs by $50 \%$ in dollar terms, assisted by a weaker pound and a $20 \%$ increase in total production. By 2017 , there were clear signs of a recovery in investment, project activity and asset acquisition; in late 2018 and early 2019 the improving outlook was reinforced by two significant gas discoveries, Glendronach and Glengorm.

As the new regulatory regime takes shape and industry activity recovers, we examine the possible impact of the new statutory objective of MER UK on future gas production from the UKCS. The paper also assesses whether the OGA's current projections of gas production to 2035 are plausible and achievable and examines the risks and issues underlying the projections.

The paper focuses on natural gas, which accounts for more than $40 \%$ of total UKCS hydrocarbon production (1.77 mboe/d in 2018) and about $30 \%$ of the remaining proven and probable reserves $(5.4$ billion boe) and contingent resources ( 7.5 billion boe). Oil and gas production are intimately linked and co-dependent in many parts of the UKCS, so the medium-term prospects for UKCS gas production are closely linked to those of oil. Gas production is distinguished from oil production by its greater dependence on offshore and onshore infrastructure, the regional nature of gas pricing and the constant policy debate over security of gas supply, which does not apply to oil in the same way. MER UK does not differentiate between oil and gas resources but the impact of the new regulatory regime on future production may not be felt equally by oil and gas.

Section 2 describes briefly the history of the development of the UKCS and long-term production trends and Section 3 summarises the main features of UK offshore gas use and production; those familiar with the UKCS upstream industry may wish to skip these sections. Subsequent sections discuss the key determinants (revenues, costs and taxes) of the economics of UKCS production, the recent regulatory reforms, the OGA's projections of future gas production, the gas resource base, licensing and exploration activity and offshore and onshore gas infrastructure. Section 10 then sets out the prospects for gas production in each of the five major regions of the UKCS and the last section sets out the main conclusions of the paper.

The paper draws only on published information, supplemented by interviews with offshore and onshore operators and the OGA. It does not address the prospects for onshore UK shale gas production, which may make a modest contribution to UK output in the future if the resumption of hydraulic fracturing in 2018 produces commercially favourable and environmentally acceptable results. Nor does it cover the ultimate potential of biomethane, already injected on a small scale into the GB gas transmission network. 

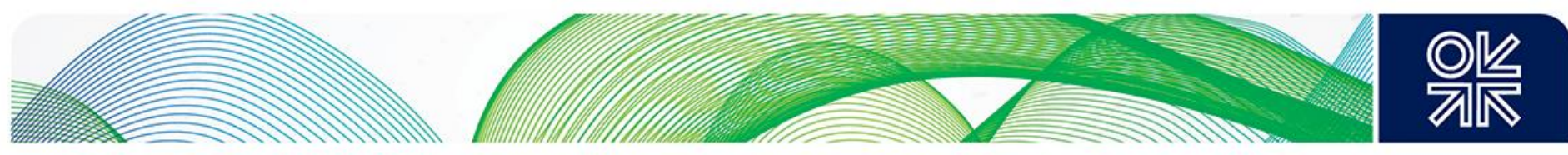

The progressive decarbonisation of the UK economy to 2050 and the role of natural gas, or decarbonised gas, in meeting the UK's 2050 emissions targets is beyond the scope of this paper. So too is the role that depleted offshore fields may play in future carbon capture and storage projects. In the short term, gas remains the default marginal fuel for the UK economy, facilitating the continuing expansion of low carbon sources of energy by providing flexibility and back-up generation capacity, as well as providing an important degree of national energy supply security. The current position of natural gas as the largest source in the UK energy mix, accounting for almost $40 \%$ of primary inland energy demand, is attributable largely to the discovery of indigenous natural gas resources on the UKCS in the 1960s and 1970s. We expect that the future rate of decline of indigenous UKCS gas production as resources are depleted will influence the role that gas plays in heating, industry and electricity generation as UK decarbonisation proceeds through the 2020s and 2030s towards the new net zero emissions target in 2050.

\section{Background: A Short History of UKCS Gas Development}

Production of natural gas on the UK Continental Shelf (UKCS) began in 1967 when the West Sole gas field, discovered by BP in 1965, delivered its first gas from the shallow waters of the Southern North Sea (SNS) to Bacton in eastern England. After the discovery of other large gas fields such as Leman, Indefatigable and Hewett, it was soon evident that the SNS would be able to meet all UK demand for natural gas for many years. These fields were developed successively under long-term supply contracts negotiated with the state-owned Gas Council (renamed the British Gas Corporation in 1972) which was at the time the sole buyer of gas for the domestic market. ${ }^{1}$ In the early years of the offshore industry, gas from the North Sea displaced both town gas manufactured from coal or oil and smaller volumes of imported natural gas. The development of offshore resources was accompanied by the expansion by the British Gas Corporation of its onshore infrastructure and the creation of end-user markets for this new indigenous resource. The process of converting the entire GB market from town gas to lower-cost natural gas from the North Sea began in 1968 and was largely completed by 1975. The UK gas market grew from $15 \mathrm{bcm}$ in 1970, mainly of town gas, to $35 \mathrm{bcm}$ in 1975 , of which natural gas supplied $33 \mathrm{bcm} .{ }^{2}$ Total UK gas use continued to expand almost every year thereafter until it finally stalled in 1987-1990 at about $55 \mathrm{bcm}$ per year.

Exploration success in the SNS stimulated activity in the Central North Sea (CNS) which produced the discovery of the giant Forties oil field in 1970 and the first production of oil from the field in 1975 . The rise in international oil prices in 1973-74 and 1978-80 provided a huge stimulus to new exploration and to the development of new oil discoveries in the CNS and the Northern North Sea (NNS). As offshore activity in the North Sea moved northwards, gas production moved from the Triassic, Permian and Carboniferous plays of the SNS, where gas discoveries were largely dry with a high proportion of methane, to the younger Jurassic and Cretaceous age rocks of the CNS and NNS, where most gas was associated with oil. The first gas produced from the NNS and delivered to the onshore gas terminal at St. Fergus in Scotland came from the Frigg field in 1977. The first gas from the CNS was associated gas from the Piper field delivered via the same pipeline. Later, the development of the huge Brent field underpinned the construction in the FLAGS gas pipeline which brought its associated gas ashore in 1982 to a new terminal at St Fergus. ${ }^{3}$ Gas production from the CNS and NNS lagged that of oil throughout the 1980s since it was constrained by the size of the growing domestic market for gas and the need to remunerate the cost of construction of new gas infrastructure to bring associated gas ashore. Gas was discovered in the Irish Sea in 1974 and the first production of dry gas from the Morecambe South field began in 1985.

\footnotetext{
'The Official History of North Sea Oil and Gas' (2012) in two volumes by Alex Kemp provides a comprehensive account of the early development of the UKCS, in particular the negotiation of the early gas contracts.

2 BEIS historical gas database: gas production and consumption and fuel input 1920-2017, July 2018

3 'The Resurgence of UK Gas Production', Michael Stoppard, OIES 1994, provides a thorough, concise account of UKCS gas development and the 'dash for gas' in electricity generation in the early 1990s.
} 

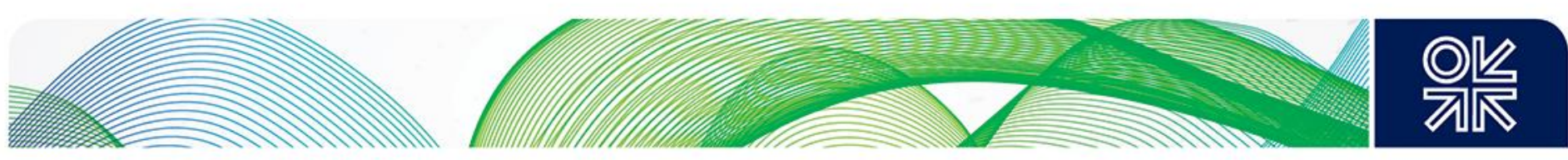

Figure 1: UKCS Oil and Natural Gas Production 1970-2018

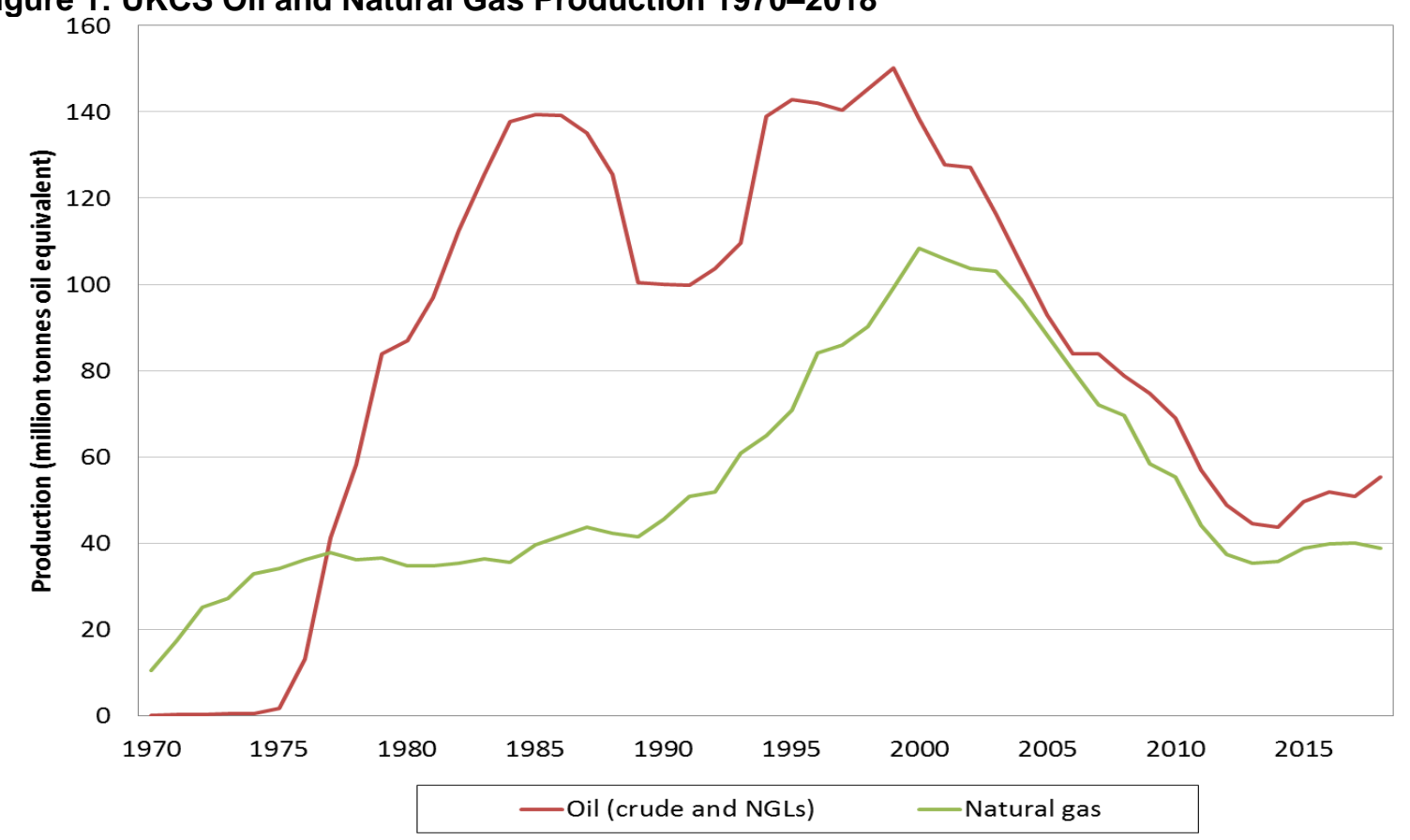

Source: BEIS, 2019

Since the beginning of production in the CNS and NNS, oil and gas have been closely linked through the co-production of liquids and associated gas. However, aggregate production of liquids and gas has followed contrasting patterns, as shown in Figure 1. Oil field development and production were determined by market economics and short-term revenue maximisation without regard to the domestic UK energy market since there was no restriction on oil exports. Stimulated by the oil price rises of 1973-74 and 1978-80, oil production reached an initial peak of $2.7 \mathrm{mb} / \mathrm{d}$ in 1985 before falling back following the collapse in oil prices in 1986 and the sharp contraction of UKCS investment in subsequent years. Liquids output reached a new peak of $2.9 \mathrm{mb} / \mathrm{d}$ in 1999 as new gas infrastructure allowed the development of large gas condensate fields through the 1990s and the tie-in of progressively smaller discoveries into existing infrastructure to replace declining output from older oil fields.

Gas production followed a very different path, dictated by the gradual reform of the onshore UK markets for gas and electricity. Until the development of the Markham field in 1992, all UKCS gas production was landed in the UK. Production was constrained between about 1975 and 1990 by the size of the domestic market, the lack of offshore infrastructure, the British Gas monopsony, the lack of commercial third-party access to its transmission infrastructure and regulated domestic gas prices which encouraged producers to pursue oil developments in preference to gas projects. These early constraints on gas sales often required development plans for fields with both oil and gas resources to re-inject gas and to defer gas sales; sometimes this led later to sub-optimal hydrocarbon recovery over the life of producing fields. The influence of traded gas prices on the development and production of UKCS gas is much less evident than the influence of oil prices on the development of oil resources.

The UK gas market went through a phased liberalisation in the 1990s as the monopoly position of British Gas in purchasing, transmission and supply was whittled away between 1988 and 1995 and third parties gained commercial access to its infrastructure. UKCS producers began to market their own gas to industrial end-users and power generators and field development decisions gradually became less dependent on long-term contracts. The 'dash for gas' in the newly-privatised power generation sector raised the domestic demand for gas dramatically (see Figure 2) and accelerated the development of existing discoveries and new fields. By 1995, the UK market had become acutely 

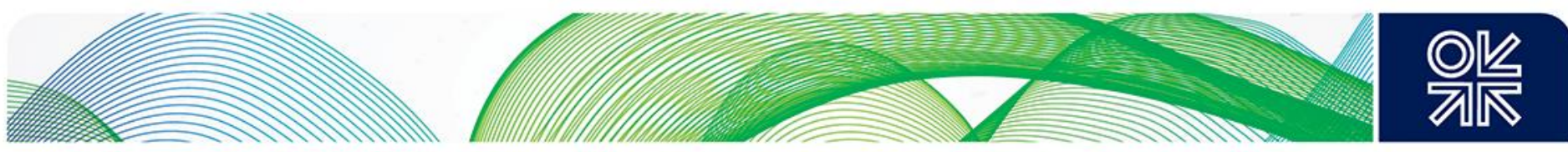

over-supplied. Spot prices fell below long-term contract prices, putting ultimately unsustainable pressure on British Gas's long-term sales contracts and leading producers to search for export markets in continental Europe. The successful development of the hub gas market at the National Balancing Point (NBP) of the regulated GB transmission network completed the process of liberalisation of pricing and marketing of UKCS gas by allowing resource holders to bring their gas to market more quickly without the need to negotiate long-term contracts. This liberalisation of gas and power markets and the opening of the Bacton-Zeebrugge Interconnector in 1998 allowed UKCS gas production to expand rapidly from $48 \mathrm{bcm}$ in 1990 to a peak of $115 \mathrm{bcm}$ in 2000, a year later than the peak in oil production.

Figure 2: UK Natural Gas Production and Gas Demand 1960-2018

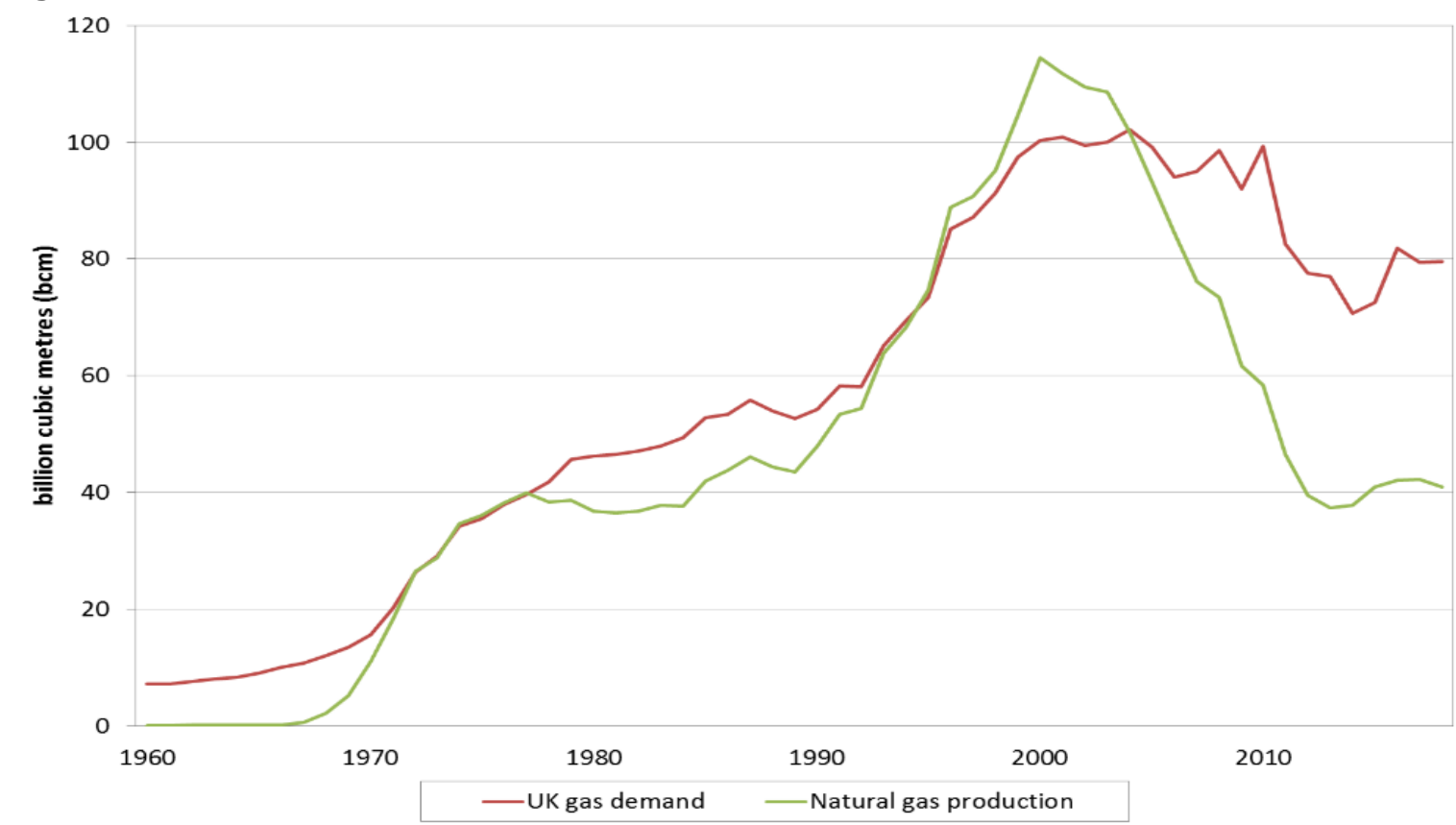

Source: DECC/BEIS annual data

From this near-coincident peak in 1999-2000 until 2013-14, both oil and gas production followed a very similar path of decline associated with progressive depletion of developed resources, diminishing exploration activity, very few sizeable new discoveries and a gradual trend towards higher unit operating costs exacerbated after 2010 by the plateau in oil prices above $\$ 100 / \mathrm{bbl}$ in 2011-14.

An essential feature of the development of the UKCS oil and gas resources after 1979 was the absence of any explicit resource management policy dictated by legislation or decided by government. Exploration and development were conducted within a legislative and fiscal framework but field development decisions and depletion of resources were determined essentially by market forces and commercial decisions of the licence holders and operators. The responsible government department ${ }^{4}$ approved individual development projects but relied upon competition for upstream acreage and commercial behaviour of operators to dictate the pace and timing of resource development, including the balance between oil and gas. In the case of gas resources, development of UKCS resources could proceed only through negotiations between mainly privately-owned licence holders and British Gas, which held a legal monopoly on purchases of gas for the domestic market until 1982. After the successive privatisations of BNOC/Britoil (1982-85), British Gas (1986) and BP (1987), the state had no direct or indirect upstream equity participation in the UKCS. The government

\footnotetext{
${ }^{4}$ Department of Trade and Industry (DTI) 1970-2007, Department for Business, Enterprise and Regulatory Reform (BERR) 2007-09, Department for Energy and Climate Change (DECC) 2008-16 and the Department for Business, Energy and Industrial Strategy (BEIS) 2016-19.
} 

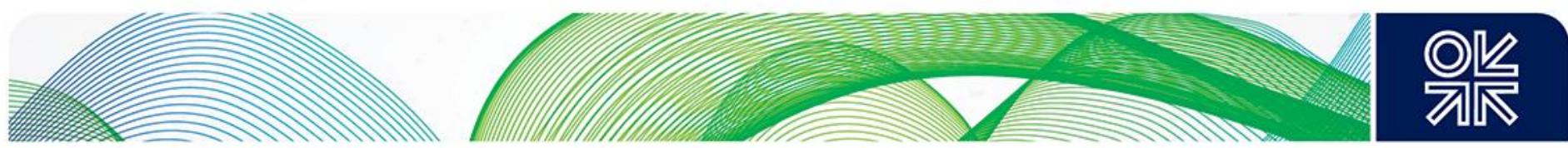

simply relied upon its energy department to act as the licensor and regulator of offshore operations. This UK model stands in stark contrast to the development of resources on the adjacent Norwegian Continental Shelf (NCS) where the state played a direct, determinative role, backed by a stable legislative framework, from the very beginning in the 1960s.

Figure 3 shows the decline in gas production from each of the main regions of the UKCS from 2000 to 2017 based on receipts of gas at onshore terminals. Output of dry gas from the SNS and the Irish Sea peaked in 2000 while output of predominantly associated gas from the CNS and NNS peaked slightly later in 2002-03. The chart shows two periods of accelerated decline in UKCS gas output. The first occurred in 2004-07 when output from all areas (and almost all major producing fields) fell sharply due to gradual, and usually expected, depletion at mature fields and very few new projects started production. This phase of decline was largely anticipated by the industry and prompted investment to construct new gas import pipelines from Norway (Langeled) and the Netherlands (BBL) and to build or to expand LNG regas capacity at Milford Haven and the Isle of Grain. The two pipelines started operations in 2006 and the LNG regas terminals were commissioned in 2008-09.

Figure 3: UKCS Gross Gas Production by Region 2000-2018

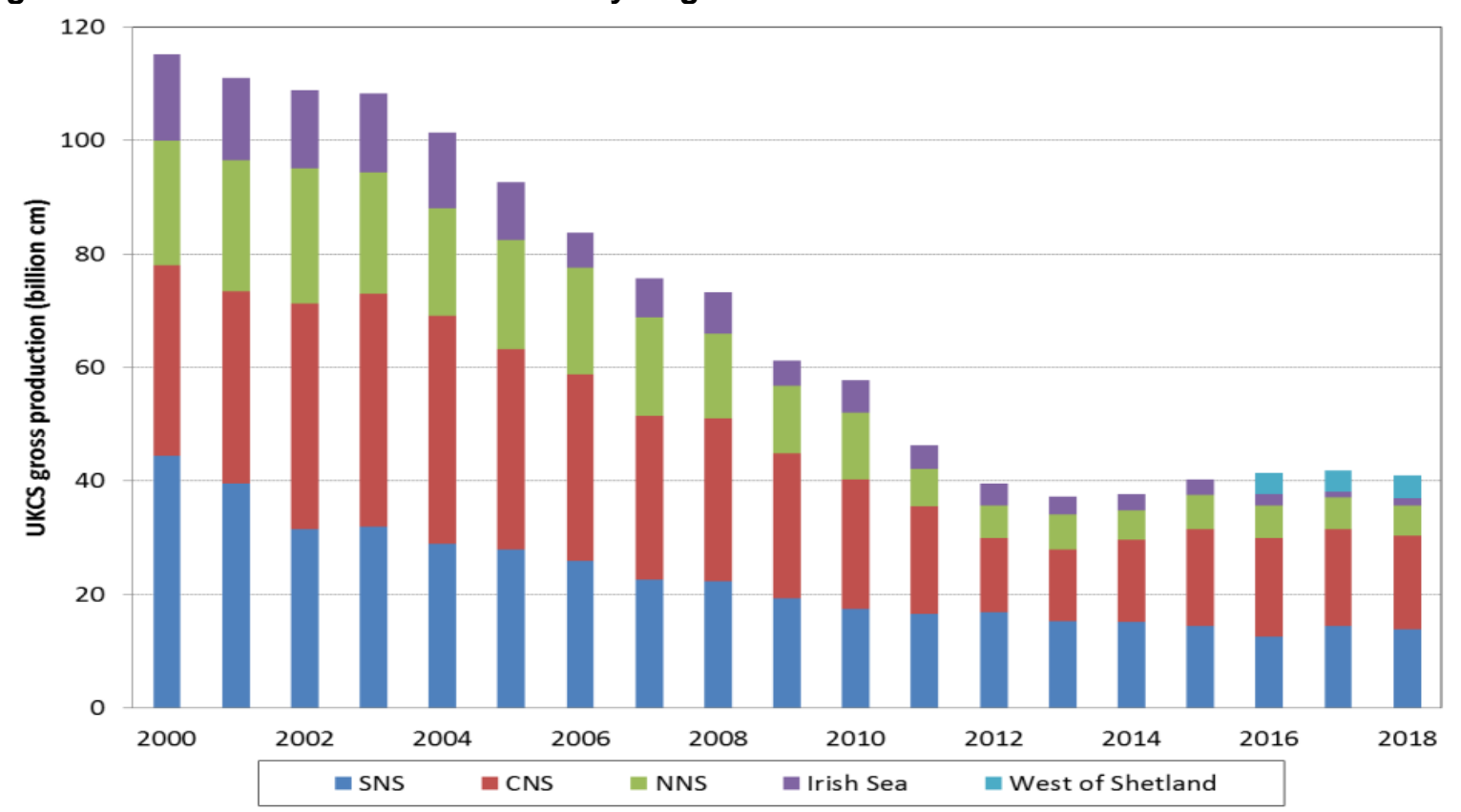

Source: UK DUKES data for 2000-2017 and BEIS monthly data for 2018

The second phase of accelerated contraction occurred in 2011-13 when deteriorating asset reliability and a series of accidents, particularly at gas condensate fields in the CNS, led to an unexpected decline in gross output to a 30-year low of $37.3 \mathrm{bcm}$ in 2013. It was the emerging picture of poor offshore operating performance, increasing asset unreliability and falling tax revenues which led the Secretary of State for Energy, Ed Davey, in June 2013 to commission Sir lan Wood to undertake his review of the UKCS industry.

Since 2013, UKCS gas production has recovered slightly to $42.1 \mathrm{bcm}$ in 2017 and about $41 \mathrm{bcm}$ in 2018. This modest rebound is not the result of the Wood Review itself, nor of the creation of the OGA. It is attributable mainly to remedial work undertaken by operators to restore productive capacity and reliable operations and the start-up of new fields such as Cygnus (SNS) and the Laggan and Tormore gas condensate fields west of Shetland in 2016. These fields alone accounted for more than $5 \mathrm{bcm}$ of production in 2017. The decision in 2010 by Total to develop Laggan-Tormore and to construct the Shetland Gas Plant to process the gas was a critical step in the development of the UK gas resources. When production began in 2016, it marked the first time that significant volumes of gas from fields west of Shetland (WoS) had been brought ashore. Before then, all almost gas produced 

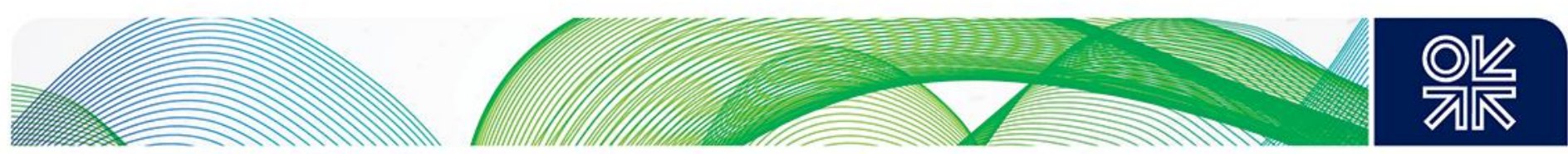

west of Shetland had been used as fuel offshore, re-injected locally or transported via Shetland to the Magnus field in the NNS for enhanced oil recovery (EOR). ${ }^{5}$ Since Laggan-Tormore began production, Total has tied in two other fields, Edradour and Glenlivet, and the recent Glendronach discovery is expected to add to production from the area delivered to Shetland and St Fergus after 2020.

\section{Gas Production, Offshore Gas Use and the Loss of Swing}

In 2017, gross production of natural gas in the UK was $42.1 \mathrm{bcm}$ (464.9 TWh). The aggregate figure comprises $41.9 \mathrm{bcm}$ from 305 offshore fields and $0.2 \mathrm{bcm}$ from 35 small, conventional onshore fields. Offshore gas production is now dominated by small fields connected via offshore hubs to pipeline systems; only six fields reported production of more than $1 \mathrm{bcm}$ in 2017. ${ }^{6}$ Net production of gas in 2017, after deduction of $4.3 \mathrm{bcm}$ used by operators in their upstream operations ('producers' own use'), amounted to $37.8 \mathrm{bcm}$. Gross production includes producers' own use but excludes gas reinjected into reservoirs and gas vented or flared under consents issued by the OGA. ${ }^{7}$ Both the reported aggregate gross and net production figures refer to marketable dry gas meeting the quality specifications of the onshore transmission network, not the wellhead flows of wet and dry gas which contain not only methane but also natural gas liquids (NGLs) extracted at onshore gas processing terminals. ${ }^{8}$

Gas is produced offshore from a wide range of reservoir types and a huge range of facilities and infrastructure types, reflecting in part the developments in offshore technology over the last 50 years. Almost two thirds of gross production (28 bcm in 2017) is estimated to be associated gas produced from oil fields or gas condensate fields. The remaining non-associated gas (14 bcm) came from dry gas fields, found mainly in the SNS and Irish Sea. Associated gas is generally separated from liquids at offshore platforms and transported ashore in dedicated gas pipelines but the development of multiphase transportation has permitted in some cases the transportation of both liquids and gas in the same pipeline. The most common production system in the SNS and Irish Sea is the small steel platform. Elsewhere on the UKCS, sub-sea tie-backs, usually connected to an adjacent platform, are the most common system for production of oil and gas and normally have lower operating costs than fixed platforms.

An estimated $35 \mathrm{bcm}$ of the net production of $37.8 \mathrm{bcm}$ in 2017 entered the onshore National Transmission System (NTS) operated by National Grid. The only offshore production not to enter the NTS is the gas from producing fields in the most southerly part of the SNS connected to the Dutch offshore network (1.2 bcm in 2017) and some deliveries from onshore UK terminals direct to industrial end-users and power generators. In 2017, gross production included $0.7 \mathrm{bcm}$ of gas from the Rough field which was granted approval to cease storage operations in 2017 and began to produce the estimated $4 \mathrm{bcm}$ of the recoverable cushion gas.

Gas produced offshore has three possible uses: as fuel for offshore operations, re-injection into the source (or adjacent) reservoir or delivery ashore for commercial sale. UK production data record total use in upstream operations including onshore processing terminals $(4.3 \mathrm{bcm})$ but the data is not available by field or pipeline system. The total quantity of gas re-injected into producing fields is not published by BEIS or the OGA. This means that is it not possible to construct even a rudimentary offshore gas balance for the UKCS as a whole, for particular areas or for individual fields. Unlike Norway, where reinjection volumes are available by field, offshore flows of gas remain largely undisclosed on the UKCS. Partial, unverified field data submitted to the OGA show that in 2017

\footnotetext{
${ }^{5}$ From 2003, some gas from west of Shetland oil fields transported to Magnus was re-directed to St Fergus when the Magnus EOR project was not in operation.

6 The six fields were Britannia, Franklin, Laggan, Rhum, Statfjord and Cygnus.

7 Gross production data exclude gas re-injected into reservoirs, gas vented or flared and occasional unauthorised leaks or releases. Gas may be flared temporarily at producing facilities and terminals by consent granted by the OGA. In 2017, gas flared at offshore installations was reported to be $1.39 \mathrm{bcm}$. The volume of vented gas is not reported.

${ }^{8}$ In 2017, NGLs extracted from UKCS production were 3.45 million tonnes (approx. $109 \mathrm{~kb} / \mathrm{d}$ ). The onshore terminals at St Fergus and Teesside accounted for an estimated $57 \%$ of these NGLs.
} 

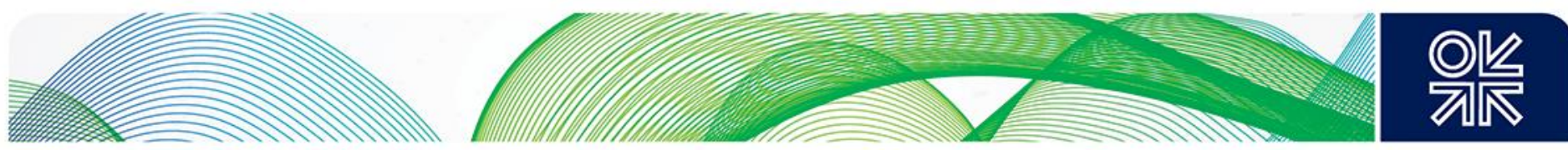

$1.7 \mathrm{bcm}$ of gas was re-injected at producing oil fields, mainly in the CNS and the NNS, or at fields producing through Floating Production, Storage and Offloading units (FPSOs). These data suggest that gas re-injection has now become a marginal activity on the UKCS, even in the mature parts of the CNS and NNS.

Early in the development of the CNS and NNS, the discovery of oil fields with associated gas at a time of limited gas pipeline capacity and a limited UK gas market led to the enforced re-injection of gas into producing reservoirs. Similarly, the first oil fields developed west of Shetland in the 1990s were obliged to re-inject any gas beyond their fuel needs given the restrictions on gas flaring. Unfortunately, there are no reliable time series data for gas re-injection. As offshore gas infrastructure developed in the North Sea in the 1980 and 1990s, fewer sources of gas lacked an economic route to market and gas was subsequently usually produced for sale as soon as possible. Beyond the early instances of enforced re-injection of gas at oil fields, there have been very few major UKCS fields where associated gas has been developed and re-injected for the purpose of maximising oil recovery over the life of the field: Brent and the cross-border Statfjord field were perhaps the most notable examples. The UK government, as UKCS regulator until 2016, seldom, if ever, gave priority in the approvals process or its post-approval supervision to the maximising of oil recovery rates by insisting upon the re-injection of gas in the field development stage. The use of available gas remained essentially a commercial matter for the resource holder and operator.

Operators on the UKCS are required to submit monthly oil and gas production data to the OGA as part of the Petroleum Production Reporting System (PPRS). ${ }^{9}$ Since 2001, aggregate figures for UK gas production have been based principally on receipts of gas at onshore terminals rather than wellhead production data by field. PPRS provides monthly data on gas produced from every offshore and onshore field as either 'associated gas' or 'dry gas'. Data are released after two months, to preserve company confidentiality, but are often incomplete, inaccurate or subject to major revision months later. PPRS data are also difficult to reconcile with production data based on terminal receipts since for most fields the PPRS submissions record wet gas flows. According to PPRS, total UK gas production in 2017 was $47.4 \mathrm{bcm}$, comprising 32.2 of associated gas and $15.2 \mathrm{bcm}$ from dry gas fields. The principal reason for the large discrepancy with the official aggregate gross production figure of $41.2 \mathrm{bcm}$ is the inclusion of NGLs in the PPRS field data but there also appears to be some double-counting where gas from one field passes across a platform at another field. The complexity of offshore and onshore gas transportation and processing arrangements make reconciliation of aggregate data and field-level PPRS data almost impossible, even for individual gas pipeline systems. ${ }^{10}$ Throughout this paper, we use the reported BEIS figures based on terminal receipts for aggregate and regional gas production and the PPRS data for estimated field production only.

Many of the dry fields of the SNS and Irish Sea were developed in the 1970s and 1980s when British Gas was the sole buyer of gas at the beach for the UK market. These fields were designed to meet the seasonal variation in demand but, as the fields were gradually depleted, they were no longer able to provide the same degree of swing and the seasonal variation in output progressively diminished. Seasonal variation in demand was met increasingly by storage, notably by the offshore Rough field which was converted from production to storage in 1985, and later by imports. Field-specific supply contracts with seasonal swing endured but became increasingly marginal in meeting demand variations. The last of the major swing contracts for gas, from the then Shell-operated Sean field, finally expired in 2012-13. Since that time, the observable monthly variation in production at fields producing both dry gas and associated gas, shown in Figure 4, has been attributable to either planned maintenance in the summer months or unplanned operational outages.

\footnotetext{
${ }^{9}$ Responsibility for PPRS passed in 2016 to the OGA which has powers to request further information and data on production from operators. The published data remain of poor quality. In the opinion of the author, more detailed daily data would need to be available to the OGA to undertake reliable scrutiny of asset stewardship.

${ }^{10}$ The OGA is making an effort to improve the poor quality of PPRS data but it remains dependent on operators' data submissions to achieve this.
} 

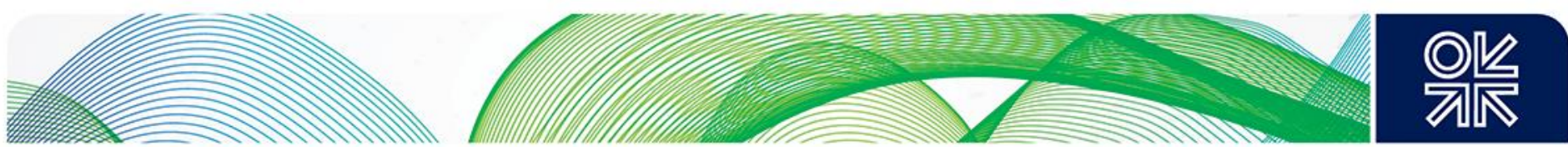

Figure 4: Monthly Production of Associated and Dry Gas Jan 2010-Dec 2018

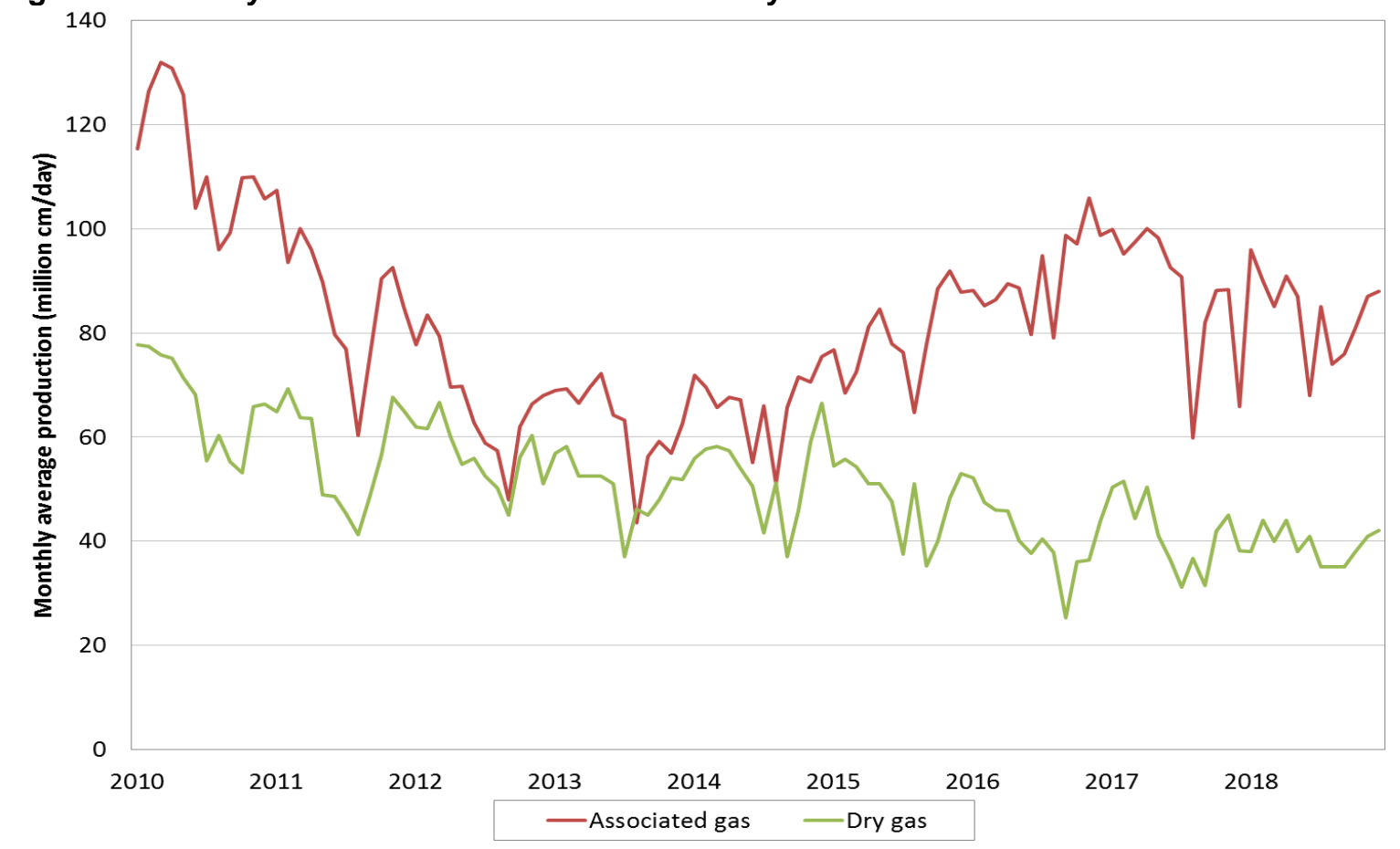

Source: OGA's PPRS database

Figure 4 illustrates the impact of both planned summer maintenance at oil and gas fields and occasional unexpected events such as the Forties system outage in December 2017 which led to the shut-in of about $25 \mathrm{mcm} / \mathrm{d}$ of gas production from fields in the CNS after a leak from an onshore liquids pipeline. The effect of other interruptions, such as the serious gas leak at the Elgin gas condensate field in March 2012 which caused a shutdown of all production from the Elgin and Franklin fields for 12 months and a production 'loss' of $10 \mathrm{mcm} / \mathrm{d}$, can also be seen in the chart. Real time and daily data available at NTS entry points, such as Bacton, Teesside and Morecambe, that receive mainly gas from UKCS fields reveal constant small-scale variations arising from unpredictable fluctuations in field-level flows. For all intents and purposes, outside periods of planned maintenance, operators seek simply to maximise gas flows at field level and to minimise unplanned downtime. Operators no longer have the physical or contractual flexibility to modulate gas production or flows to the NTS and generally cannot do so for commercial advantage. In this respect, gas production on the UKCS is quite different from operations on the Norwegian Continental Shelf (NCS) where operators hold some flexibility and commercial discretion over production and pipeline export flows.

\section{Economics of UKCS Production: Profitability, Costs and Taxation}

The UKCS has always been a highly capital-intensive part of the international upstream oil and gas industry. In its early years, it provided a proving ground for technological and engineering innovation in offshore field development. As a relatively high-cost producing province, its profitability has always been highly sensitive to fluctuations in oil and gas prices. Oil revenues have always provided a disproportionately large share of total production revenues because of the lower value of gas, expressed in energy-equivalent terms, compared to oil. Between 1996 and 2018, prompt NBP averaged just $60 \%$ of the value of dated Brent; annual average values were normally in the range 45 $75 \%$. In 2018, oil accounted for $59 \%$ of UKCS hydrocarbon production but more than $70 \%$ of estimated total hydrocarbon sales revenues of $\$ 38$ billion. Since the emergence of a hub gas market at the NBP in the mid-1990s and the subsequent renegotiation of inflation-linked, fixed-price, 'legacy' contracts, almost all gas produced on the UKCS has been sold by producers at NBP-related prices. 

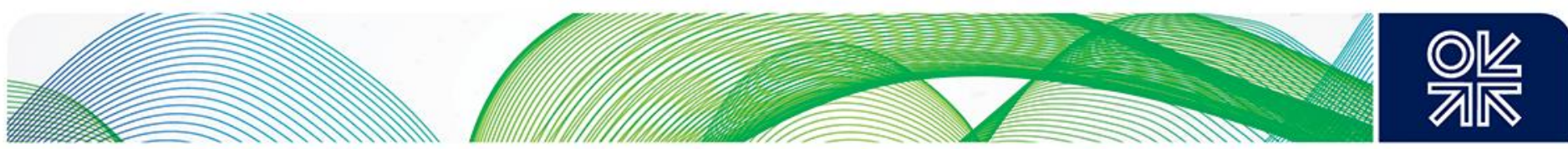

There is still a wide variety of commercial contractual arrangements for the sale and delivery of UKCS-produced gas but NBP prices or indices determine the basis of gas producers' revenues just as BFOE (Brent) prices determine total crude oil revenues.

The Office for National Statistics (ONS) publishes a quarterly index of the profitability of UKCS oil and gas producers. Its 'net rate of return', reproduced in Figure 5, is an accounting measure of profitability which expresses the operating surplus of UKCS operators before tax as a percentage of capital employed net of depreciation. It is not a measure of the post-tax return on capital employed (ROCE) used in the industry to track profitability or the return on investment used in making investment decisions but it illustrates the trends in UKCS pre-tax profitability. From a low in 2015-16, the index recovered modestly in 2017-18 as oil prices recovered, UKCS output increased and production reliability improved. However, this index of pre-tax profitability still stands well below the levels recorded when oil prices last traded in the range of $\$ 50-70 / \mathrm{bbl}$. Other sectoral measures published by the ONS, such as 'gross trading profits' of UKCS companies, record a similar, if less dramatic, recovery in UKCS profitability from $2015-16$ to $2017-18 .{ }^{11}$

Figure 5: Indicative Profitability of UKCS Industry 1Q 2000-4Q 2018

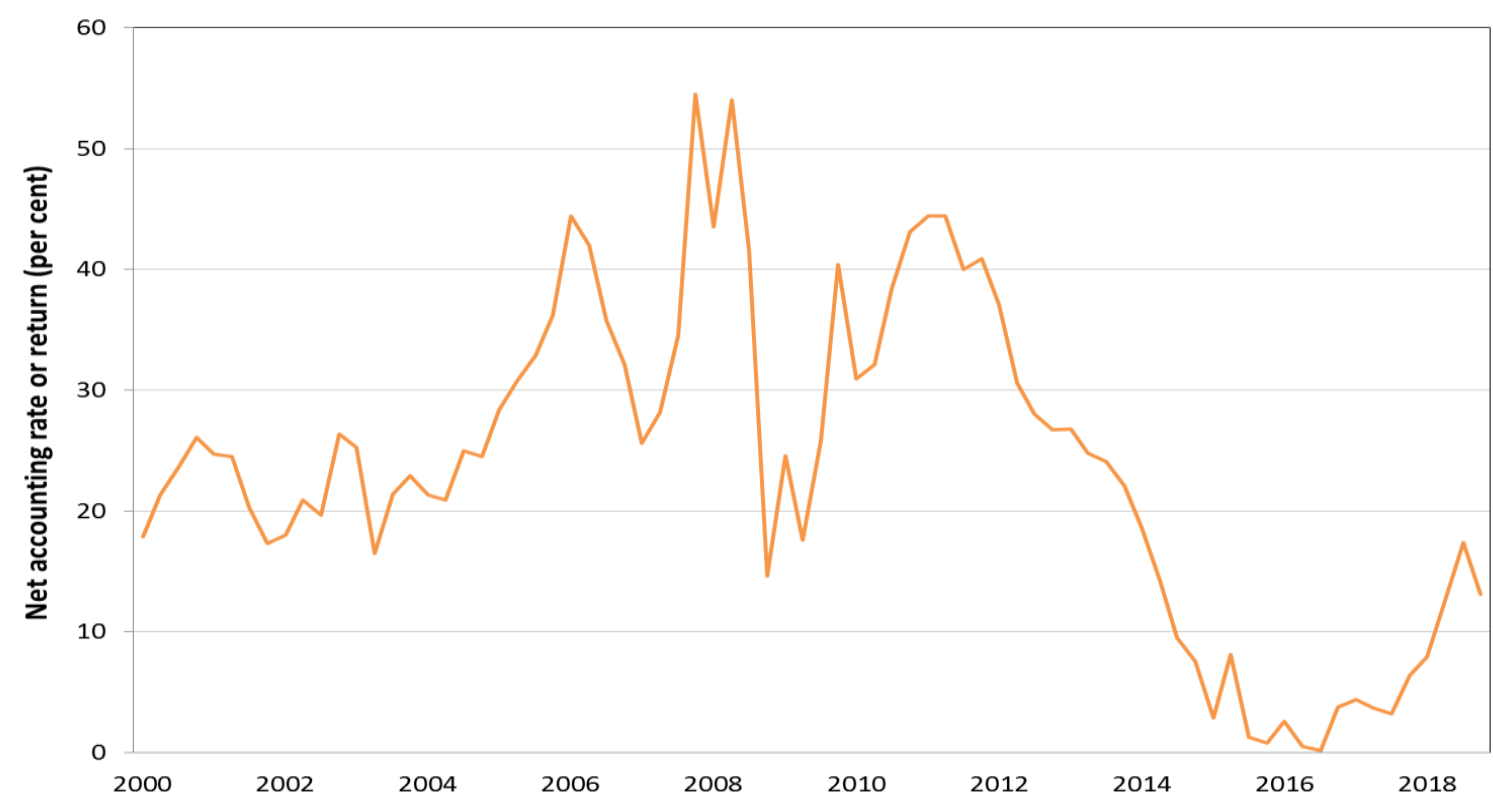

Source: Office for National Statistics, Profitability of UK Companies, April 2019

There may be transparency over UKCS gas revenues but there is little transparency or uniformity over the costs of producing gas. The principal reason for this opacity lies in the co-production of oil and gas on most of the UKCS and the impossibility of reliably allocating shared field, infrastructure and facilities costs between liquids and gas produced, in many cases, from the same reservoir. The UKCS is rightly described as a relatively high-cost producing province by international standards even after the recent phase of cost reduction. The demanding offshore operating environment, tight environmental standards and the preponderance of numerous small and medium-sized fields means that unit production costs are considerably higher than in other major gas-producing provinces supplying NW Europe. Few if any UKCS gas producers could match the low cost of production and supply from sources such as Russia, Qatar or the US Gulf Coast. 

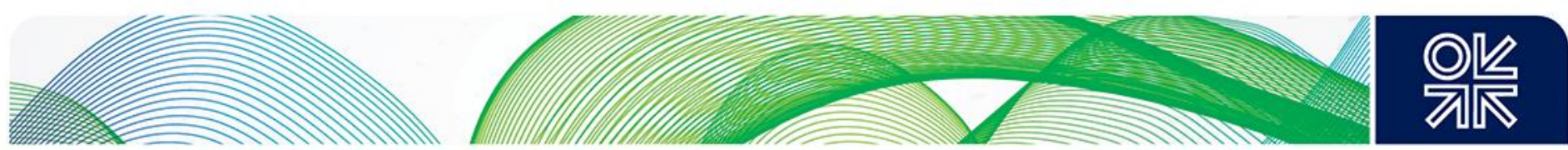

Figure 6: UKCS Unit Operating Costs (UOC) and Brent Oil Price 2005-18

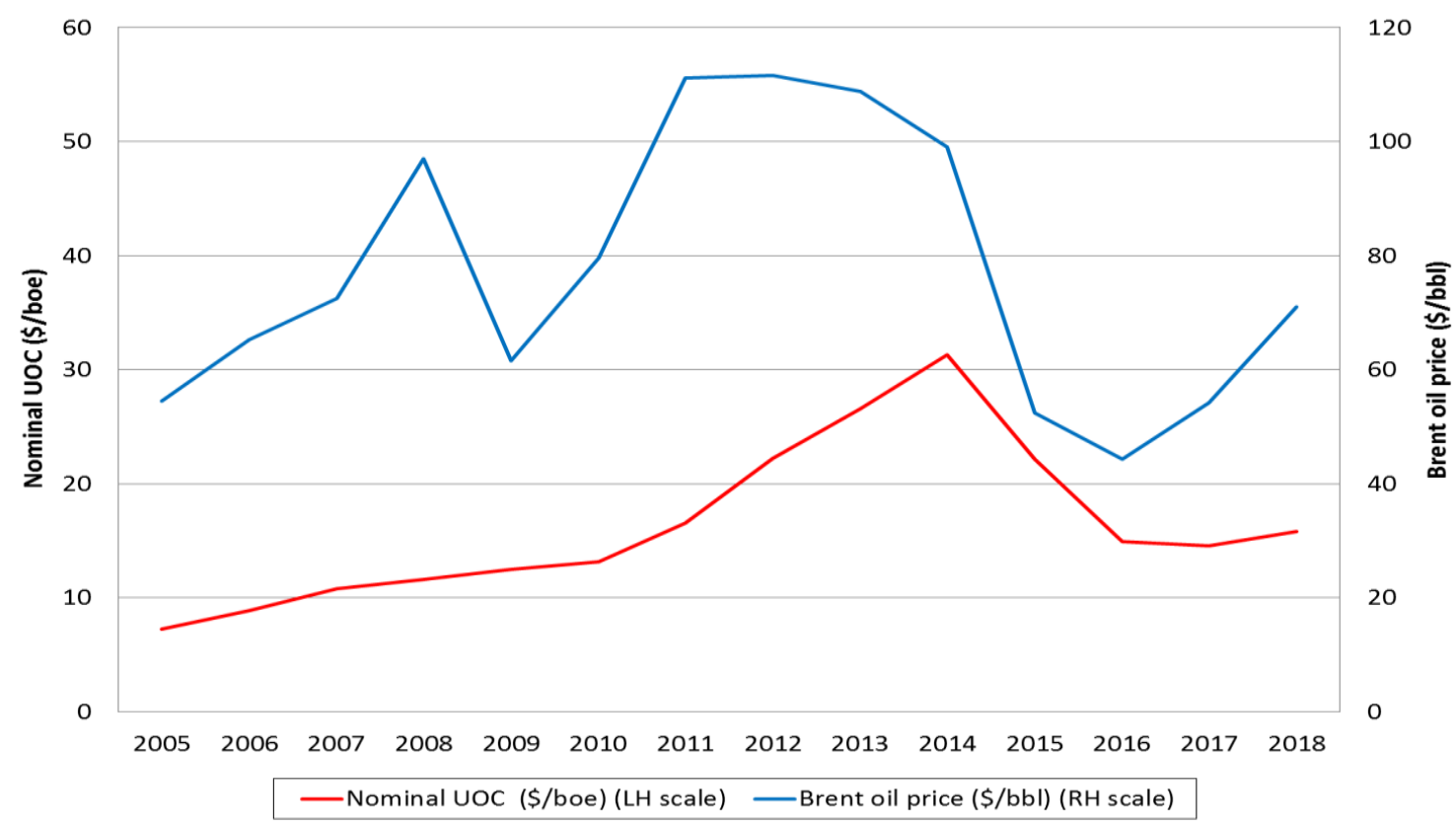

Source: OGA, Projections of UK Oil and Gas Production and Expenditure 2018 Report, March 2019

Figure 6 shows the evolution of nominal unit operating costs $(\mathrm{UOC})$ of hydrocarbon production on the UKCS from 2005 to 2018 and the Brent oil price. The published cost data, expressed for all UKCS hydrocarbon production, do not identify oil and gas production costs separately. The chart illustrates the observed link between the prevailing oil price and UKCS operating costs and the gradual trend towards higher unit costs as developed fields are depleted and production declines. The escalation of UOC between 2011 and 2014 was particularly acute due to the simultaneous failure to contain costs in a high oil price environment and the deterioration of operational performance which curtailed shortterm output. This tendency for operating costs for equipment, services and labour to follow oil prices quickly in the last commodity price cycle served to depress profitability on the UKCS and to make the industry more vulnerable to the inevitable fall in oil prices when it began in 2014.

Through its efforts to restore profitability and to improve operational efficiency, the UKCS industry achieved an impressive reduction in unit operating costs (UOC) between 2014 and 2017, as revealed by the results of the OGA's Stewardship Survey. ${ }^{12}$ Total operating expenditure (opex), expressed in 2017 prices, fell from $£ 10.0$ bn to $£ 6.7 \mathrm{bn}$; the accompanying $15 \%$ rise in oil and gas production over these three years ensured a cumulative fall in average unit operating costs (UOC) of $40 \%$. Total industry employment declined by an estimated 180,000 over the three years. ${ }^{13}$ Expressed in dollar terms, UOC declined by more than $50 \%$, from $\$ 31.7 /$ boe in 2014 to just $\$ 15 /$ boe in 2017 , thanks to the Brexit-related depreciation of sterling over this period. This rate of unit cost production, accompanied by an improvement in asset integrity, exceeded even the most optimistic projections made in 2015 as the industry began its drive to reduce costs. However, as the OGA observed in projecting a modest $5 \%$ increase in UOC in 2018 , the recent period of pronounced cost reduction may now be over. Indeed, in its projections to 2023 , the OGA expects unit opex to be broadly flat as total opex declines at roughly the same rate as total production.

\footnotetext{
${ }^{12}$ UKCS Operating Costs in 2017, OGA, October 2018

${ }^{13}$ Total employment attributable to the UKCS (comprising direct, indirect and induced employment) is estimated to have fallen from 464,000 in 2014 to 280,000 in 2017 according to Oil \& Gas UK's Workforce Report 2018.
} 

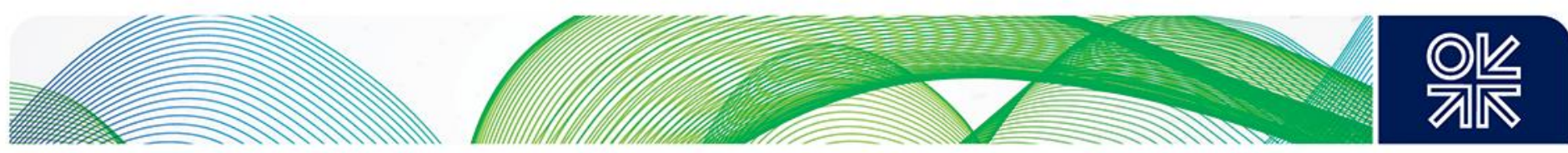

The OGA's survey reveals the huge range of UOC among producing fields on the UKCS, reflecting the diversity in the age of individual fields, production facility type and extraction complexity. Almost one-sixth of fields in the 2017 survey had a UOC of less than $\$ 6.50 /$ boe but almost the same number had a UOC of more than $\$ 40 / \mathrm{bbl}$. The OGA's analysis provides an analysis of total operating costs by producing region of the UKCS, by infrastructure category (field, pipeline or terminal) and by facility type (manned or unmanned platform, FPSO or sub-sea tie-back). Field opex, comprising spending on physical facilities, logistics and administration and wells, accounted for $89 \%$ of total UKCS opex, onshore terminals $9 \%$ and pipelines $2 \%$.

The published data do not identify oil costs and gas costs separately and are presented for the five main producing UKCS regions, but not by field or by pipeline system. Within these limitations, it is still possible to make some tentative observations. The gas-producing SNS and Irish Sea have a high proportion of fields that are more than 30 years old and tend therefore to have higher unit opex, but this seems to be compensated by the high proportion of small manned and unmanned platforms which tend to have lower costs. The survey's data also indicate that operators of fields in the SNS have been better able to resist the recent upward pressure on unit opex than those in the CNS and the NNS. This may simply reflect the fact that SNS operators did not really benefit from higher oil prices in 2011-14 and kept costs under better control than other oil-producing regions of the North Sea. Overall, in 2017, the share of total reported UKCS opex (17\%) incurred in the SNS and the Irish Sea in 2017 was broadly similar to its share of total UKCS output (620 million boe), indicating that the average operating cost was close to $\$ 15 /$ boe or $\$ 2.60 / \mathrm{mBTU}$ (20 pence/therm). It is not possible to derive any reliable indication of the cost of producing gas in other areas of the UKCS because of extensive oil and gas co-production.

The taxation of oil and gas production on the UKCS is notoriously complex and it has been subject to frequent revision in the past 40 years. Governments sought to recover a 'fair' share of the economic rent in the context of prevailing oil prices at the time while preserving an incentive for operators to continue to invest. The fiscal regime was for a long time characterised by high marginal rates of tax on profits (but lower than those in Norway) and extensive capital or investment allowances which alleviated the incidence of profit-based taxes for those willing to invest in exploration and development. The frequent changes in taxation had earned the UK an unwelcome reputation for fiscal complexity and instability among upstream investors by the time the government began a major fiscal review in 2014. The conclusion of this review led to a sizeable reduction of the tax burden in 2015 and 2016 which has made the UKCS more competitive and more attractive for international investors.

The UKCS fiscal regime comprises three distinct taxes: Ring Fence Corporation Tax (RFCT), Supplementary Charge (SC) and Petroleum Revenue Tax (PRT) ${ }^{14}$ RFCT is calculated on company profits from upstream activities in the same way as mainstream, onshore corporation tax (CT) but losses from other activities may not be set against profits from the upstream. Profits on which RFCT is payable may be reduced by $100 \%$ first-year capital allowances for capital expenditure on exploration, appraisal or development. Supplementary Charge is an additional tax charged at the company level on top of RFCT but without a deduction for finance costs. Profits subject to SC may be reduced by application of the Investment Allowance or the Cluster Area Allowance. The third tax element, PRT, is a field-based tax introduced in 1975 which was charged on profits from fields approved for development before March 1993.

The declared aim of the review in 2014 was to ensure that the taxation of the UKCS was consistent with the new statutory objective of MER UK and to ensure that the UKCS remained internationally competitive for new investment. Critically, the conclusion of the review ${ }^{15}$ was that the government needed to reduce the overall tax burden on the UKCS and to ensure that the fiscal regime would be

\footnotetext{
${ }^{14}$ The UK EITI Report for 2016 (April 2018) provides a helpful, simplified summary of the UKCS tax regime.

15 'Driving investment: a plan to reform the oil and gas fiscal regime', HM Treasury, December 2014
} 

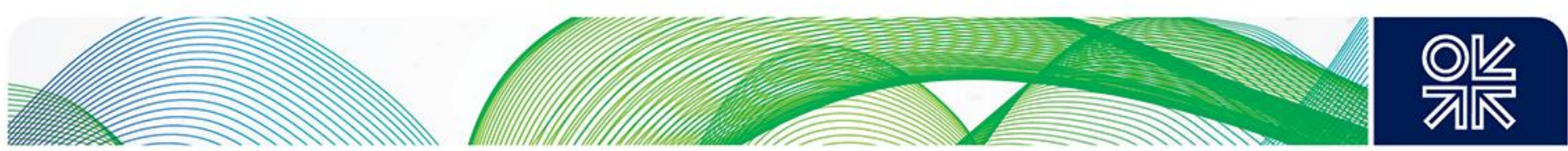

more competitive, simple and predictable in the future. These conclusions informed the main changes to the fiscal regime announced in 2015 and 2016:

- the introduction of a UKCS-wide Investment Allowance $(I A)$, replacing the numerous generic field-based allowances which had been introduced between 2008 and 2013

- a reduction, in two steps, in the rate of Supplementary Charge (SC) from $32 \%$ to $10 \%$ with effect form 1 January 2016

- a permanent reduction in the rate of PRT from 35\% to zero, effectively suppressing all PRT payments while allowing rebates of previously paid PRT for decommissioning

The rate of RFCT was left unchanged at $30 \%$. For non-PRT paying fields, the effect of the changes was to reduce the headline tax rate from the application of RFCT and SC from $62 \%$ (30\% plus $32 \%$ ) to just $40 \%$ (30\% plus $10 \%)$. For those companies investing sufficiently to utilise fully the new Investment Allowance and gaining full SC relief, the effective rate of tax would fall to $30 \%$. This represents the lowest headline and effective rates of taxation in the history of the UKCS. For older, pre-1993 fields still in production, the headline rate of tax fell from $75 \%$ to $40 \%$. The new rate of PRT was set permanently to zero from 1 January 2016 but was not abolished so that losses arising from PRT-liable fields could continue to be carried back against past PRT payments. Setting the rate of PRT to zero meant that all UKCS fields face the same tax rate for the first time since 1982. It should be noted that in cutting the rate of SC to just $10 \%$, the government's reforms also cut the value of available investment allowances. The reform package did not include any specific new allowance or incentive for exploration but the reduction in tax rates did raise the post-tax value of both existing resources and future discoveries.

Figure 7: Government Tax Revenues from the UKCS 2004-2018

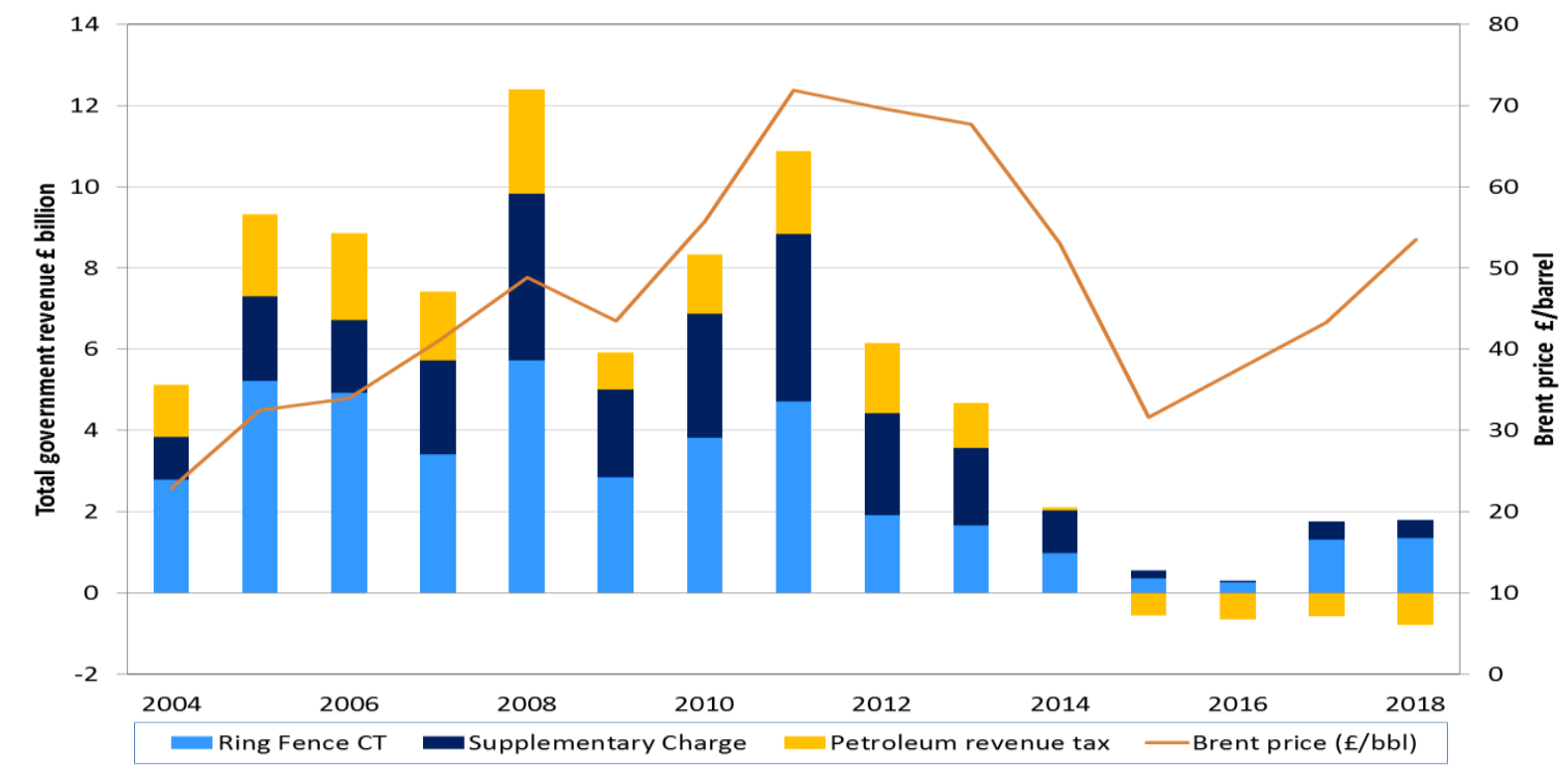

Source: HMRC, 2019. Revenues and prices are shown for each tax year (April-March).

The annual history of revenues raised from these three taxes since 2004 is shown in Figure $7 .{ }^{16}$ The sharp and unexpected contraction in total tax revenues between 2011-12 and 2014-15 at a time of high oil prices was attributable largely to the deterioration of offshore reliability, rapidly rising costs and the increase in capital investment in this period. Total net tax paid was marginally negative in both 2015-16 (-£2m) and in 2016-17 (-£350m) due to the weakness in oil prices, the reduction of tax

\footnotetext{
${ }^{16}$ Figure 7 excludes licence fee income (£62m in 2017-18). Royalties on production were abolished in 2002-03.
} 

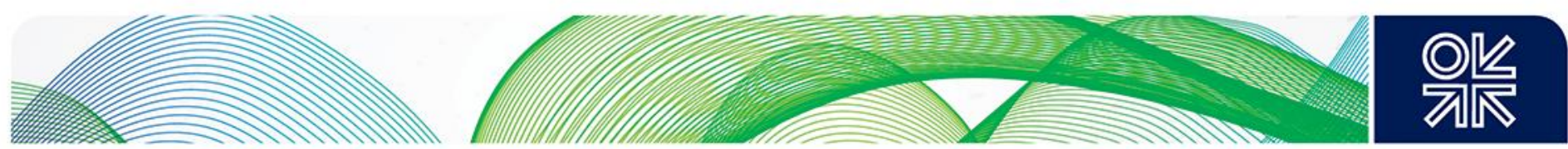

rates in 2016 and the gradual increase in PRT repayments as older PRT-liable fields such as Brent were decommissioned. Net tax revenue recovered to £1.2 bn in both 2017-18 and 2018-19. The consequence of the tax reforms of 2016 is that total government tax revenue has become less sensitive to changes in oil prices and more dependent on the pace of decommissioning. Net PRT payments have been negative in the last four tax years (2015-18) and are expected to remain so as decommissioning proceeds. The OGA estimated in 2018 that the total cost of decommissioning all UKCS infrastructure would be $£ 45-77 \mathrm{bn}$ with a central estimate of $£ 58.3 \mathrm{bn}$ at 2017 prices. ${ }^{17}$ Based on this central figure, the National Audit Office (NAO) estimates that decommissioning will cost the government, and indirectly the taxpayer, £24bn in tax repayments and tax forgone through lower profits. This represents more than $40 \%$ of expected total decommissioning costs but the government's share is highly uncertain since the range of cost estimates is still very wide. ${ }^{18}$

Oil and gas are not differentiated in the tax system which bases taxes payable on reported profits from operations after the application of eligible allowances. It is widely acknowledged that standalone oil projects have usually generated higher pre-tax and post-tax financial returns to investors than comparable gas projects of comparable resource size, in part because of the higher revenues per boe generated by oil production. The tax system has seldom fallen equally or equitably on existing oil and gas producers or on prospective oil and gas developments. The unexpected, last-minute increase in SC from $20 \%$ to $32 \%$ in March 2011, designed to raise UKCS tax revenue by £2bn per year, certainly had a more adverse short-term impact on existing gas producers than on oil producers. ${ }^{19}$ This briefly incited calls to recognise the different economics of gas production in the tax system but the technical and legal difficulties of such tax differentiation proved an insurmountable obstacle.

Between 2008 and 2013, a series of generic and bespoke allowances were introduced to promote investment in particular types of fields (e.g. heavy oil fields or high-pressure, high-temperature (HPHT) fields). This led to growing complexity in the system of allowances, which was corrected by the introduction of a single UKCS-wide Investment Allowance in 2016. The one allowance which may be said to favour new gas projects is the Cluster Area Allowance (CAA) which was introduced in 2014 with the expressed aim of promoting development of high-capital cost HPHT gas condensate fields in the CNS. The Culzean field, due to begin production in mid-2019, was the first such field to take advantage of this allowance.

The data and reports released by the UK Extractive Industries Transparency Initiative (UK EITI) to promote tax transparency set out annual payments (or repayments) of RFCT, SC and PRT by individual companies operating on the UKCS. Reported tax payments are classified by operating company, not by field, since RFCT and SC are levied at company level. It is not possible from these published data to reliably compare the underlying profitability of gas-producing operations on the UKCS compared to those focused on oil production. Annual tax payments may be distorted by fluctuating patterns of investment, timing effects, operational factors and the sale and purchase of assets. However, it is notable that some of the highest payments of RFCT and SC in 2017, in aggregate and per boe produced, were made by companies whose operations are focused on large, low-cost oil fields like Buzzard and that the gas-oriented producers of the SNS were among the companies paying less per barrel than the industry average. Once a longer time series of company tax payment data is available, the trends and differences in profitability and tax payments may become more apparent.

Recent changes in UKCS taxation have addressed not only the rates of tax payable on profits and capital allowances against SC but also the transfer of decommissioning tax relief when assets change hands. After extensive consultation, HM Treasury introduced transferable tax history (TTH) with effect

\footnotetext{
${ }^{17}$ UKCS Decommissioning: 2018 Cost Estimate Report, OGA, June 2018

18 'Oil and Gas in the UK: Offshore Decommissioning', National Audit Office, January 2019

${ }^{19}$ The tax increase in March 2011 led Centrica to temporarily cease gas production from its operated fields in Morecambe Bay in the Irish Sea for extended maintenance, as reported in Upstream, 2 May 2011
} 

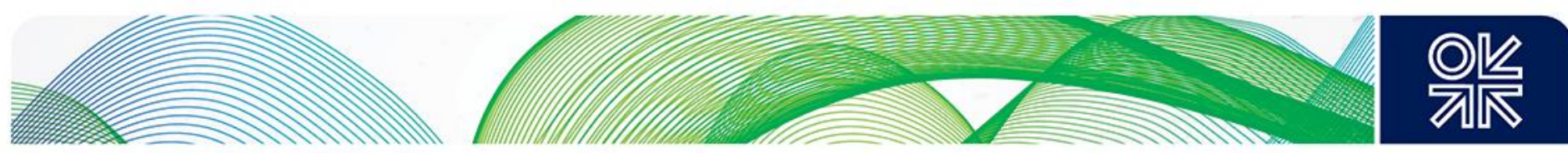

from November 2018 to permit sellers of UKCS oil and gas fields to transfer some of their tax history to their buyers, thereby allowing buyers of the assets to set some of their future decommissioning costs against the tax history of the particular assets. Before the reform, tax rules prevented such decommissioning tax relief from being transferred from sellers to buyers, thereby acting as a potential obstacle to asset purchases. ${ }^{20}$ The change does not affect all operators but may be significant in facilitating the sale and purchase of assets and in assisting in the OGA's declared aim to put 'the right assets in the right hands'.

\section{MER UK, Regulatory Reform and the Role of the OGA}

The deterioration of the operating and financial performance of the offshore industry in 2011-13 prompted the Secretary of State for Energy, Ed Davey, in June 2013 to ask Sir lan Wood, a wellrespected figure in the offshore industry, to conduct an independent review of the sector. Its remit did not include taxation but a fiscal review led by HM Treasury soon followed its publication. After an interim report and extensive consultation, 'UKCS Maximising Recovery Review: Final Report' was published in February 2014. This became universally known as 'the Wood Review'.

The report made four main recommendations, all of which were fully accepted by the government.

- Government and industry should commit themselves to a 'new strategy for maximising economic recovery from the UKCS' which became known as 'MER UK'

- A new independent regulator should be created and charged with effective stewardship of UKCS oil and gas recovery and collaboration across the industry

- The new regulator should have new powers to pursue implementation of MER UK

- The new regulator should work with industry to develop and to implement six 'sector strategies' for exploration, asset stewardship, regional development, infrastructure, technology and decommissioning.

The report described some of the failings of industry asset stewardship, the excessively competitive behaviour of some operators and the inadequacies of the existing 'light touch' regulatory regime. It enumerated a number of specific actions to be adopted but in some areas, such as licensing terms, the report was less prescriptive, leaving options open for further consideration. The report drew muted criticism from some parts of industry concerned about a more intrusive regulatory regime with tougher obligations imposed on operators. However, the recent poor performance of the industry and the evidence presented in the report of the deficiencies of the prevailing regime made the case for the proposed reform almost unanswerable.

The report reproduced the prevailing estimate at the time that 12-24 billion boe remained to be produced from the UKCS. It also expressed the view that full implementation of its recommendations would deliver at least an additional 3-4 billion boe in the following 20 years to 2035, worth an estimated £200 billion to the UK economy. The incremental volume was expected to come from several sources (increased exploration, effective enhanced oil recovery (EOR), improved use of infrastructure and deferral of decommissioning) but the basis of this estimate was not disclosed.

The Government accepted the Wood Review recommendations in July 2014 and moved quickly to establish the new regulator, to be called the Oil and Gas Authority (OGA), as a successor to DECC and to prepare for its independent operation. Clauses were included in the Infrastructure Bill requiring the government to publish the Strategy to achieve MER UK and to establish a levy on industry to fund an independent OGA. The Infrastructure Act was enacted in February 2015 and the OGA was created as an executive agency within DECC on 1 April 2015. The legislative proposals to make the OGA independent and to define its powers and functions were introduced in July 2015 in a new Energy Bill. In November 2015, the government proposed a draft MER UK Strategy which, after some revisions

${ }^{20}$ An Outline of Transferable Tax History, HM Treasury, November 2017. 

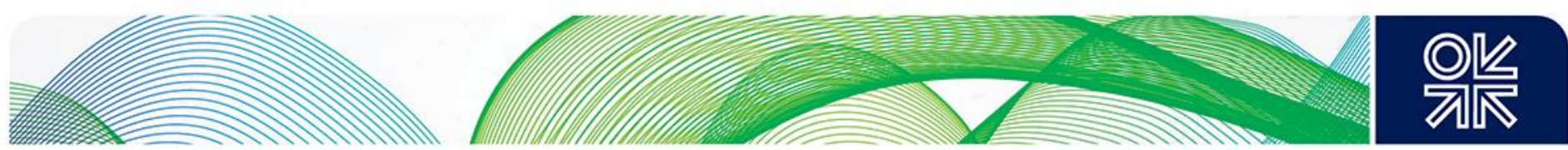

through consultation, was approved by Parliament and came into force on 18 March 2016. The 'central obligation' of MER UK, binding on all 'relevant persons' and the OGA, is to 'take the steps necessary to secure that the maximum value of economically recoverable petroleum is recovered from the strata beneath UK waters' ${ }^{21}$ This is supplemented by 'supporting obligations' in exploration, development, asset stewardship, technology and decommissioning, and a series of 'required actions and behaviours'. Balancing these obligations on all industry participants are a number of 'safeguards' intended to mitigate the potential adverse impact of MER UK on the expected financial returns of individual industry participants.

Despite broad cross-party support, the passage of the Energy Bill through Parliament was delayed by contention over the proper scope of the OGA's responsibilities, in particular whether it should have an ancillary responsibility for meeting the UK's climate change targets. In the end, the Bill passed in Parliament effectively restricted the OGA's role to that of an economic resource regulator and it finally became law on 12 May 2016. The OGA, a government company with the Secretary of State for Energy as the single shareholder, was vested with powers under the Energy Act 2016 and began independent operation on 1 October 2016. ${ }^{22}$ In addition to regulation of offshore exploration and production, the OGA also regulates offshore carbon capture and storage, offshore gas storage and offshore gas unloading activities and onshore licensing. The levy to fund the OGA was to be paid by industry licence holders on the 'user pays' principle adopted for other UK sectoral regulators. The initial levy in 2016-17 was set at £21.6 million and the OGA's staff, based in London and Aberdeen, quickly rose in number to about $150 .^{23}$

The OGA was not given legal responsibility for environmental regulation, decommissioning or offshore safety in order to avoid any potential internal conflicts of interest. Environmental regulation, enforcement and decommissioning remained with the government department (BEIS) and its agency, the Offshore Petroleum Regulator for Environment and Decommissioning (OPRED). Offshore safety continues to be regulated by the Energy Division of the Health and Safety Executive (HSE). Responsibility for upstream taxation remained with HM Treasury, the UK finance ministry, but the OGA acts as advisor to the Treasury and the Office for Budget Responsibility (OBR) on fiscal matters.

The statutory objective of MER UK is expressed as maximisation of the economic value of recovered resources, not the volume recovered. The legislation does not provide a definition of 'economic'; that contentious issue is left for the OGA itself. The debate over MER UK took place against the background of the campaign preceding the Scottish independence referendum in September 2014. The political context ensured that the discussion of MER UK included a public recognition of the economic contribution of the offshore industry to the onshore economy, in particular through employment in the supply chain and offshore service sector. ${ }^{24}$ The economic contribution of the UKCS could not be measured solely by its tax payments to the UK government. This widening of the scope of the economic contribution of UKCS oil and gas production to include the onshore economy has been reflected in the attention given by the OGA to maintaining a domestic UK supply chain to serve field developments, offshore operations and decommissioning. It can also be seen in the OGA's endorsement of the industry's aspirational 'Vision 2035' which aims to raise UKCS oil and gas production to 2035 by 3 billion boe and to increase the turnover and exports of the UK-based supply chain.

In addition to the existing powers of the licensing authority transferred from the government, the Energy Act 2016 grants the OGA new powers to resolve disputes, to require the reporting of information and samples, to attend technical and operator meetings and to serve a sanction notice on

\footnotetext{
${ }^{21}$ MER UK and the obligations of the OGA extend to the UKCS only and exclude onshore petroleum. However, the OGA has responsibility for onshore licensing and technical regulation of onshore petroleum activities.

${ }^{22}$ The full relationship between the UK government and the OGA is summarised in the Framework Agreement available on the OGA website.

23 The budget in 2019-20 stands at £31.3m (including the new NDR) of which the levy provides £23.4m.

24 'Scotland's Independent Expert Commission on Oil and Gas: Maximising the Total Value Added', Scottish Government, June 2014 marked a significant contribution to the political debate over MER UK.
} 

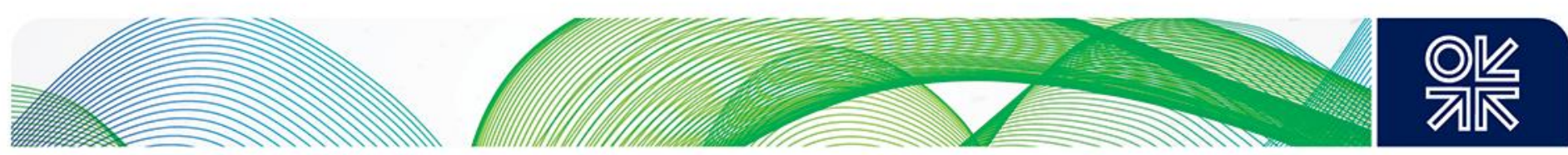

those companies which fail to act in accordance with MER UK. The OGA has powers to make binding decisions in disputes over third party access to infrastructure, discussed in section 9 . In other disputes between parties, it can make only non-binding recommendations. It has at its disposal a graduated array of sanctions for any party which breaches the requirements of MER UK or the terms of its licence. These range from issuing an enforcement notice directing compliance, financial penalties up to $£ 1$ million, revocation of a licence or, in the most severe cases, removal of the operator. ${ }^{25}$ Any exercise of these sanction powers is, of course, subject to judicial review.

The corollary of this array of formal sanctions is a series of safeguards for investors and operators. MER UK does not require any party to breach existing legislation, including UK and EU competition law. Investors shall not be required to make any investment or to fund any activity which does not deliver a satisfactory expected commercial return (SECR). Finally, MER UK will not require any action by the OGA or industry participants which would damage the confidence of UKCS investors.

The OGA differs in an important respect from most other UK sectoral regulators in that it has a threefold responsibility to 'regulate, influence and promote'. It is expected not only to enforce the new regulations and to encourage a collaborative industry culture but also to promote investment in the UKCS and exports by the UK-based supply chain. This role in promoting the industry, particularly among foreign investors, marks a recognition that the UKCS will need to attract new sources of capital as investment by the established international oil majors continues to diminish. However, it may in future create a tension with its role to be an impartial, expert regulator arbitrating between commercial interests. Managing these different roles while retaining industry trust will require skill and dexterity.

Since becoming independent, the OGA has focused, in the practical implementation of MER UK, on improving data transparency and reporting, on giving prescriptive guidance to industry as to how to meet its new obligations and on introducing forums for more collaborative behaviour. It has conducted three annual Stewardship Surveys which require operators to submit more detailed data on resources, production, costs and expenditure and it has introduced a number of Area Plans designed to bring companies together to discuss investment, exploration, operations and decommissioning at particular projects, fields and infrastructure within a designated geographical area. It has been active on all the main priority issues identified in the Wood Review and can claim some credit for laying the foundations for improved industry collaboration. In particular, the opening of the National Data Repository (NDR) in March 2019 to make geophysical, sub-surface, well, field and infrastructure data available to the entire industry marks an important step in improved data transparency which may create opportunities for greater collaboration and financial rewards for individual companies. ${ }^{26}$ The NDR aims to build on the long experience of the industry-funded Common Data Access (CDA) in seeking to widen access to better, recently acquired data and to permit earlier and higher-quality analysis by industry participants.

On a few occasions, notably over OGA proposals in some Area Plans and the proposed interpretation of a 'satisfactory expected commercial return' (SECR) on investment, the OGA's proposals have met some criticism from industry. ${ }^{27}$ However, the overall impression it has created so far is broadly one of sensible pragmatism as it seeks to use its new powers to promote more collaborative industry behaviour. The OGA does not disclose publicly the details of its regulatory activity, only the number of instances it investigates. So far, the main areas of investigation have been asset transfers, the performance of licence commitments and access to infrastructure. In its latest report, it records that it has so far successfully intervened in 60 instances, 39 of which it had resolved through 'facilitation' and exercise of its influence; 15 instances were resolved by 'formal intervention' and only five required the exercise of its formal powers. ${ }^{28}$ The value of these cases and the impact on resource

\footnotetext{
${ }^{25}$ The sanctions notices are described in sections 43-48 of the Energy Act 2016.

${ }^{26}$ OGA press releases on NDR, 15 October 2018 and 25 March 2019

27 'Guidance on Satisfactory Expected Commercial Return (SECR)', OGA, August 2018

${ }^{28}$ OGA Overview 2019, March 2019, page 11
} 

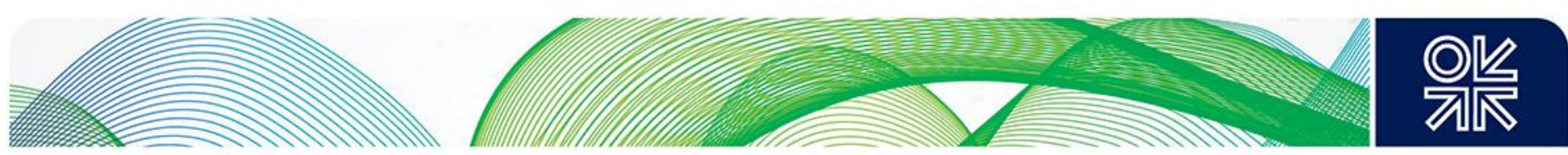

recovery are not disclosed, so we cannot evaluate the contribution of what the OGA describes as its 'successes'. The OGA has not yet issued any formal sanctions, nor apparently any warnings of possible sanctions. This indicates that, so far, it has sought to use its influence to persuade industry participants to change their behaviour, rather than to exercise its formal legal powers. The sanctions it has available have not yet been tested, possibly because the industry has so far preferred to cooperate fully with the OGA and to comply with its requests and directions.

There are numerous occasions in the existing approvals process where the OGA has an opportunity to exercise its licensing powers to pursue the objective of MER UK: in the preparation and submission of an initial Field Development Plan (FDP), at the application for an amendment to an existing FDP and at an application for Cessation of Production at the end of the life of a field before eventual decommissioning. The issue of extensive OGA guidance on all approvals processes is intended to ensure operators can reliably anticipate how the OGA will interpret the requirements of MER UK in the exercise of its powers. There are signs in the new guidance notes that the OGA will be more active in setting upper and lower production limits when a field receives production consent and that operators will be required to re-apply for consent if production falls outside these limits.

The existence of innumerable commercial agreements between offshore participants, especially for transportation and processing, poses a more difficult issue for the OGA. Many of these agreements date back decades and were drawn up long before MER UK was introduced. There may be instances where such agreements frustrate MER UK and the performance of the contracts might lead to premature decommissioning of offshore or onshore facilities. The OGA has no powers to force revision of existing, lawful commercial agreements between companies and it has indicated it has no wish to do so. However, it may conclude that reliance on contractual rights is producing an outcome contrary to MER UK and subject to sanction if continued. In addition, if an operator or owner is unwilling to invest in continued operation or expansion which the OGA considers meets a satisfactory expected commercial (SECR), it may require an operator to offer the ownership or operatorship of existing facilities to third parties on reasonable terms at a fair market price. However, it cannot force an asset sale if there is no willing buyer. Late-life decisions over decommissioning may therefore present a greater challenge for the OGA in pursuing MER UK than decisions over new field developments. It appears that the OGA will have more discretion and will face fewer commercial constraints in pursuing MER UK in less mature areas of the UKCS where infrastructure is incomplete and resource depletion less advanced than in the most mature areas with extensive legacy commercial arrangements where fields are approaching the end of their economic lives.

Both the Wood Review and the regulatory reform process referred to the production and recovery of UKCS hydrocarbon resources, without distinction between oil and gas. The Wood Review cited particular gas-specific issues, such as the 'urgent need' for a regional plan for the gas-producing SNS and the possibility of new fiscal measures to encourage development of HPHT fields or 'off spec' gas. It also referred to the unfavourable comparison between access to gas infrastructure in the UK and the Netherlands but generally it left the definition of detailed issues for the new regulator. Perhaps significantly for future gas resource recovery, onshore operators of gas infrastructure such as processing terminals are brought within the regulatory scope of MER UK as 'relevant persons'.

The OGA does not treat gas separately from oil in its strategy but its work programme does contain a number of elements which concern gas resources primarily or exclusively:

- $\quad$ SNS. The OGA undertook a study of the potential for the development of known tight gas resources in the $\mathrm{SNS}^{29}$ and offshore gas-fired generation and transmission of electricity to shore using existing capacity installed for adjacent wind farms in the SNS and Irish Sea. ${ }^{30}$

- Area Plans. At least six of the OGA's current Area Plans, covering specific areas of the SNS, CNS and WoS regions, include discussion of gas which involves possible sharing of existing facilities, joint investment in infrastructure or negotiated access to existing facilities.

\footnotetext{
29 Southern North Sea Tight Gas Strategy, OGA, June 2017

${ }^{30}$ Gas-to-Wire:UK Southern North Sea and East Irish Sea, OGA, September 2018
} 

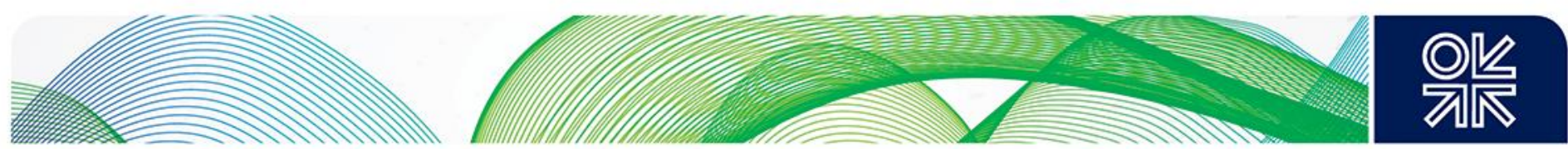

- Infrastructure. Apart from its role as regulator of access to existing gas infrastructure, the OGA is involved in ensuring that decommissioning of offshore platforms and pipelines and onshore terminals minimises the risk of stranded resources and in encouraging the 'replumbing' of offshore pipelines to promote late-life production, further near-field exploration and offshore access to gas as fuel.

All discussions between licence holders in forums mediated by the OGA take place within the constraints imposed by EU competition law, so parties cannot exchange information to distort or restrict competition in the market for goods and services. The potential advantage of such meetings is that the OGA has an appreciation of 'the big picture' and can encourage parties to search for bi-lateral or multi-lateral commercial solutions which might not otherwise have been evident to individual parties. Where the total economic value available to companies participating in a particular area can be increased through co-operation, the OGA has an obligation to pursue the optimal solution for MER UK even if the value realised by one party is reduced in the collectively optimal solution. In many cases, all participants will realise a higher expected commercial return but in those where some players are made worse off by MER UK, the OGA will have to facilitate agreement between parties or, if that fails, to impose its preferred solution. So far, such cases of value re-distribution appear to have been rare but, as the UKCS matures, the difficulties of pursuing MER UK and maintaining investor confidence may become more evident.

\section{Projections of Future UK Gas Production}

Since 2000, the government department responsible for energy ${ }^{31}$ has made regular projections of future oil and gas production based on data provided by offshore operators. In 2016, responsibility for publishing the output projections passed to the new Oil and Gas Authority. ${ }^{32}$ These official projections form the basis of projections of the government's tax revenues from the UKCS up to five years forward published by the Office for Budget Responsibility (OBR) under its own oil and gas price assumptions. Since March 2015, BEIS/OGA has published projections of oil and gas output to 2035.

Between 2000 and 2013, as UKCS production declined almost every year, official output projections consistently over-estimated gas production in the coming five years. From 2003, the projections correctly anticipated the fall in gas output but the pace and extent of the fall consistently exceeded official expectations. In common with private sector projections, the forecasting error increased sharply when poor offshore operating performance led to an acceleration of the decline in 2011 and 2012. By 2013, the official projections correctly anticipated a short-term stabilisation of net gas output in 2014-15.

The accuracy of the five-year production projections has not improved significantly in recent years. Since 2015, BEIS and the OGA have consistently under-estimated out-turn UK oil and gas production, reversing the error of earlier years. As shown in Figure 8, all official projections since March 2015 have shown a progressive fall in net gas output in the coming five years. Yet, net gas output rose from a low of $33.8 \mathrm{bcm}$ in 2014 to $37.8 \mathrm{bcm}$ in 2017. ${ }^{33} \mathrm{In}$ March 2015, BEIS/OGA projected net output in 2017 of only $30.4 \mathrm{bcm}$ in 2017, an under-estimate of out-turn production of almost $20 \%$. Some of the reasons for the recent under-estimates could not have been expected, such as the closure of the Rough storage facility and the commencement of production from the cushion gas in 2017. In our view, the OGA continues to be somewhat too pessimistic about UKCS gas output to 2024 despite the progressive upwards revisions to its forecasts in the last four years.

\footnotetext{
${ }^{31}$ Department for Trade and Industry (DTI), the Department for Business, Enterprise and Regulatory Reform (BERR), the Department for Energy and Climate Change (DECC) and the Department for Business, Energy and Industrial Strategy (BEIS). ${ }^{32}$ The latest projections appeared as 'Projections of UK Oil and Gas Production and Expenditure', OGA, 8 March 2019 ${ }^{33}$ Provisional figures indicate net gas production fell to about $36.5 \mathrm{bcm}$ in 2018.
} 

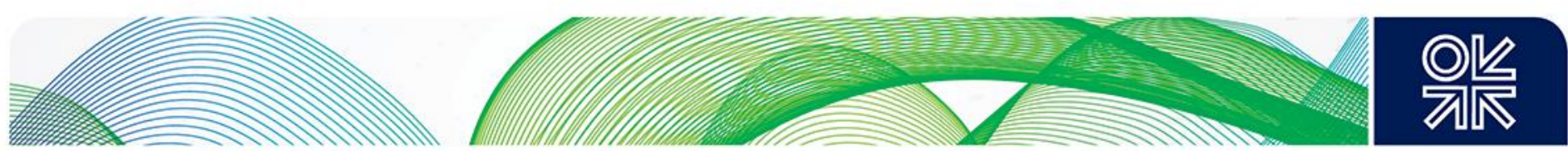

Figure 8: OGA Projections of UK Net Gas Production to 2035

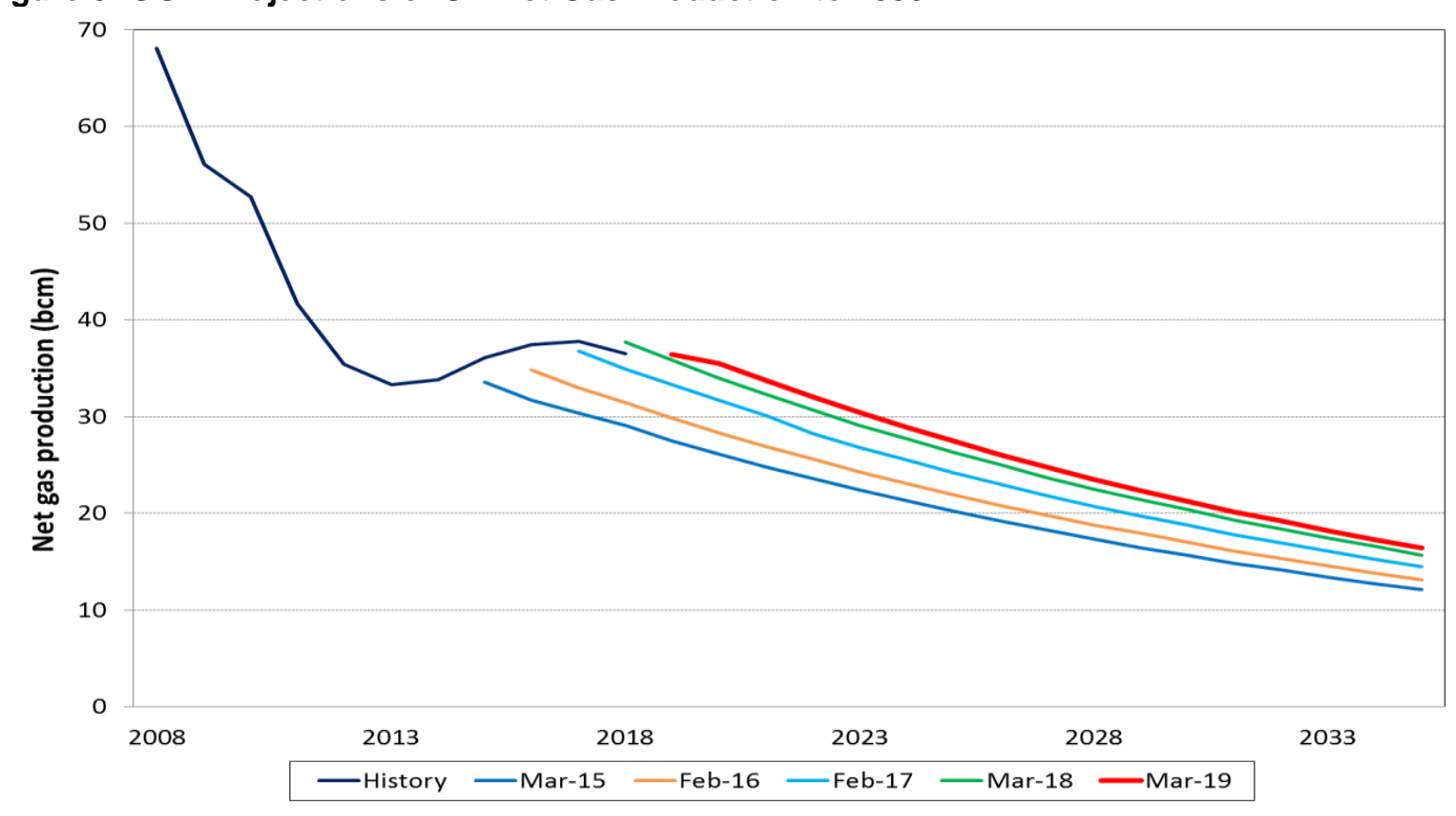

Source: BEIS, OGA

The OGA's longer-term projections to 2035 reflect the simple assumption that, beyond 2020, gas output declines at a constant rate of $5 \%$ per year. The OGA currently projects a decline in net gas output from $37.8 \mathrm{bcm}$ in 2017 to $29 \mathrm{bcm}$ in 2024, falling to $16.4 \mathrm{bcm}$ in 2035. The projected figure for 2035 lies within the range of other published industry projections. The OGA does not provide a regional breakdown of projected output, there is no confidence range attached to the single-point projections and the contribution from currently undiscovered resources is not identified. It is therefore difficult to assess the plausibility of these projections, particularly in the absence of any explicit assumptions about future prices, costs and taxation. Some indication from the OGA of the future contribution from currently undeveloped or undiscovered resources would help industry interpret its production projections.

Making projections of short-term UKCS gas production is fraught with difficulties arising from infrastructure outages and the inter-related nature and co-dependence of oil and gas operations, as highlighted by the Forties oil pipeline outage in December 2017. In the medium term, to 2035, fluctuations in oil and gas prices, taxation, the rate of new investment and decommissioning and the possibility of new discoveries will all influence the course of gas production. The OGA bases its projections on the sum of operators' submissions in its annual Stewardship Survey, to which it then applies a probabilistic, UKCS-wide contingency factor to reflect unplanned outages and project slippage, under-performance or cancellation. At times in recent years, the contingency factors applied to reduce the sum of operators' submissions of future gas production have been as much as $15-30 \%$. In other words, the over-optimism of some, but not all, operators has been corrected by the OGA through a single adjustment to arrive at its published output projections. The OGA is seeking to improve its scrutiny of operators' submissions to improve the reliability of the data but the sheer complexity of offshore operations and the dearth of reliable field-level production data may remain obstacles to improved forecasting.

The OGA is making efforts to improve the quality of both its resource and production data. However, given the acknowledged difficulties and errors in past forecasting, it is unfortunate that the OGA has adopted the production projections published by BEIS in March 2015 as the benchmark for the presentation of the improved operating performance of the industry and the implied contribution of MER UK and its own regulation. In March 2015, BEIS projected a decline in UK oil and gas output to 

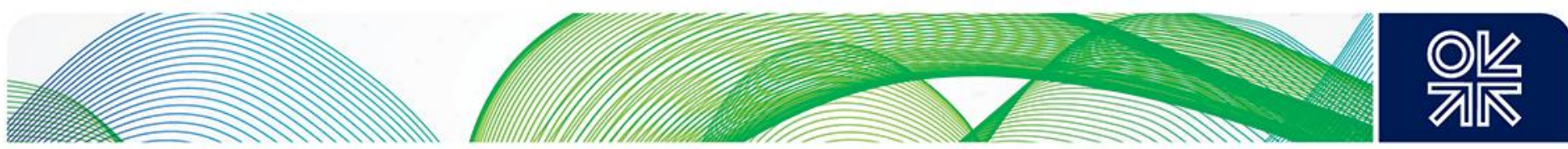

$1.4 \mathrm{mboe} / \mathrm{d}$ in 2018 at a time when industry projections were about $1.6 \mathrm{mboe} / \mathrm{d}$. The out-turn figure was $1.7 \mathrm{mboe} / \mathrm{d}$. ${ }^{34}$ The over-pessimistic BEIS/OGA projections of March 2015 marked a point of inflection in UKCS production and industry expectations. As such, they provide an inappropriate and flattering basis for the assessment of industry performance and the contribution of the OGA and MER UK. There is little doubt that industry performance and the production outlook have improved significantly since 2014-15. However, given the errors in past projections, this improvement is not well measured by the difference between projections made in March 2015 and those made in March 2019.

The OGA's projections of UKCS gas production to 2035 are based on operators' assessment of the economic viability of the discovered resource base in the context of the statutory objective of MER UK and the assumption of continued government and public support for the development of UKCS resources. In contrast, the projections of UKCS gas supply produced by National Grid in its annual 'Future Energy Scenarios' (FES) assume that future UKCS production will be sensitive to UK demand for gas, the costs of meeting the UK's 2050 decarbonisation targets and the extent of political support for continued production from the UKCS in competition with imported sources.

Figure 9: National Grid's UKCS Gas Supply Projections (FES 2018)

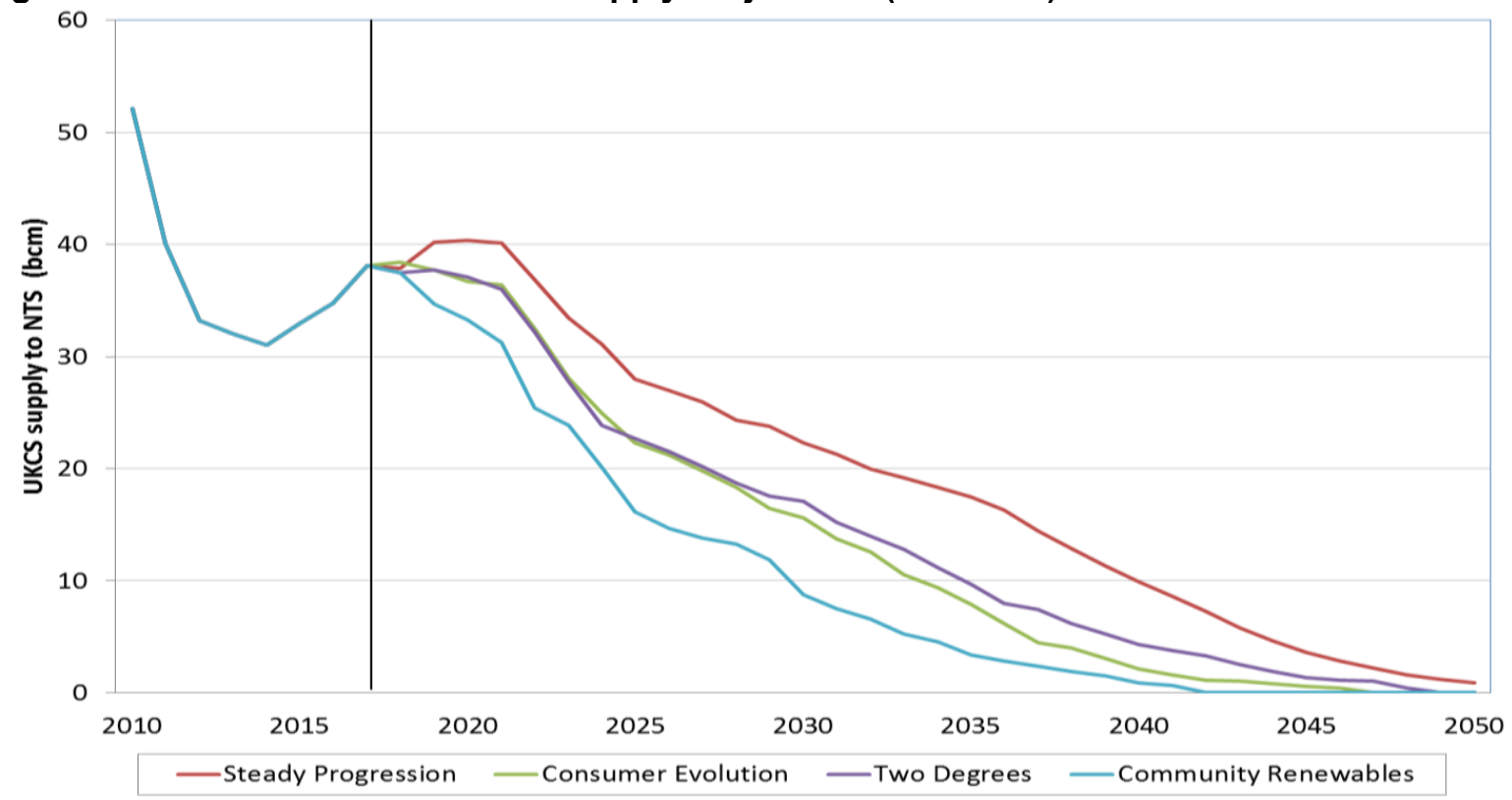

Source: National Grid, Future Energy Scenarios, July 2018

The latest FES ${ }^{35}$ sets out four scenarios for gas and electricity demand to 2050 with different paths for both UK gas demand and gas supply. Figure 9 illustrates the UKCS projections in the four scenarios. Two of the scenarios, Steady Progression and Consumer Evolution, include variants, not shown in the chart, in which shale gas makes a significant contribution to UK gas supply from the late 2020s. Steady Progression shows the slowest reduction in both UK gas demand and UKCS production between 2018 and 2050 while Community Renewables incorporates a much more rapid replacement of gas in domestic heating and the elimination of all UKCS production by 2040 . The UK remains a net importer of gas in all four scenarios. Paradoxically, the highest degree of dependence on gas imports is in the scenario with the lowest gas demand (Community Renewables). The OGA's production projections to 2035 resemble most closely the Steady Progression scenario which projects UKCS output of $17 \mathrm{bcm}$ in 2035 and the cessation of production in 2050.

\footnotetext{
34 'Projections of UK Oil and Gas Production and Expenditure', OGA, 8 March 2019

${ }^{35}$ Future Energy Scenarios, National Grid, July 2018. Gas supply scenarios are discussed on pages 114-121.
} 

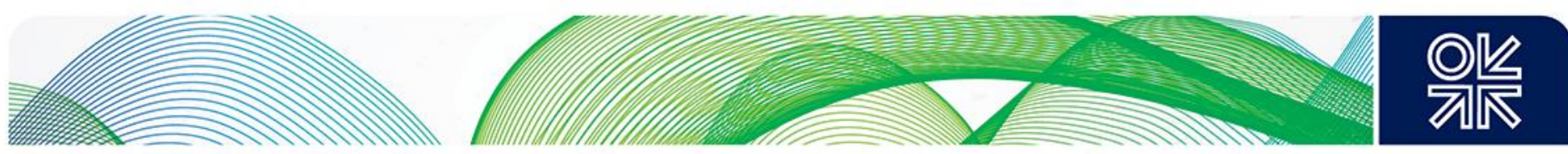

The approach to UKCS supply in the FES is controversial since it appears to ignore the wider economic contribution of UKCS production, especially in Scotland, and the lower GHG emissions associated with UKCS production compared to imported LNG and long-haul pipeline gas. It is also at odds with current government policy which is based on the assessment that MER UK is compatible with the UK's decarbonisation targets and carbon budgets. However, the FES approach does highlight the need for the UKCS to retain government and public support for its continued operation its so-called 'license to operate'. Although the FES approach is not based explicitly on a supply cost model, it does serve as a useful reminder that gas demand is vulnerable to progressive erosion as the UK economy is de-carbonised and that the UKCS must remain competitive with more flexible sources of imported gas if it wishes to meet that demand. It also implies that, in certain decarbonisation scenarios, buyers of UKCS gas may need economic access to fast-cycle onshore storage if the UKCS is to remain a competitive source of supply to wholesale markets.

The OGA has also published projections of UKCS oil and gas production as far as 2050, first developed with industry in 2016-17 as part of its aspirational 'Vision 2035' for the UKCS. ${ }^{36}$ These projections are shown in Figure 10 together with the OGA's own projections published in March 2015 and February 2019. Although Vision 2035 does not identify gas production separately, it is clear that the implied level of gas production is much higher than the OGA's latest projections throughout the period 2020-2050. The geological, economic and financial assumptions behind the projections in Vision 2035 have not been disclosed, so it is difficult to comment on whether these much more optimistic projections are more plausible or credible than the OGA's own projections.

Figure 10: Projections of UKCS Oil and Gas Production 2015-2050

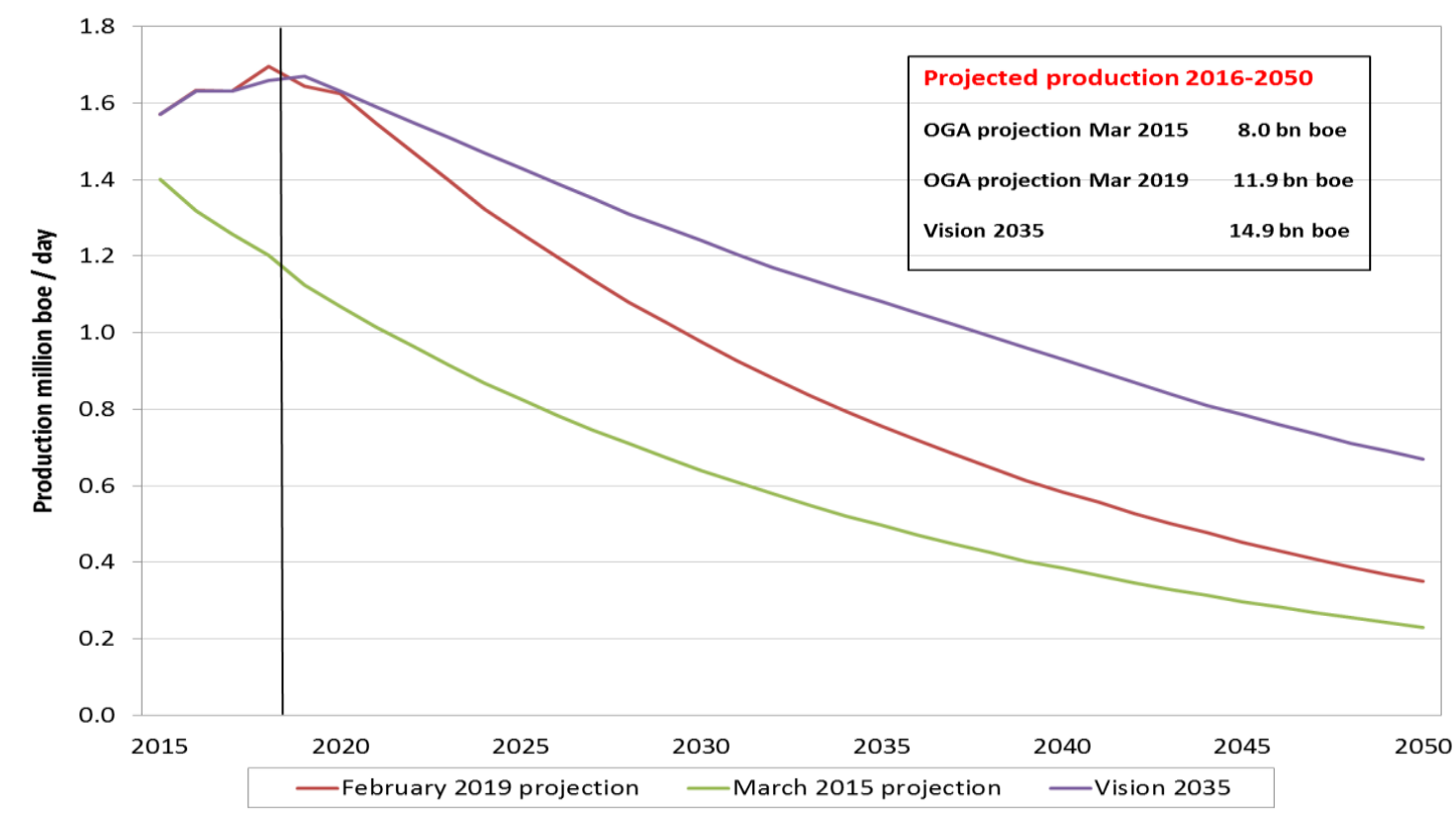

Source: OGA

The Wood Review in 2014 cited a range of $12-24$ bn boe for remaining recoverable resources but offered no supporting analysis. Yet the OGA's projections of production published in March 2015 showed output between 2016 and 2050 of only 8 bn boe, as summarised in Figure 11. Since 2016, the OGA has prudently adopted an expected range of 10-20 bn boe for remaining recoverable resources but has progressively revised up its estimate of cumulative production to 2050. By March 2019, its cumulative production figure between 2016 and 2050 had reached 11.9 bn boe, a net increase in four years of $3.9 \mathrm{bn}$ boe. In the intervening four years (2015-18), the UKCS produced 2.4 

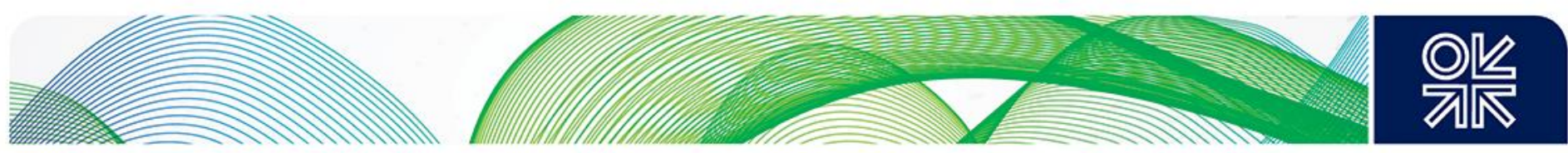

bn boe. In seeking to account for this upward revision of almost $50 \%$, the OGA cites recent 'project sanctions' and 'future exploration' as the most important factors. But it fails to acknowledge what are possibly the two most important underlying factors behind the more optimistic outlook: the tax reductions in 2016 and the industry's success in reducing development and operating costs.

Figure 11: Projections of Cumulative UKCS Production to 2050

\begin{tabular}{lccccc} 
& \multicolumn{3}{c}{ Oil and gas production (mboe/d) } & \multicolumn{2}{c}{ Cumulative production (bn boe) } \\
& $\mathbf{2 0 2 0}$ & $\mathbf{2 0 3 5}$ & $\mathbf{2 0 5 0}$ & $\mathbf{2 0 1 6 - 2 0 5 0}$ & $\mathbf{2 0 1 9 - 2 0 5 0}$ \\
OGA projection (March 2015) & 1.07 & 0.49 & 0.23 & 8.0 & 6.6 \\
OGA projection (March 2019) & 1.63 & 0.76 & 0.35 & 11.9 & 10.1 \\
Vision 2035 (2019) & 1.63 & 1.08 & 0.65 & 14.9 & 13.1
\end{tabular}

Source: OGA, 2019

The more optimistic outlook in Vision 2035 projects even higher production to 2050 (14.9 bn boe) and by implication, continued production well into the second half of the century and total resource recovery towards the top of the range cited in the Wood Review. This aspirational outlook appears optimistic given the known resource base but it has found support from modelling conducted by the University of Aberdeen which concluded that at much as $14.8 \mathrm{bn}$ boe would be produced from the UKCS between 2018 and 2050 at a prevailing oil price of $\$ 60 / \mathrm{bbl}$ and 55 pence/therm (c. $\$ 7.2 / \mathrm{mBTU}$ ) for gas. ${ }^{37}$ Expressed on the same basis as the OGA's own projections, this represents 16.0 bn boe of cumulative production in the period 2016-2050. This marked a significant upward revision from $11 \mathrm{bn}$ boe which was published by the same authors just 18 months earlier. ${ }^{38}$ The results highlighted the importance of reductions in development and operating costs and improved asset reliability achieved since 2014 and the sensitivity of long-term prospects to exploration activity and success rates.

\section{Gas Resources and Reserves}

The discontinuation of the government's annual publication, 'The Development of the Oil and Gas Resources of the UK', known as the 'Brown Book', in 2000 marked the end of a period in which UKCS oil and gas resources, production and revenues were a major issue in the analysis of UK public finances. The government energy department continued to publish annual estimates of proven, probable and possible reserves and 'potential additional resources' (PARS) but its resources devoted to the exercise were allowed to dwindle. The creation of an independent regulator, the OGA, has begun to reverse this earlier neglect of the offshore oil and gas resource base. Recognising the importance of publishing reliable, regular assessments of the remaining resource base as a means of attracting new exploration investment, the OGA is now devoting resources to improving the quality of the publicly available data, its geological modelling and its published annual resource estimates. The launch of the National Data Repository (NDR) in March 2019 for data from wells and seismic and geophysical surveys and information on fields and infrastructure marks an important step in improving access to information needed by prospective investors. ${ }^{39}$ There are already signs of improved quality, timeliness and availability of subsurface data and in the detail of published resource data but it may take some years before the tangible benefits are visible.

\footnotetext{
37 'An Economic Re-assessment of the Long Term Prospects for the UKCS: Can Vision 2035 Become a Reality?' Prof. A Kemp and L Stephen, University of Aberdeen North Sea Study Occasional Paper No.143, October 2018.

38 'The Prospects for Activity in the UKCS to 2050 under Lower for Longer Oil and Gas Price Scenarios and the Unexploited Potential', Prof. A Kemp and L Stephen, North Sea Study Occasional Paper No.138, February 2017.

39 'OGA launches one of the largest ever public data releases', OGA press notice, 25 March 2019.
} 

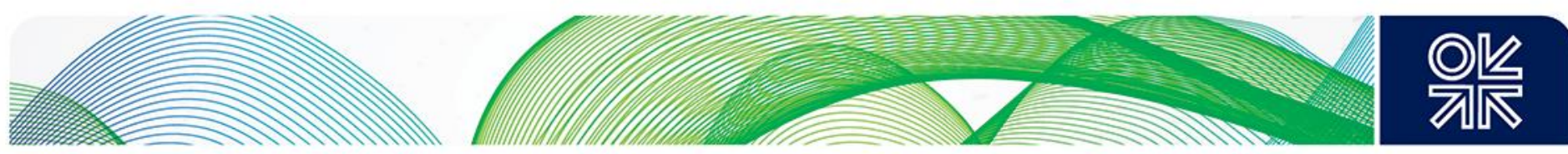

In November 2018, the OGA published its second detailed annual estimates of UK oil and gas reserves and resources. ${ }^{40}$ It estimated that, at the end of 2017, remaining resources of oil and gas on the UKCS were between 10 and 20 billion barrels of oil equivalent, having produced up to that date a total of 44 bn boe. It believes that the resource base 'could sustain UKCS production for another 20 years or more'. Less than one third of the discovered resources on the UKCS are natural gas but curiously more than $60 \%$ of the recently revised estimate of undiscovered resources is believed to be gas. This anomaly may be corrected in future publications as the scope of the resource analysis is extended. The OGA's published figures exclude estimates of unconventional onshore resources of shale oil and gas and coal bed methane.

In 2017, the OGA revised the UK's resource classification system to bring it closer to that of the Petroleum Resources Management System (PRMS) of the Society of Petroleum Engineers (SPE). The three broad categories in the new classification system are 'reserves', 'contingent resources' and 'prospective (undiscovered) resources'. Reserves are discovered, remaining volumes which are recoverable and commercial. Contingent resources are discovered quantities of hydrocarbons which are potentially recoverable but are not yet considered commercial. Each of these categories is subdivided to reflect different levels of confidence over future producibility. In the OGA's published data for end-2016 and end-2017, oil and gas resources in each category were identified separately and three estimates were published for each to reflect different levels of confidence.

In sensibly adopting a more conservative definition of 'reserves' based only on projects which have been sanctioned by participants and have received approval, the OGA downgraded some resources from 'reserves' to 'contingent resources'. The OGA remains largely dependent on operators' own submissions of reserves and resources in existing licensed acreage in the annual Stewardship Survey and does not audit them. However, it develops its own estimates of contingent resources in 'marginal discoveries' (formerly 'unsanctioned discoveries') and of undiscovered or yet-to-find resources. In its published end-2017 resource figures, the OGA widened its definition of undiscovered resources to include a new sub-category of resources in (unmapped) 'plays' but it did not identify oil and gas separately within this new sub-category.

The composition of the OGA's gas resource estimates at the end of 2015, 2016 and 2017 is shown in Figure 12. At the end of 2017, the OGA identifies proven and probable (2P) gas reserves of $275 \mathrm{bcm}$, and a further $380 \mathrm{bcm}$ of contingent resources comprising resources in producing fields, proposed new developments and marginal discoveries in licensed and unlicensed acreage.41 In addition, a mean estimate of undiscovered gas in almost 3,500 'prospects and leads' was put at 410 bcm. ${ }^{42}$ Excluded from the chart are undiscovered resources in unmapped 'plays'. The resource figures for the end of 2017 exclude any volumes associated with the Glendronach gas discovery announced by Total in September 2018 and the Glengorm discovery announced by CNOOC in January 2019. We expect a significant upward revision to the gas reserve estimates for end-2018 and a further reclassification of contingent and undiscovered gas resources.

\footnotetext{
40 UK Oil and Gas Reserves and Resources as at end 2017, OGA, November 2018.

41 The sub-category of contingent resources, 'marginal discoveries' corresponds roughly to 'potential additional resources' or PARs in the earlier government classification.

42 For the new, stochastic methodology and risk-based estimates on the undiscovered gas resource, see 'UK Oil and Gas Reserves and Resources as at end-2017', OGA 2018, pp18-26.
} 

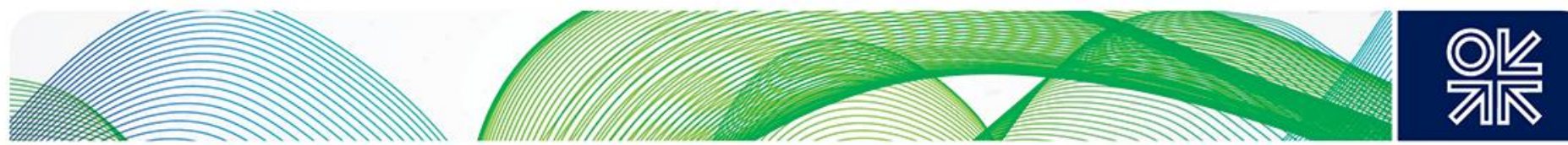

Figure 12: Composition of UKCS Gas Resources 2015-2017

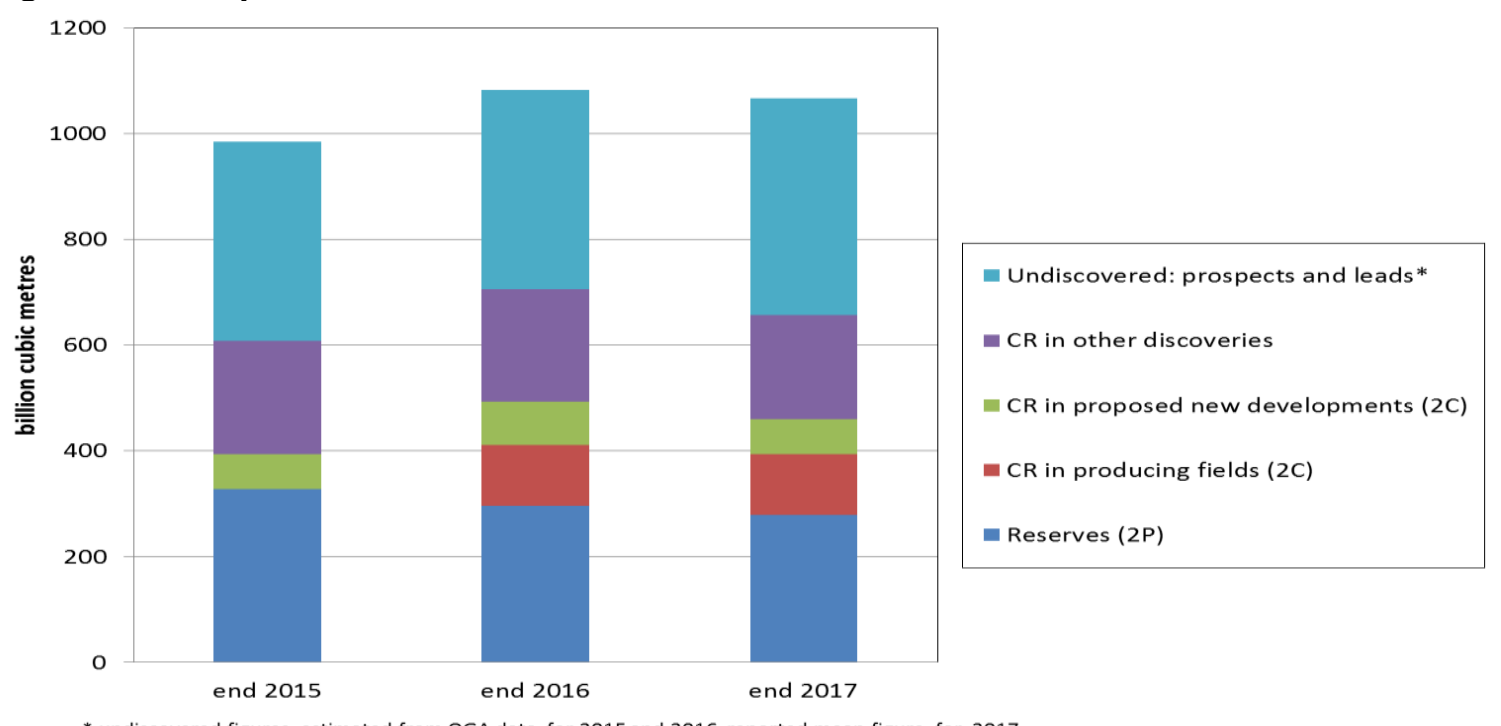

Source: OGA 2017, 2018

The changes in the classification system mean that the published data for 2016 and 2017 are not directly comparable to those published for 2015 and earlier years. However, it is instructive to look at the evolution of official figures for UKCS gas reserves and estimated ultimate recovery (EUR) over the last 45 years. Figure 13 shows cumulative gas production and remaining reserves from 1973 to 2017. Between 1973 and 1995, both remaining gas reserves and the EUR rose progressively but since 1995 remaining reserves have been in steady decline, falling to $275 \mathrm{bcm}$ at the end of 2017 . The figure for EUR has stabilised at about $3,000 \mathrm{bcm}$ because of the persistently low rate of gas discoveries and reserve replacement in recent decades. The clear implication of the latest end-2017 reserves figures is that $80-90 \%$ of the ultimate recoverable gas resource has already been produced and there is uncertainty over how much of the remaining gas resource base can be economically recovered.

Figure 13: Cumulative UKCS Gas Production and Remaining Reserves 1973-2017

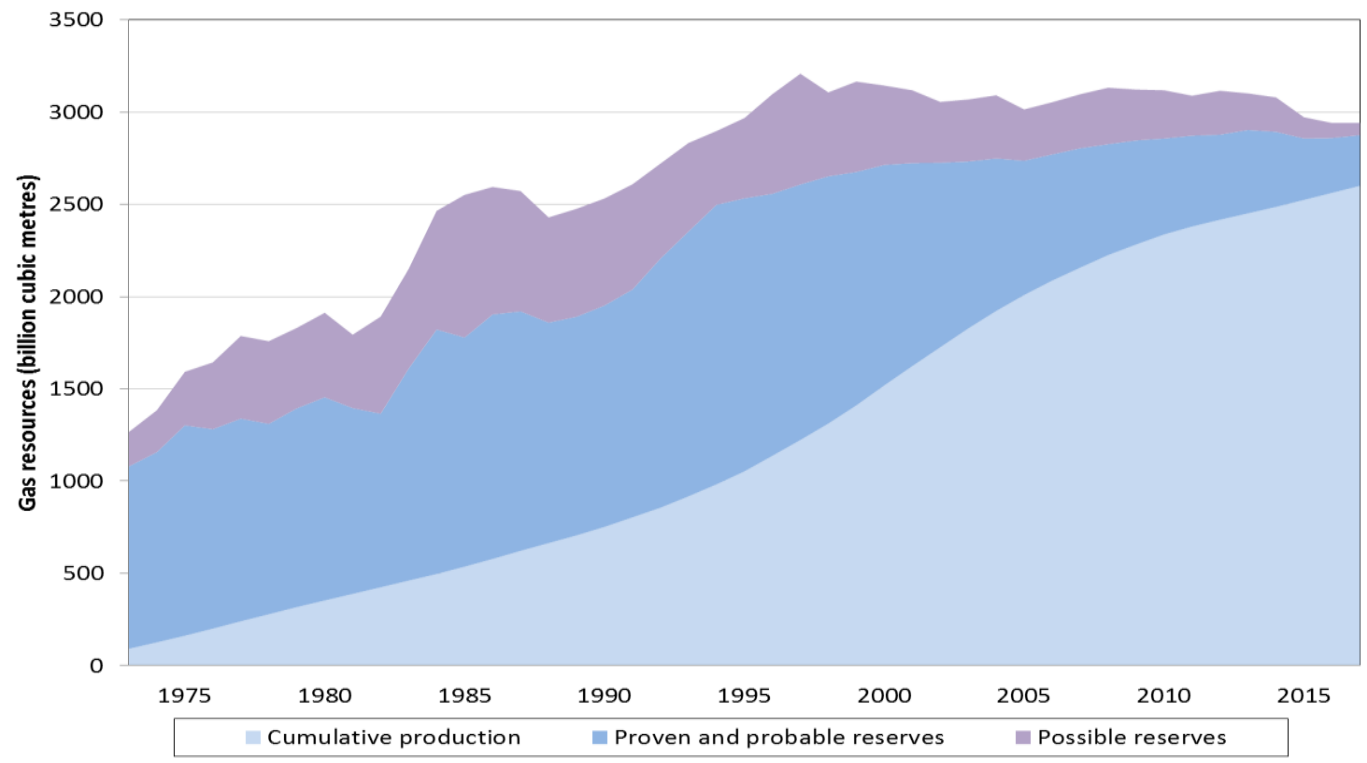

Source: DECC, OGA 2018 

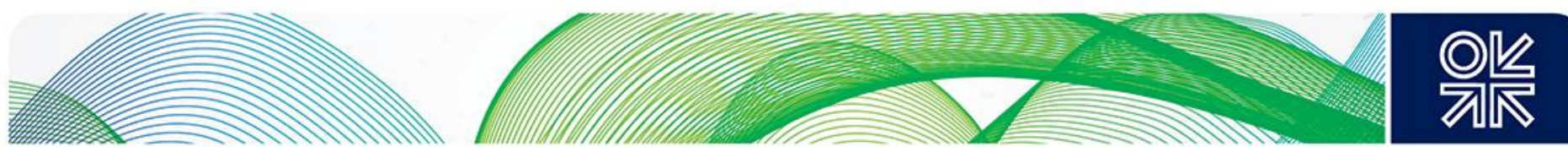

Gas makes up $31 \%$ of both UKCS hydrocarbon reserves (2P) and UKCS contingent resources (2C) but the OGA estimates it accounts for more than $60 \%$ of identified undiscovered resources. The OGA provides a regional breakdown of reserves and contingent resource data but unlike the NPD in Norway it does not release individual field data in order to protect commercially sensitive company information. Nor does it specify the economic assumptions regarding the oil price or gas price on which the resource estimates are based. The OGA has improved disclosure of resource data by providing a breakdown of both reserves and the sub-categories of contingent resources by the five regions of the UKCS. It also published in 2018, for the first time, a breakdown by region of prospective undiscovered resources in 'prospects and leads'. The regional distribution of total gas reserves and resources at the end of 2017 is presented in Figure 14. It highlights, above all, the importance of the Central North Sea (CNS), where the largest gas condensate fields are located, and the mature Southern North Sea (SNS) in the existing gas reserve base from which most gas will be produced in the 2020s. It also shows the considerable longer-term potential of the higher-risk discovered and undiscovered resources West of Shetland.

\section{Figure 14: Distribution of UK Gas Reserves and Resources at End of 2017}

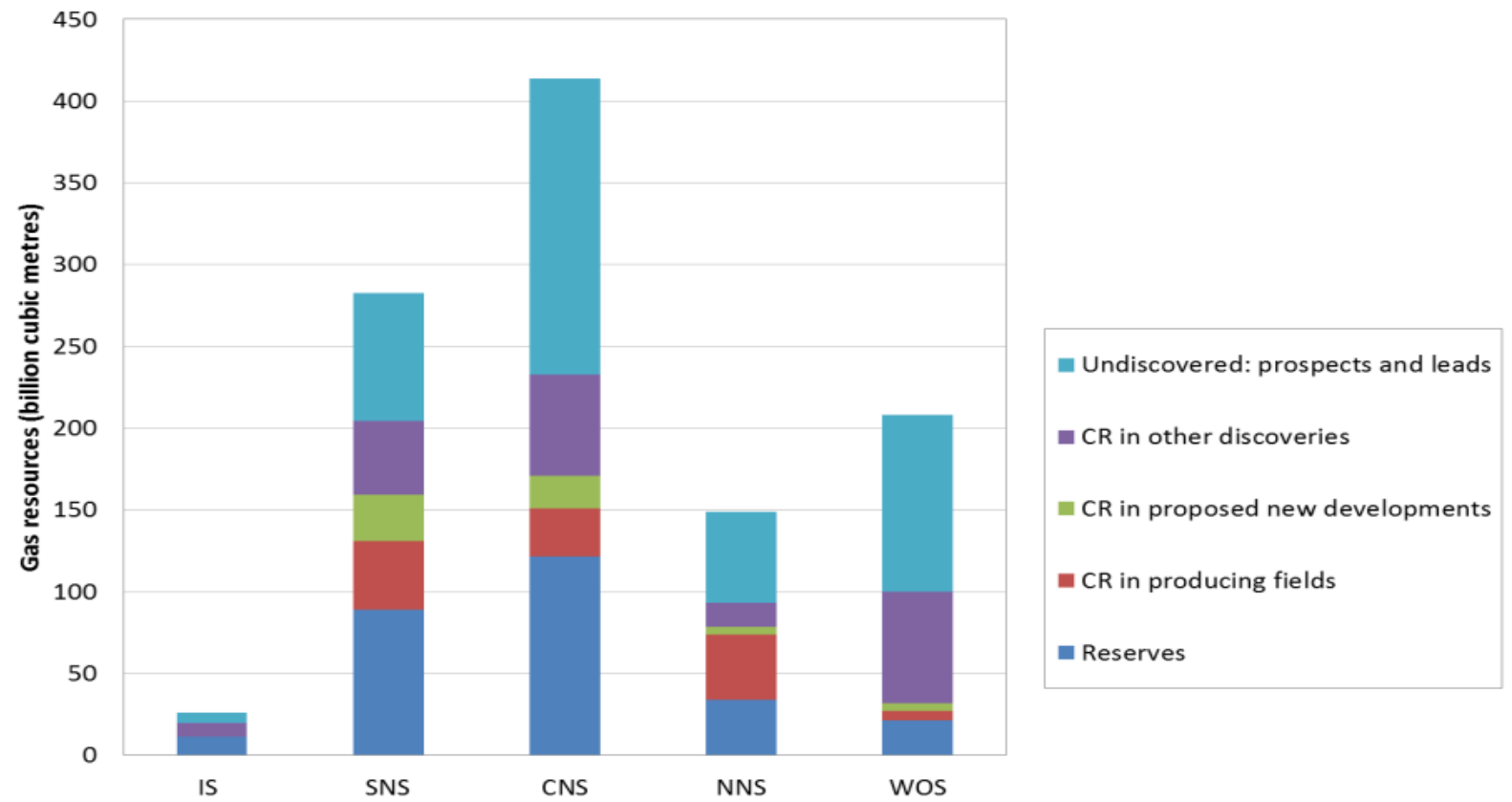

Source: OGA 2018

The OGA now also publishes a breakdown of $2 \mathrm{P}$ gas reserves and resources in proposed developments (2C resources) by field type, which distinguishes between dry gas, gas from gas condensate fields and associated gas produced from oil fields. At the end of 2017 , these sources amounted to about $330 \mathrm{bcm}$ of gas. Figure 15 presents these data by field type, revealing the significant weight of both gas condensate fields, mainly in the CNS, (122 bcm) and dry gas in the SNS $(86 \mathrm{bcm})$ in the proven and probable reserve base. It is notable that the OGA downgraded its estimate of gas condensate $2 \mathrm{P}$ reserves by $30 \mathrm{bcm}$ or almost $20 \%$ between end-2016 and end-2017 but it offered no commentary on the revision. 

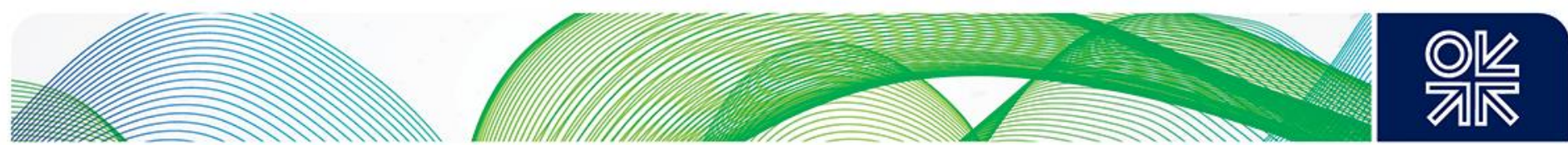

Figure 15: Gas Reserves and Resources by Field Type at End of 2017

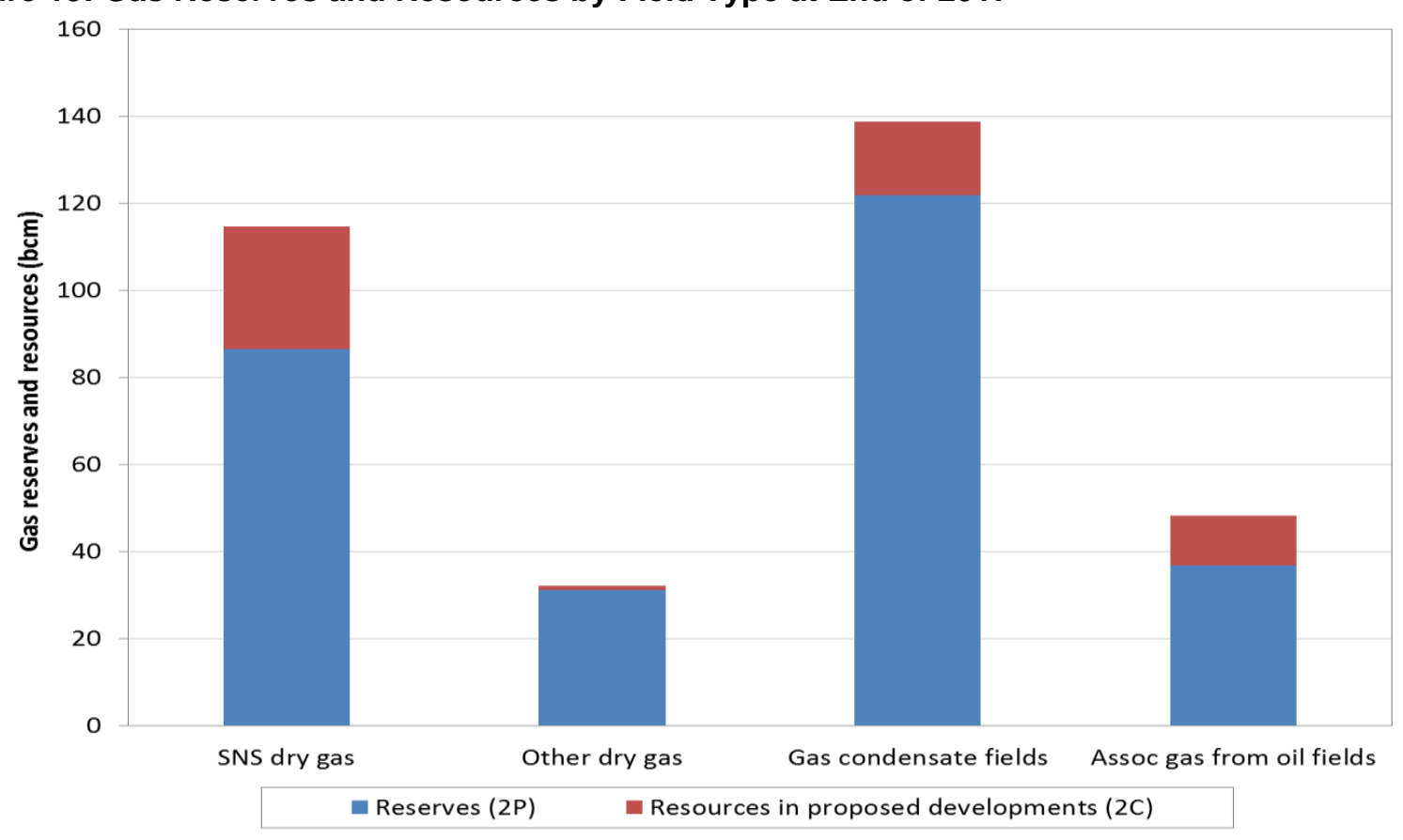

Source: OGA 2018

The latest OGA figures show that the composition of the UKCS reported gas resource base is rather different from that of oil and the implied level of confidence in the gas resource base is somewhat lower than for oil. Gas reserves represent a shorter expected life of about seven years at current production rates of about $40 \mathrm{bcm}$ per year, compared to about 10 years for oil. Secondly, the contingent gas resources reported by operators in producing field and proposed new developments is proportionately much smaller; more than half the contingent gas resources are in 'marginal discoveries' which is assessed by the OGA, not by operators. Finally, a much higher share of the total expected resource is currently undiscovered since so much of the undiscovered hydrocarbons are believed to be gas. This discrepancy between and oil and gas is perhaps to be expected since, from an operator's point of view, the economics of discoveries of oil are generally more favourable than those of a gas discovery of the same size, in part because of the greater dependence of gas developments on infrastructure. This is reflected in the different composition of discovered reserves and resources of oil and gas West of Shetland where gas infrastructure has been developed much later than in the North Sea. At the end of 2017, less than $10 \%$ of the oil identified West of Shetland was categorised as 'marginal discoveries' but for gas the share was almost $70 \%$. More than $40 \%$ of the discovered oil resources West of Shetland were classified as reserves but only $20 \%$ of discovered gas was classified in this way.

As the OGA itself acknowledges, the expected rate of rate of decline of UKCS gas production in the 2020s will be dependent on the development of discovered gas condensate fields in the CNS, some of which are technically demanding high-pressure, high-temperature (HPHT) fields, and on the development of the remaining dry gas reserves of the mature SNS before the decommissioning of existing infrastructure. Beyond about 2025, the area West of Shetland offers a considerable opportunity to slow the rate of UKCS production decline if existing and new discoveries can be brought into production as gas-gathering infrastructure is gradually extended and expanded. Although analysis of the reported gas resource base cannot anticipate possible future gas discoveries, it reinforces the firm expectation that future UKCS gas production will depend on three important factors: 

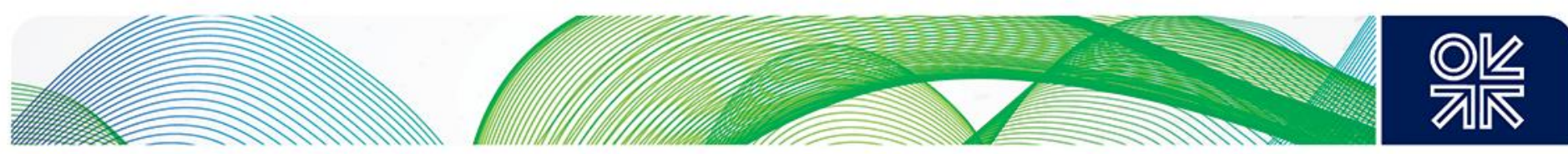

- the economics of joint liquids and gas production, especially in gas condensate fields

- the economic viability and longevity of the SNS as a producer of dry gas and

- the maturing of existing discoveries of gas in the less mature area west of Shetland.

The OGA is committed to improving the quality of its published and unpublished data on the undiscovered resource base with a view to promoting investment in both mature and frontier areas of the UKCS. It has adopted a new approach and worked with external entities including the British Geological Survey (BGS) to develop more reliable, risk-based estimates and improved geological modelling. It is interesting to note that its latest mean estimate of undiscovered resources in almost 500 prospects and leads (4.1 bn boe) has a much higher share of gas $(61 \%)$ than the previous upper estimate of 9.2 bn boe in 3000 prospects and leads which included only $38 \%$ gas. Further elaboration of the methodology is expected and further revisions of the published estimates for undiscovered gas may follow.

The adoption by the OGA of the new resource classification system in 2016-17 and its efforts to improve the quality and availability of its resource and sub-surface data represent a welcome step in the right direction. However, the changes are coming rather late in the life of the UKCS and it remains to be seen whether improved data quality and availability will be enough to stimulate new exploration and appraisal drilling.

\section{Licensing Policy and Exploration Activity}

UK legislation vests all rights to oil and gas resources in the Crown and gives the OGA (formerly the government) the authority to grant licences and to confer exclusive rights to explore for or to produce petroleum. The OGA has discretion in both the granting of exploration and production licences and in the enforcement of the obligations assumed by licence holders as it seeks to meet its obligation to promote MER UK.

The first offshore licences to explore and to produce petroleum were awarded in 1965. Licensing rounds held over the following decades were led principally by industry interest in UKCS exploration rather than a consistent, sustained approach by the government as licensor to promote resource discovery systematically in designated areas. Since it assumed responsibility for licensing in 2015, the OGA has adopted a more systematic and predictable approach to offshore licensing with the explicit aim of re-vitalising UKCS exploration activity to promote MER UK.

The Wood Review endorsed the existing UKCS licensing model but deplored the 'critically low level of exploration activity'. In 2013, only 15 exploration wells were drilled on the UKCS. The Review described this as 'totally inadequate to exploit the undiscovered potential of the UKCS within the lifespan of existing infrastructure'. ${ }^{43}$ Few would have disagreed but submissions to the review revealed different interpretations of the underlying reasons. Some industry submissions cited the unattractive tax regime, especially for new entrants, and restricted access to capital but others placed more emphasis on the deterioration in geological prospectivity, falling exploration success rates and the loss of international competitiveness. Unlike the regime in Norway, the UK tax system does not offer any particular incentive to exploration. Explorers need to have existing production to benefit from the Investment allowance (IA) and to alleviate the costs of unsuccessful exploration. In Norway, the costs of unsuccessful exploration attract full tax relief or a cash reimbursement for investors without existing production. In 2018, 53 exploration and appraisal (E\&A) wells were drilled in Norway but only 17 on the UKCS.

\footnotetext{
${ }^{43}$ Four years later, in June 2018, Sir lan Wood, in something of an under-statement, described the current level of exploration as 'disappointing' in evidence to a parliamentary committee. In 2018, only 8 exploration wells were drilled on the UKCS.
} 

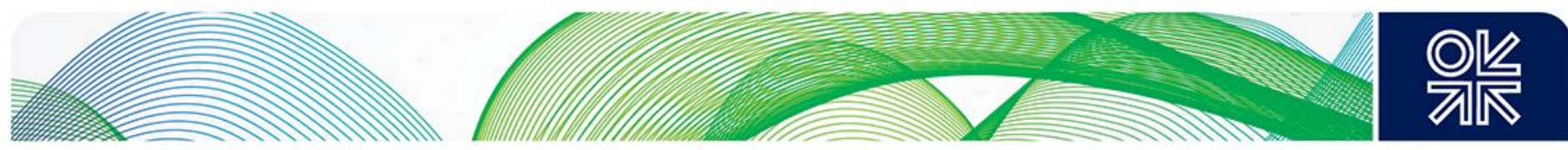

The Wood Review recommended the adoption of an Exploration Strategy and identified no fewer than 12 action points covering the promotion of future exploration, new seismic data acquisition, improved data sharing and efforts to reduce drilling costs. On licensing policy and licence terms, it recommended the consideration of greater flexibility in the performance of drilling commitments and earlier release of data acquired by licensees. Since 2015, broadly speaking, the OGA has followed these recommendations in setting out its Exploration Strategy ${ }^{44}$ and in making significant changes to the licensing process. It was backed in this effort to revive exploration by two rounds of direct government funding for new seismic data acquisition in under-explored areas of the UKCS. In 2015 and 2016, the government allocated a total of $£ 40$ million to two programmes to acquire new seismic data which was made available free of charge to stimulate interest in new licensing rounds. A further $£ 5 \mathrm{~m}$ of government funding was allocated to the OGA to promote exploration in September 2017.

The OGA's new approach to licensing recognises that the UKCS is highly differentiated in its degree of maturity. Some parts, such as areas west of Shetland and the Atlantic margin, remain underexplored and can accurately be described as 'frontier' areas. In contrast, many areas of the SNS and CNS are undeniably highly 'mature' with much less scope for large discoveries in future. Within these more mature areas, the OGA has placed a new emphasis on improving access to updated subsurface data and on exhausting all exploration potential near existing fields and existing infrastructure, so called 'infrastructure-led exploration'.

In a move which replicates the Norwegian approach to licensing, the OGA introduced annual licensing rounds with alternating offers of frontier and mature acreage. The 29th Round, launched in 2016, offered acreage in under-explored and frontier areas in the Rockall Trough and the Mid North Sea High covered by the government-funded seismic programme; it was also the first to use the OGA's new flexible 'Innovate' licence. In 2017, in its first mature licensing round, the 30th Round, the OGA offered a huge acreage across the UKCS with new seismic data made available in many areas. This elicited strong interest from the industry and led to the award of 123 new licenses to 61 companies, including 14 licences which will proceed directly to the field development stage. Although firm commitments to drill only 8 wells were made, the round was deemed a success in re-awakening investor interest. In July 2018, the OGA launched the 31st Round which extended the acreage available in frontier areas beyond the west of Shetland and the east Shetland platform to the English Channel and the South West Approaches. The industry response marked a further increase in industry interest from the 29th frontier round; the award of licenses is expected in mid-2019. In November 2018, the OGA took the unusual step of launching a 31st Supplementary Round dedicated to the mature Greater Buchan area of the Outer Moray Firth in the CNS where there are a number of undeveloped discoveries in a remaining resource base of $150-300 \mathrm{mboe}$. In the summer of 2019, the OGA will formally launch the 32nd licensing round in mature areas of the UKCS.

Figure 16 shows that since 1965, more than 2500 exploration wells and almost 1900 appraisal wells have been drilled on the UKCS. Over short periods, one can observe changes in exploration activity linked to fluctuations in the oil price, discretionary cash flow and changes in the UKCS fiscal regime. However, it is difficult to overlook the steady increase in exploration activity in the first 25 years between 1965 and 1990 in what was a highly prospective, new producing province and the subsequent irregular decline in the following 28 years as geological prospectivity and expected discovery size gradually diminished and post-tax exploration economics deteriorated. In 2018, only 8 exploration wells and 9 appraisal wells were drilled, the lowest level since the first year of exploration in 1965.

\footnotetext{
${ }^{44}$ Exploration Strategy, OGA, October 2016
} 

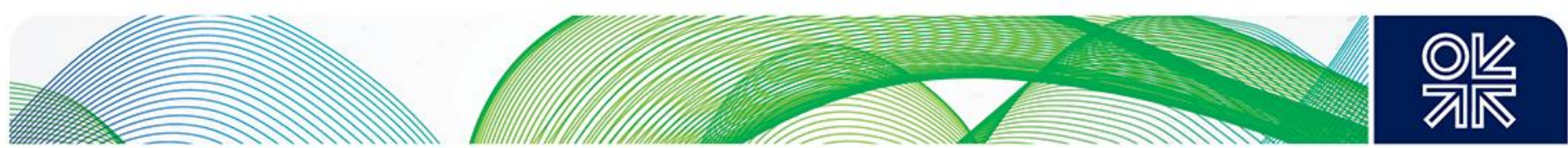

Figure 16: UKCS Exploration and Appraisal Wells Drilled 1965-2018

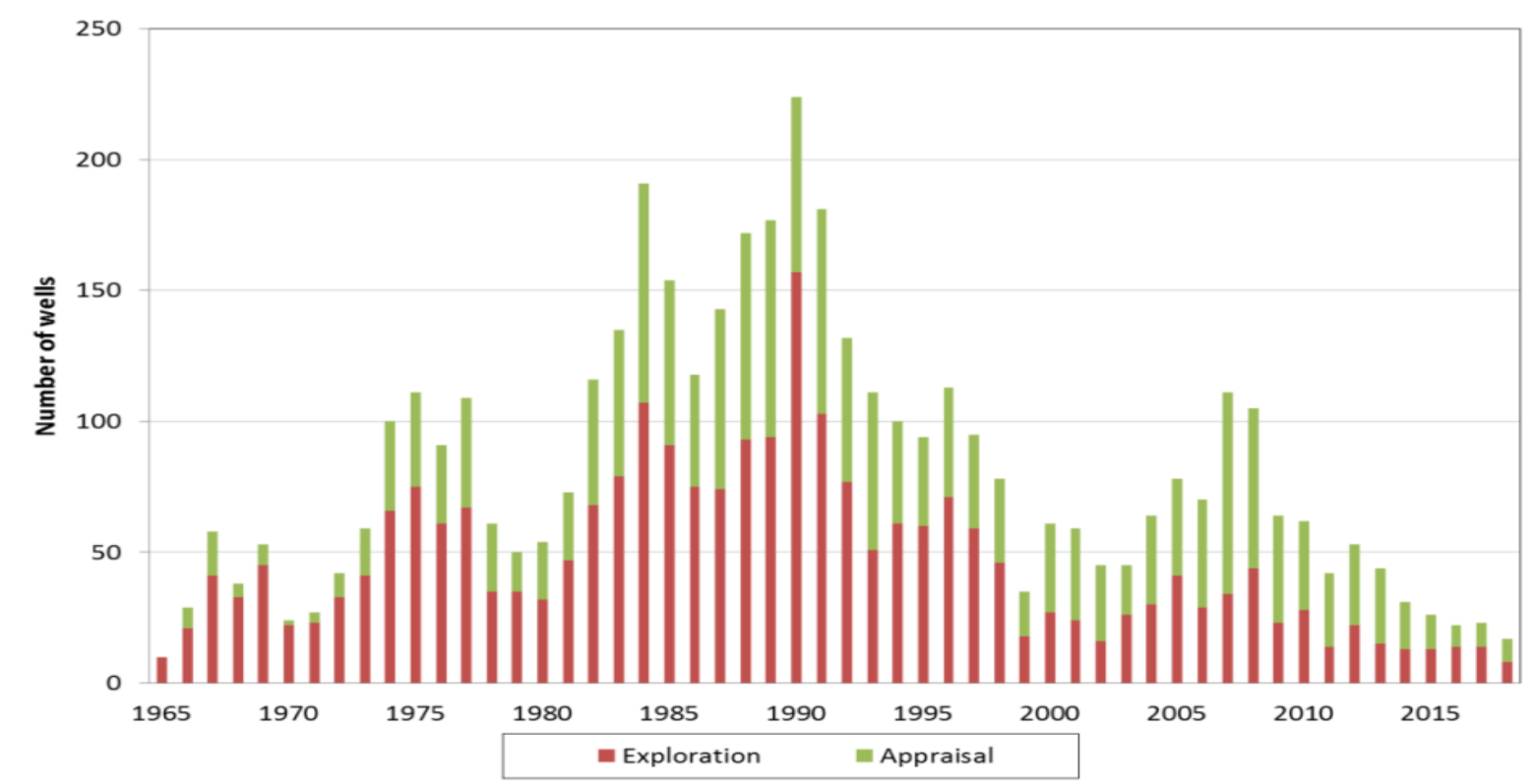

Source: BEIS, OGA

There is little doubt that one of the fundamental reasons for the downturn in exploration drilling after 2008 was an extended run of disappointing results. The Glendronach and Glengorm gas discoveries in 2018-19 provide a welcome reversal of this trend. The CNOOC-operated Glengorm discovery announced in January 2019, estimated at 250 mboe, is the largest gas discovery on the UKCS since the Culzean gas condensate field was discovered in 2008. Nevertheless, it remains true that the UKCS has not recently produced a major, world-class discovery of 1-2 bn boe comparable to the discovery of Johan Sverdrup in 2010, which transformed the investment environment in the mature North Sea area of the NCS.

Figure 17: Exploration and Appraisal Wells Drilled by Region 2000-18

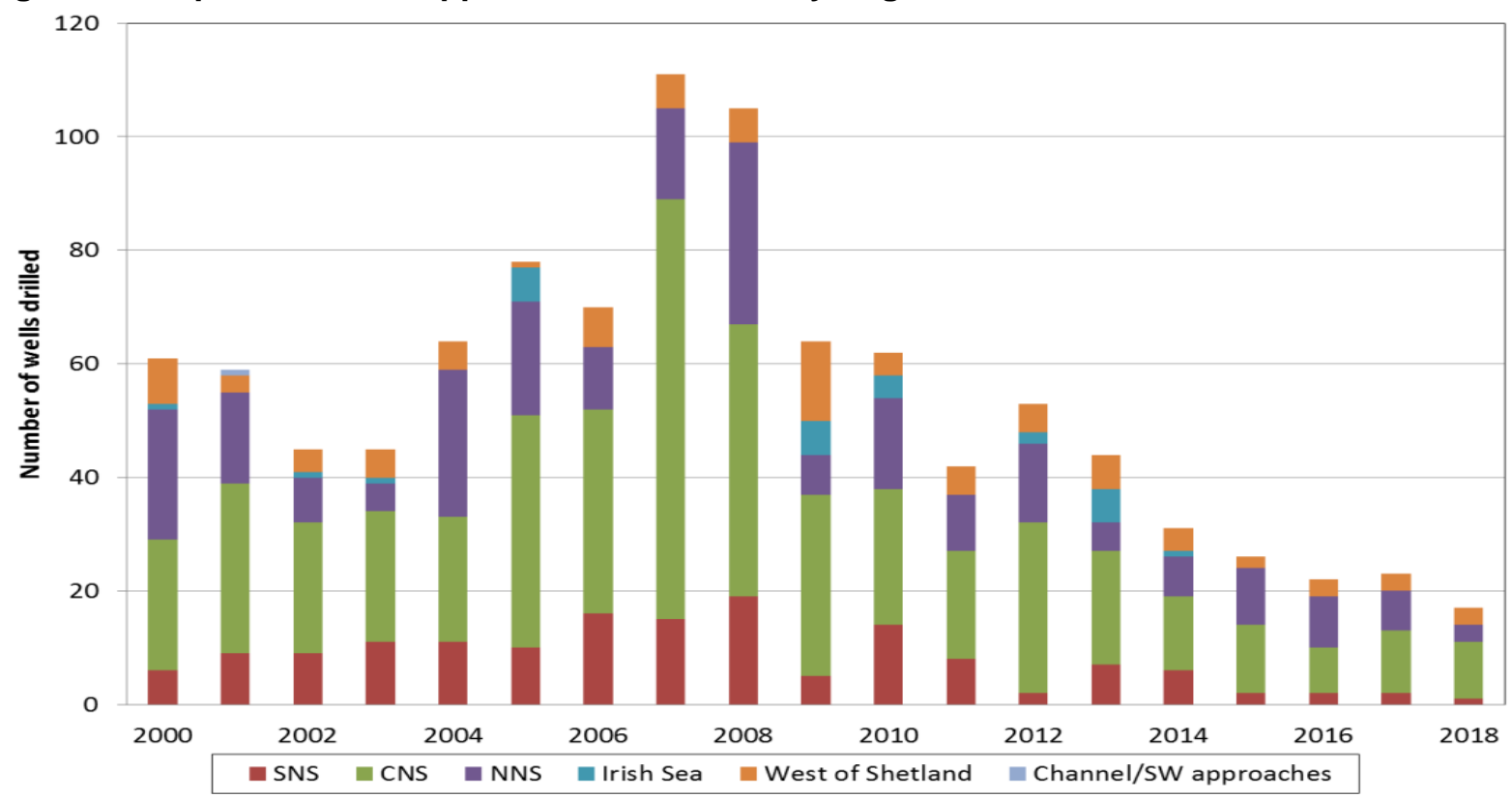

Source: Drilling Activity on UKCS, OGA, April 2019 

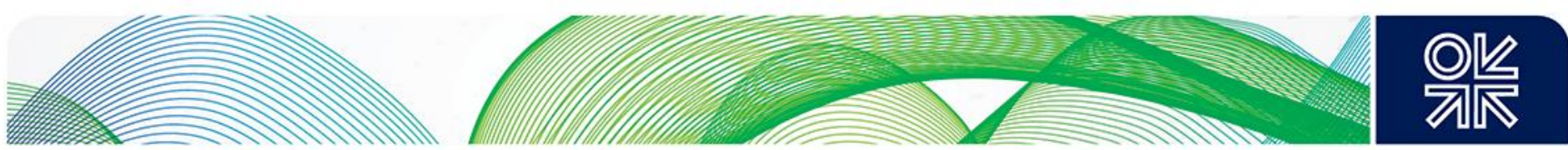

Exploration and appraisal (E\&A) drilling has contracted steadily in all regions of the UKCS since 2008, as shown in Figure 17. The CNS continues to account for about half the E\&A wells drilled in the UKCS. Drilling in dry gas regions dwindled to just one exploration well in the SNS in 2018; the last well spudded in the Irish Sea was in 2014. Even west of Shetland, the number of E\&A wells drilled fell to just three per year in 2016-18. The scale of the challenge facing the OGA in revitalising exploration should not be underestimated. The barriers to exploration investment comprise both 'below ground' factors, such as geological complexity and data access and quality, and 'above ground' factors, such as the cost of risk capital, infrastructure access and partner misalignment. The OGA has made progress in improving data quality and access, notable through its seismic programmes and the creation of the National Data Repository (NDR). It is also promoting its Area Plans as a means of improving collaboration and reducing some of the 'above ground' barriers. Despite the recent increase in investor interest in the licensing rounds since 2016, the scale of new drilling commitment has so far been modest. Even when commitments are made, operators have sometimes sought to postpone drilling by requesting the extension of their licenses. The OGA has already signalled that licence extensions may not be granted so readily in future. ${ }^{45}$

The annual resource data do not attribute resource additions each year to exploration but the OGA discloses annual estimates of discovered resources through exploration and appraisal. These data, reproduced in Figure 18, show the disappointing results of UKCS exploration between 2011 and 2017. In 2019, it reported additional discovered resources in 2018 were 245 mboe, making 2018 the best year for discoveries since 2010. In 2017, the OGA set out a new 'key performance indicator' for exploration to generate additional recoverable resources of 200 mboe per year as a 5-year average. It cannot ensure this target will be met but at least the oil and gas discoveries made in 2018-19 and renewed industry interest in exploration will provide a welcome fillip to further E\&A activity.

Figure 18: Discovered Resource Additions through Exploration 2005-18

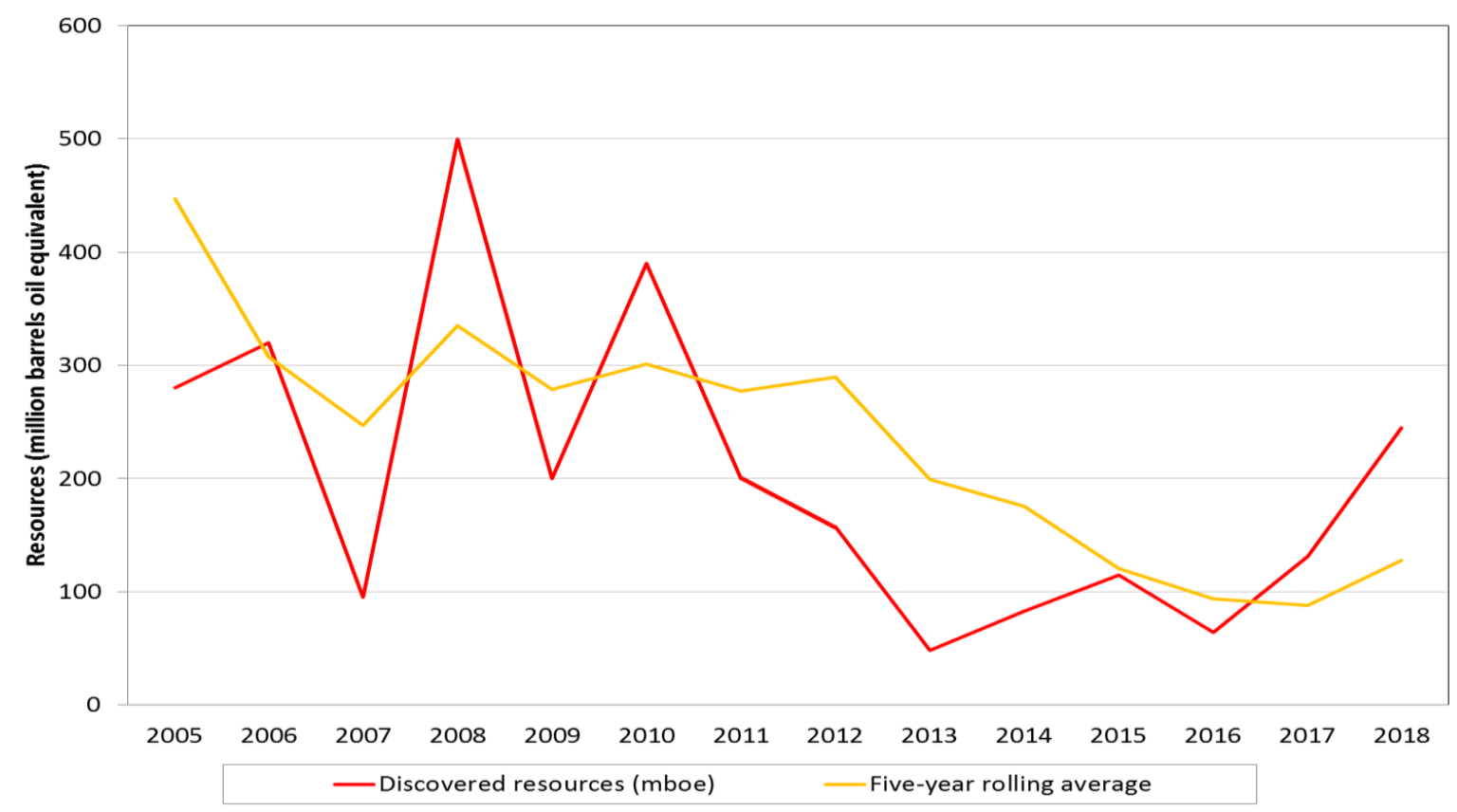

Source: OGA, 2019

There are already signs that the lowering of tax rates, the fall in drilling rig rates and renewed industry interest shown in the $30^{\text {th }}$ and $31^{\text {st }}$ rounds will lead to a modest increase in E\&A drilling in 2019-20. New drilling may also be stimulated by the recent improvement in commercial success rates and the

45 'OGA signals patience is running low over work commitment slippage', Upstream, 3 January 2019 

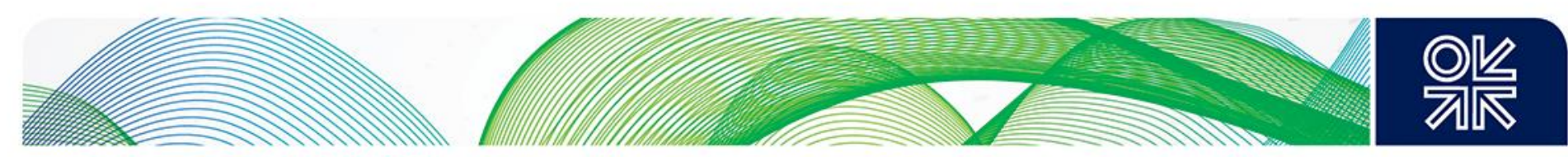

sizeable gas discoveries made in 2018-19. An increase to 20-30 E\&A wells is currently expected in 2019 but sustaining the recovery in 2020 and beyond is not assured. Restoring both the quantity and quality of exploration drilling on the UKCS is perhaps the most pressing challenge for the OGA. If the expected recovery in 2019 is not sustained, the OGA and the government may need to review the regulatory and fiscal approach to exploration set out in 2015-16. Without a sustained recovery in exploration, the aim of MER UK will be seriously jeopardised.

Figure 19: Main UK Offshore and Onshore Gas Infrastructure

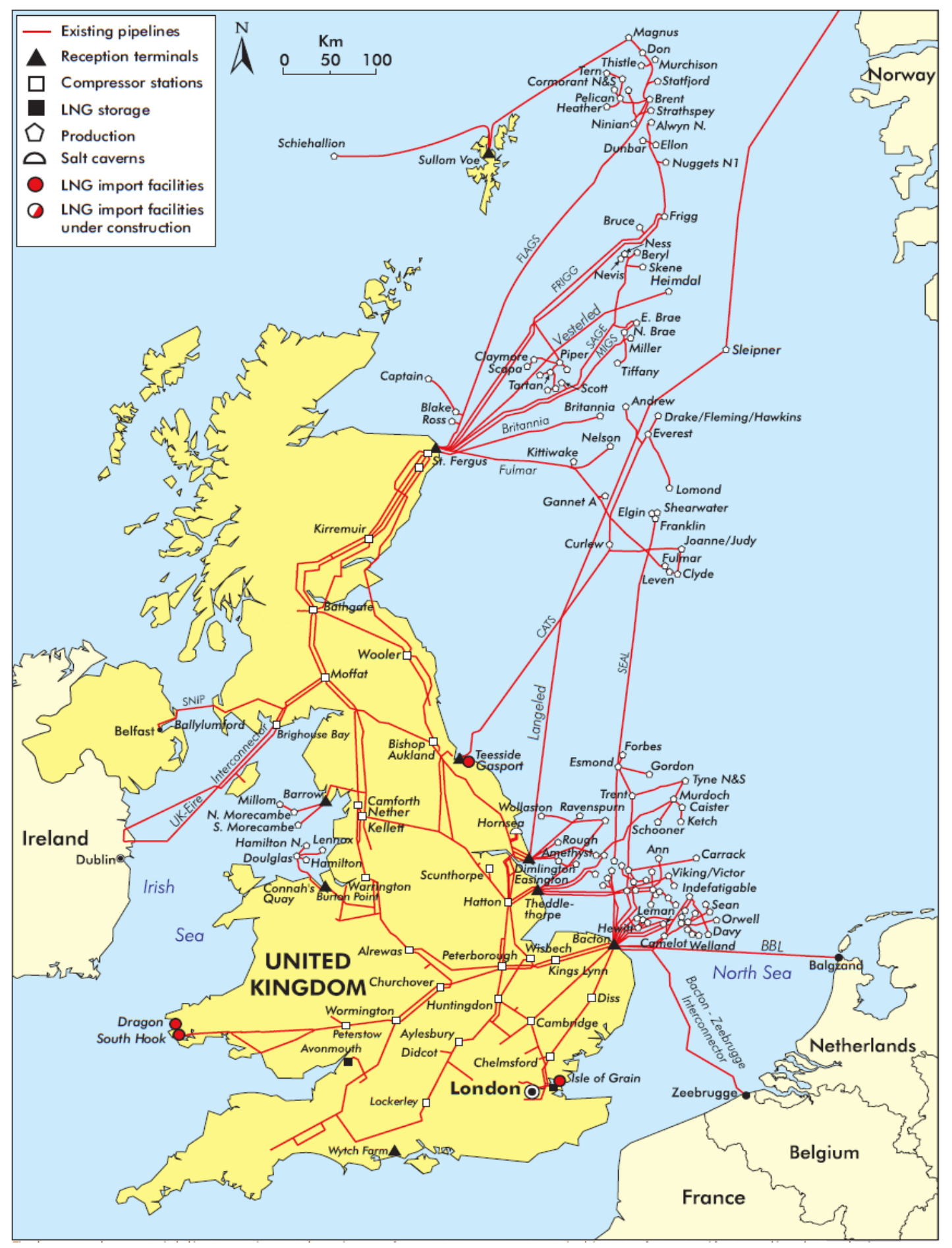

Source: DUKES, 2018 

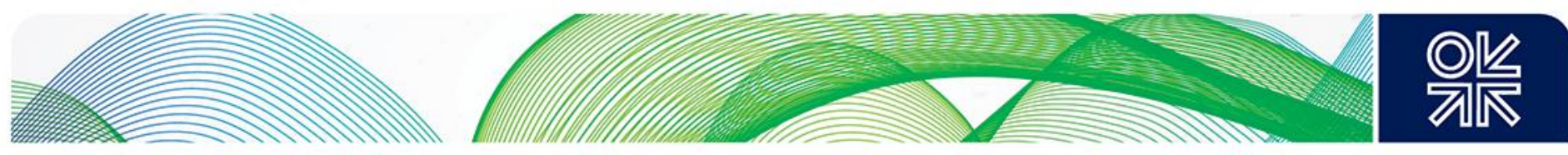

\section{Gas Processing and Transportation Infrastructure}

The physical transportation and processing infrastructure needed to deliver gas from the wellhead of almost 300 offshore fields to the entry points of the NTS comprises offshore pipelines, hub platforms and onshore terminals. The composition of the wellhead hydrocarbon flows largely determines the location and extent of gas processing to meet the tight gas quality specifications at onshore entry points to the NTS. Typically, liquids and gas are separated at offshore hub platforms before transportation by pipeline to shore. Wet or rich gas with a high proportion of liquids requires processing and fractionation at an onshore gas terminal to remove the NGLs before the remaining dry gas can be delivered into the NTS. 'Off spec' wellhead gas with a high proportion of impurities such as $\mathrm{CO}_{2}$ or $\mathrm{H}_{2} \mathrm{~S}$ may be co-mingled with other sources of gas in offshore pipelines but will usually require onshore processing to meet NTS entry quality specifications. In general, gas produced in the SNS and the Irish Sea is dry and needs limited onshore processing but flows from the CNS and NNS demand more extensive processing to strip out impurities and to extract NGLs. The two main centres for onshore gas processing and NGL extraction are St Fergus in north-east Scotland and Teesside in north-east England which between them account for almost all gas produced from the NNS and CNS. Terminals at Bacton represent the main landing points for SNS production. Figure 19 shows the main offshore gas-gathering pipeline systems and the main onshore terminals.

Gas infrastructure on the UKCS was typically originally constructed, owned and operated for their sole use by the major oil and gas companies that developed the earliest offshore fields. As spare capacity (ullage) developed, it was offered to third party users or capacity was expanded or extended to serve new discoveries tied into the existing infrastructure through commercial negotiation between infrastructure owners and resource holders. The result is that today there is a multiplicity of commercial transportation and processing agreements, some decades old, between producers and infrastructure owners on each UKCS pipeline system which ensure that produced gas can be marketed.

Throughout the history of the UKCS, infrastructure ownership has generated income through tariffs and cost-share payments from third party users. In 2017, both offshore pipeline systems and terminal operations generated income which exceeded their operating costs. ${ }^{46}$ For some offshore operators third-party infrastructure income makes up a significant share of total upstream income. As the UKCS has matured and the average size of discoveries has declined progressively, access to existing infrastructure on fair and reasonable terms has become increasingly important since new discoveries are seldom large enough to justify their own separate infrastructure.

Third party access (TPA) to existing upstream oil and gas infrastructure under fair and reasonable commercial terms has been recognised since 1975 as essential for economic development of discovered resources on the UKCS. However, the UK has relied upon negotiated commercial access with statutory powers to determine access terms used only when parties fail to agree. This approach contrasts with the position in Norway where regulated TPA was assured from the beginning of offshore resource development, privately financed infrastructure is incorporated into a single entity (Gassled) operated by state-owned (Gassco) and the financial returns to infrastructure owners are determined in legislation.

The UK industry introduced a voluntary code of practice in 1996, later revised in 2004 as the Infrastructure Code of Practice (ICOP), to set a framework for access negotiations but disputes and delays continued to arise occasionally in both oil and gas. The Energy Act 2011 updated the statutory regime and extended the scope of upstream facilities and services for which the government had

\footnotetext{
${ }^{46}$ UKCS Operating Costs in 2017, pp 9-11, OGA October 2018. Aggregate cost data indicate that gross operating costs (before
} tariff income and cost-sharing) represents 2-3 pence/therm of gas marketed in 2017. 

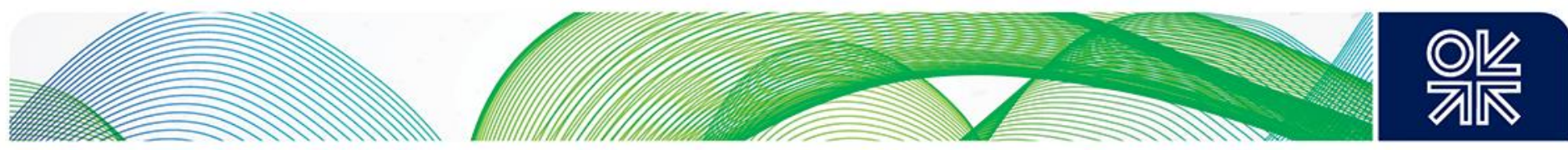

powers to determine the terms of access when a dispute arose. The Energy Act 2016 passed these dispute resolution powers from government to the OGA. Significantly, the revision of ICOP in 2017 to reflect the new role of the OGA preserved the long-standing provision which allows infrastructure owners to reserve capacity for their own use provided the reservation is based on firm plans. This provision may of course, in some circumstances, run counter to the objective of MER UK if highervalue production by a third-party producer/shipper is denied access to infrastructure by an owner whose lower-value production is entitled to take precedence.

MER UK introduces an overlay to the existing ICOP and dispute resolution process. The OGA (and its predecessor BEIS) have been called upon to intervene in infrastructure disputes on average once a year since 2010; in all but once case, the parties have reached agreement through renegotiation without the need for a formal Notice. ${ }^{47}$ The OGA has urged all companies to comply fully with ICOP and has published clear guidelines on how it expects to exercise its powers if parties cannot resolve TPA disputes. Equally importantly, it has sought to promote commercial agreement and to prevent disputes reaching the stage where they require formal resolution.

The challenge the OGA faces today in pursuing MER UK concerns not so much TPA to existing facilities as the cessation of field production and the decommissioning of existing infrastructure before all economic resources are recovered from a particular area. Resource depletion and a decline in production and infrastructure throughput will at some point make it uneconomic to continue to operate the existing infrastructure. However, the closure of offshore pipelines and onshore terminals at the point at which they cease to cover their costs may leave recoverable hydrocarbon resources stranded. The case of the closure of the Theddlethorpe gas terminal in 2018, discussed below, provides an interesting example of the current challenge faced by the OGA over decommissioning.

The size and extent of the offshore gas pipeline network reached its maximum extent in the late 1990s. As North Sea gas production has declined since 2000, so the utilisation rate of offshore and onshore infrastructure has also fallen. Although owners may be protected in the short-term by tariff payments for capacity or cost-sharing arrangements, the long-term viability of infrastructure is gradually undermined by falling utilisation as operating costs are spread over ever smaller volumes. Even the more economically secure gas pipeline systems such as CATS, which brings gas from 30 fields in the CNS to Teesside, often run today at utilisation rates well below $50 \%$ of capacity; the most vulnerable economically may run at only $10-20 \%$. In some areas of the mature North Sea, especially the SNS and NNS, elements of critical offshore oil and gas infrastructure have been identified as being at risk of premature decommissioning, which would leave some local resources stranded unless preventive measures are taken by operators.

The industry's response to falling infrastructure utilisation has been to reduce operating costs and to attract new sources of revenue. This has been achieved through consolidation of onshore facilities in mature areas like the SNS, concentration of offshore flows via fewer hub platforms by redirecting production and, where possible, by attracting new gas flows from beyond traditional producing areas. The four original Bacton terminals have been integrated to form three today. At St Fergus, the development of the Laggan-Tormore fields west of Shetland led to the construction of the new SIRGE pipeline from the Shetland Gas Plant to the NSMP St Fergus terminal. Since 2000, the FLAGS, SAGE and NSMP offshore pipeline systems have all attracted new gas flows from Norway to their respective St Fergus terminals to use ullage created by the decline in CNS and NNS production. In 2017, St Fergus received an estimated $17 \mathrm{bcm}$ of Norwegian gas in addition to the $13 \mathrm{bcm}$ from UKCS fields. Infrastructure investment in the CNS is also responding to new field development, as illustrated by Shell's recent decision to redirect gas flows from its Shearwater platform from Bacton to St Fergus to maximise NGL extraction from new fields tied back to Shearwater.

The original owners among the oil and gas majors have sold most of their gas infrastructure assets to new upstream entrants such as Ineos or to specialist infrastructure players backed by private equity

\footnotetext{
${ }^{47} \mathrm{~A}$ list of TPA disputes referred to the OGA is available on the OGA website under TPA/Disputes and Sanctions.
} 

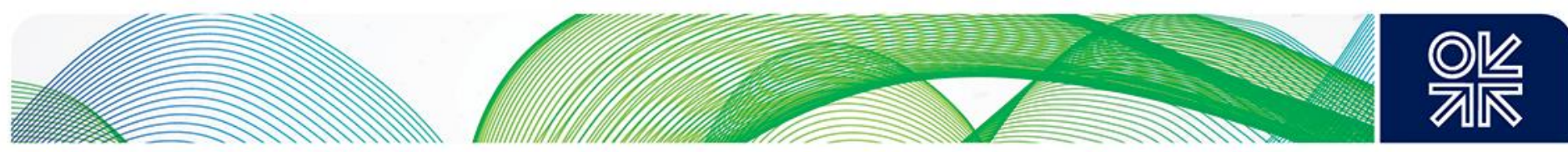

firms attracted by the relatively stable financial returns. Shell remains the only major company to have retained its gas infrastructure assets as an integral part of its UKCS upstream assets. In 2013, North Sea Midstream Partners (NSMP), backed by US private equity from ArcLight, bought the Teesside Gas Processing Plant (TGPP) and in 2015 it purchased the FUKA and SIRGE pipeline systems and the St Fergus terminal from Total. Antin Infrastructure Partners purchased interests in the CATS pipeline and Teesside processing assets from BG in 2014 and BP in 2015. In 2018, Antin bought further offshore pipeline assets in the SNS from Premier Oil to co-finance the Tolmount gas field development. In the NNS, in 2017 Ancala Midstream purchased from Apache its interests in the SAGE and Beryl pipeline systems and its onshore gas terminal at St Fergus. By 2018, more than 25\% of UKCS oil and gas infrastructure was owned by private equity or infrastructure funds. ${ }^{48}$

These new specialised infrastructure companies offer not only a low-cost operating model but also, prospectively, a higher propensity to invest to meet shippers' needs. The OGA has warmly welcomed the emergence of these new infrastructure investors as a means of aligning the interests of resource holders and infrastructure operators and creating new opportunities from existing and new infrastructure. Certainly, such investors have a potentially important part to play in the delivery of improved recovery of UKCS gas resources. There are also potential operational efficiencies which these new independent owners may be better-placed to deliver. An example is the improved coordination among operators of planned outages of oil and gas infrastructure on the Forties Pipeline System, the SEGAL System and at the NSMP and SAGE terminals at St Fergus; this is expected to reduce disruption to UKCS and NCS oil and gas production and increase facilities uptime. In the past, terminal operations lay beyond the scope of regulation and excessive regard for competition law concerns deterred such co-ordination and collaboration. These failings of the past are now, at last, being addressed by operators and the OGA as part of its wider efforts to promote collaborative commercial behaviour.

The proposed closure by Conoco of the offshore LOGGS pipeline system and the Theddlethorpe Gas Terminal (TGT) serving SNS gas fields was one of the priority cases faced by the independent OGA in 2016. The terminal began operations in 1972 but throughput, which peaked at $14 \mathrm{bcm}$ in 2000, had fallen to $2.1 \mathrm{bcm}$ in 2017. In 2014, Conoco notified its partners and third-party users that it did not intend to operate the terminal beyond the end of the existing processing contracts in 2018. Many of Conoco's own small fields were already being decommissioned. Conoco complied with all its existing contracts and regulatory obligations in ceasing terminal operations in August 2018 and has since begun the process of physical decommissioning to meet its statutory end-of-life obligations. The closure of the terminal meant that owners of the Ineos-operated Clipper South field were required to invest in a new pipeline to re-route their gas from TGT to the Shell Bacton terminal. This entailed the expenditure of $£ 80$ million and a three-month interruption of Clipper South production. At smaller fields, for which such investment was not economic, gas production ceased in 2018 and any remaining gas resources are unlikely to be recovered in future. The extent of the stranded resources has not been disclosed.

The OGA has extensive powers regarding the construction of new infrastructure or a proposed change of use of existing infrastructure since its consent is required for Field Development Plans and Pipeline Works Authorisations (PWAs). Since 2016, these long-standing powers may be used to pursue MER UK. Regarding infrastructure decommissioning, its powers and options are more limited, as the Theddlethorpe case illustrates. The OGA cannot require infrastructure operators to continue operations at a financial loss and may find itself constrained by the existence of commercial agreements which were drawn up long before MER UK was introduced. In such cases, the OGA can ensure only that affected parties are given early opportunities to search for alternative commercial arrangements, including possibly a change of ownership, and that the stranding of remaining gas resources is minimised. The issue of gas infrastructure decommissioning and the mitigation of any adverse impact on MER UK within the framework of existing commercial contracts may present itself again shortly in the east Irish Sea where production by both Spirit Energy and Conoco use the processing facilities at the onshore North Morecambe terminal operated by Spirit Energy.

${ }^{48}$ OGA Overview 2019, March 2019, p13 'Changing face of ownership'. 

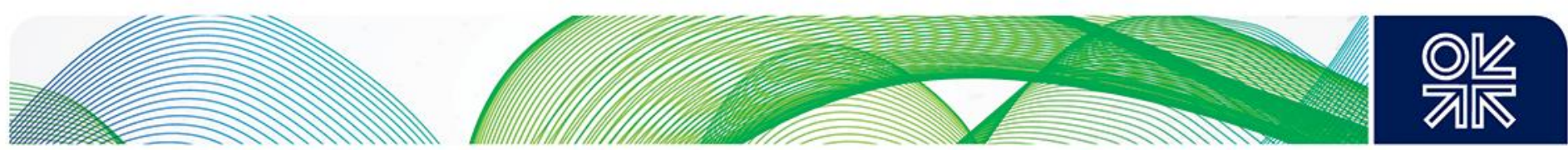

The OGA estimates that there are over 300 marginal discoveries of oil and gas within $20 \mathrm{~km}$ of existing infrastructure. In those parts of the UKCS where decommissioning of infrastructure presents a risk to the recovery of these resources, the OGA is promoting Area Plans, hub strategies or exploration activity to mitigate the risk of stranded resources. Gas infrastructure decommissioning in the 2020s and 2030s will have consequences not only for the recovery of remaining oil and gas resources but also for the shape and size of the onshore NTS operated by National Grid. The emergence of spare capacity at almost all NTS entry points receiving UKCS gas has long deterred the booking of entry capacity by shippers in auctions, leading to increasing distortion in the recovery of NTS operating costs from shippers. ${ }^{49}$ From an operational point of view, UKCS and NCS flows into the NTS are normally the most stable and predictable elements of gas supply, in sharp contrast to more price-sensitive flows from regas terminals and the two interconnectors at Bacton. As the OGA addresses the implications of gas infrastructure decommissioning for MER UK in the years ahead, so Ofgem and National Grid will have to address the implications of the commercial and physical decommissioning of entry capacity for the configuration and operation of the NTS.

\section{Gas Production Prospects by Region}

In this section, we briefly describe the outlook for gas production in each of the five regions of the UKCS to 2024, the main efforts to deliver MER UK and the basis for the 'base case' projection of gross output presented in Figure 20. Projections have been based on reported field production data to 2018 and operators' published plans for new field commissioning, development or decommissioning. The projections exclude the possible contribution from future gas discoveries and assume no further significant changes in the UKCS tax regime. The overall outlook is one of a gradual decline in UKCS output from $41 \mathrm{bcm}$ in 2018 to $33 \mathrm{bcm}$ in 2024. Production is expected to decline in all regions of the UKCS, except West of Shetland, as Figure 20 illustrates. The current position and the short-term outlook to 2024 in each of the producing regions are discussed in turn below.

Figure 20: UKCS Gross Gas Production Projections by Region 2010-2024

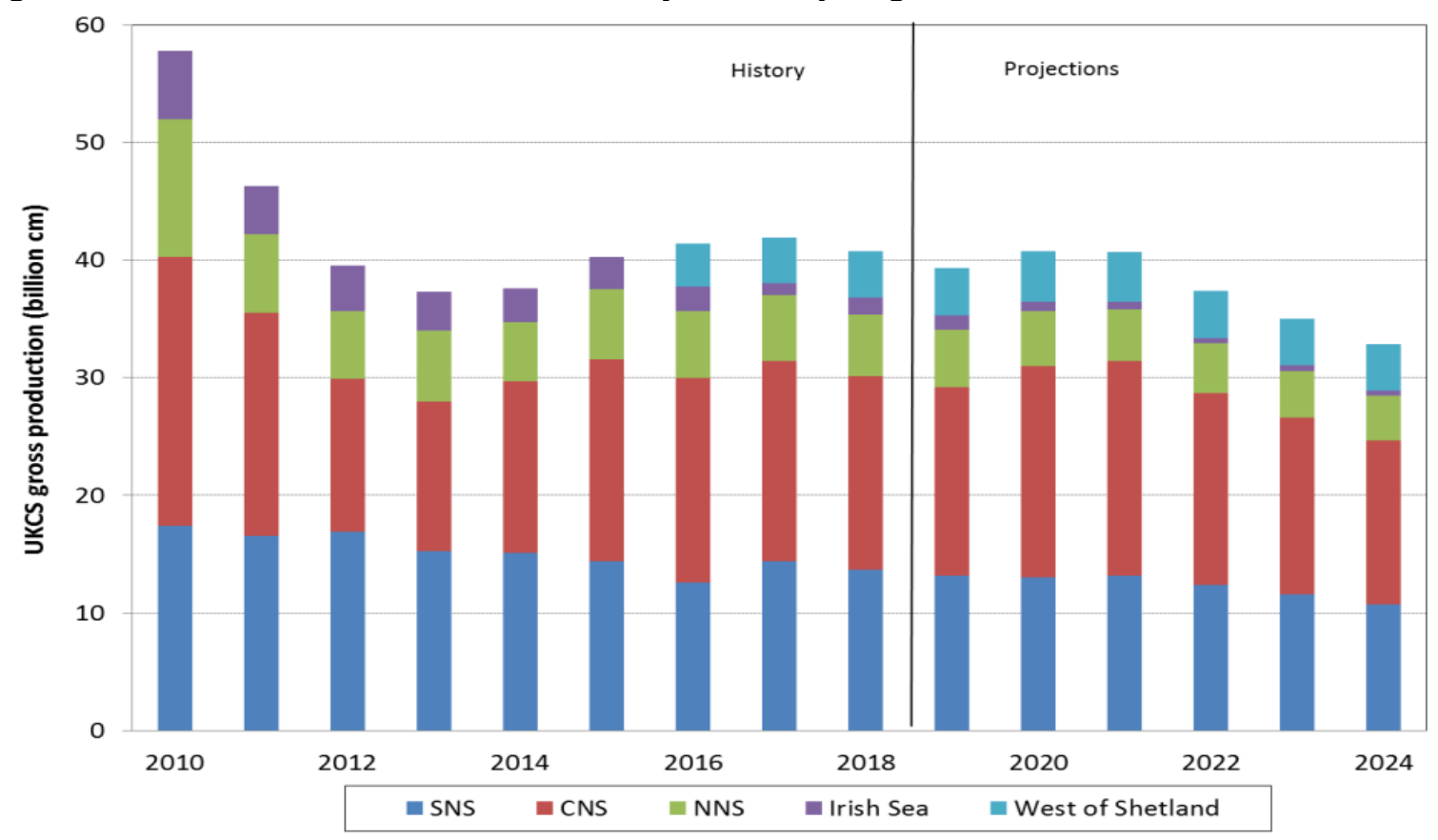

Source: UK DUKES, BEIS 2010-18, author's projections 2019-24

\footnotetext{
49 The current GB Gas Charging Review, initiated by Ofgem, is expected to reform the existing cost recovery methodology and to create a more sustainable basis for charging shippers for NTS entry capacity.
} 

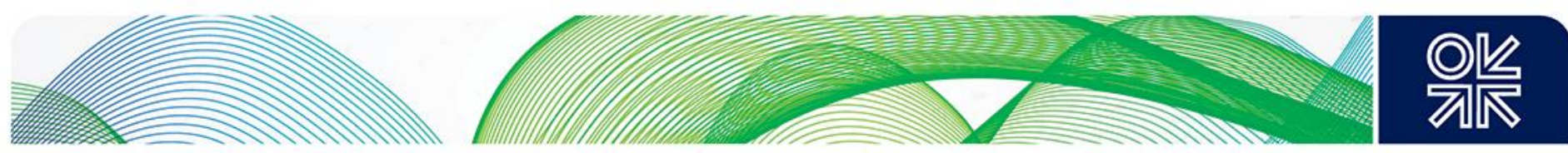

\section{Southern North Sea (SNS)}

As the earliest source of offshore gas, the shallow water SNS was the first area of the UKCS to enter a period of declining gas production and the first to face the decommissioning of offshore and onshore infrastructure. Output peaked at $44 \mathrm{bcm}$ in 2000. After a short period of rapid decline at its largest fields, between 2005 and 2017 SNS output fell at a rate of 3-7\% per year to $14 \mathrm{bcm}$ in 2017 . Producing fields deliver gas through several offshore pipeline systems to terminals at Bacton, Dimlington, Easington and, since the start-up of the Breagh field in 2013, to Teesside. The Theddlethorpe terminal ceased operations in August 2018 after 46 years, leaving a group of small fields which produced $1 \mathrm{bcm}$ in 2017 without a route to market. The most southerly SNS fields around Markham are connected to the Dutch offshore network. In 2018, they produced $0.8 \mathrm{bcm}$ and output will continue to diminish as infrastructure is decommissioned. The OGA estimates remaining $2 \mathrm{P}$ gas reserves in the SNS of $86 \mathrm{bcm}$ and a further $28 \mathrm{bcm}$ of contingent (2C) resources, including tight gas in the Carboniferous. The main SNS producing fields in 2017-18 were Cygnus (the largest producing field on the UKCS in 2017), Clipper South, Breagh, Leman, Ravenspurn and Rough which began licensed production again in 2018.

Although the SNS is sometimes dismissed as a highly mature area concerned only with decommissioning and late-life management, there have been some notable discoveries there in recent years, including Pegasus and Wingate in the Carboniferous and Tolmount in the Permian. It is also an area of the UKCS where industry cooperation among operators is already well established. The SNS had little benefit from high oil prices in 2011-14 and already had a long experience of cost control and sharing facilities. The OGA and the East of England Energy Group set up the SNS Rejuvenation Group in 2016, to continue work undertaken by the industry 'to promote exploration and appraisal drilling, to protect critical infrastructure' and, ultimately, to recover the 'estimated 3.7 tcf (105 $\mathrm{bcm}$ ) of gas from current assets'. ${ }^{50}$ The OGA has also conducted work on two specific issues which relate to the SNS in particular, so-called 'gas-to-wire' and tight gas from low-permeability reservoirs.

In August 2018, the ONS published a discussion paper on a possible partnership between offshore gas production and adjacent offshore wind farms, or 'gas-to-wire' (GTW), in the SNS and the Irish Sea. ${ }^{51}$ The OGA envisaged the use of gas to produce electricity offshore and to transmit power to shore via transmission lines built recently for offshore wind farms, rather than delivering gas to shore via existing gas pipelines. It sees this as a commercial possibility in the SNS and the Irish Sea, where offshore wind farms have been developed in the last decade close to existing gas field platforms and the gas industry is planning for further decommissioning of offshore and onshore gas facilities. As a means of extending the producing life of existing gas fields beyond the decommissioning of existing gas pipelines and onshore infrastructure and of using under-utilised offshore power transmission lines, the GTW proposal deserves further elaboration and study. However, it remains some way from commerciality given the difficult current investment economics of new gas-fired generation in the GB market.

The OGA estimates that the SNS contains $3.8 \mathrm{tcf}(108 \mathrm{bcm})$ of accessible tight gas in lowpermeability formations, mainly in the older Carboniferous rocks below existing gas-producing horizons. Producing gas from these undeveloped discoveries and prospects through horizontal drilling and fracking has long been seen as relatively high-cost and high-risk compared to alternative conventional sources on the UKCS. In 2017, the OGA set out an ambitious strategy to promote industry collaboration and technological advances to make such development economic. ${ }^{52}$ Much of the effort to promote tight gas springs from the desire to extend the life of the remaining SNS

\footnotetext{
50 'OGA and EEEGR launch SNS Rejuvenation Group', OGA press release 19 October 2016

51 'Gas-to-Wire: UK SNS and EIS', OGA September 2018.

52 Southern North Sea Tight Gas: Strategy', June 2017
} 

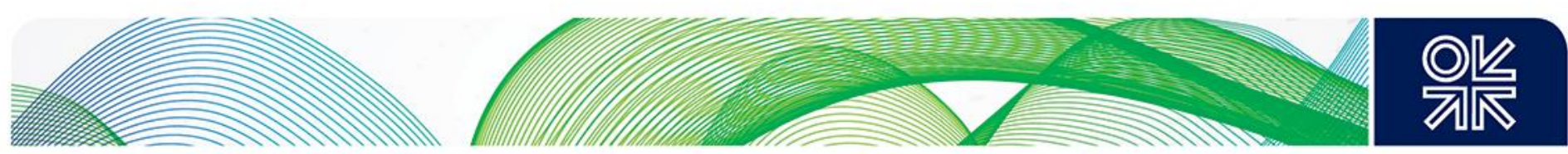

infrastructure which lies at risk in the 2020s from declining conventional production. The most recent drilling of tight gas prospects has not been encouraging. BP and Premier announced in January 2018 that a well to test the Carboniferous in Block 43/26a had been unsuccessful, setting back efforts the OGA was seeking to promote. The more recent weakness in gas prices has reinforced the pessimistic outlook for tight gas, at least for the time being.

In August 2018, Premier Oil and its licence partner Dana decided to sanction the development of the Tolmount Main gas field, the largest undeveloped field in the SNS. Gross reserves at the field, discovered in 2011, are estimated to be $14 \mathrm{bcm}$ (500 bcf) and the Greater Tolmount Area is estimated to contain about 1 tcf. The sanctioned project involves the construction of a new pipeline and an innovative financing arrangement involving a private equity-backed infrastructure partner (CATS) and use of the existing Centrica-operated terminal at Easington. First gas is expected by 2021 and planned peak output implies an annual contribution of more than $2 \mathrm{bcm}$ per year in 2021-22. Further appraisal drilling of the Greater Tolmount Area is scheduled in 2019.

There is potential for further developments even as the most mature fields are progressively decommissioned. Ineos is considering a second phase of development of the Breagh field, commissioned in 2013, to add new onshore compression and to extend field production. Spirit Energy has drawn up plans for a tie-back of the Pegasus West discovery to the Cygnus Alpha platform and Independent Oil \& Gas (IOG) is expected to seek approval from the OGA to proceed with development of the Vulcan and Blythe fields. Spirit Energy is also seeking to exploit opportunities around the Cygnus field and to alleviate the problem of a lack of 'blend gas' which has curtailed output from Cygnus at times in 2017-18. So far, OGA efforts to encourage consolidation and alignment of licenses to develop 'small pools' in the SNS, notably in the West Sole Area, have not yet borne fruit.

In June 2017, Centrica Storage announced that it was no longer economic to operate the ageing Rough storage facility and began the process to seek all relevant consents and approvals to extract the recoverable cushion gas from the reservoir. In January 2018, the OGA granted a production licence, effectively replacing the storage licence, and gave its consent to produce all the remaining gas and NGLs. Authorised small-scale gas production began in 2015 after the identification of well integrity problems at the storage facility and continued in 2016. In 2017, after the reduction in operational storage capacity, Rough production increased to $0.7 \mathrm{bcm}$ (25 bcf) and in 2018 , under the new production licence, it rose further to $1.1 \mathrm{bcm}$ (39 bcf).

The recoverable gas reserves in Rough declined from $5.2 \mathrm{bcm}$ (182 tcf) at the end of 2014, before the technical problems emerged, to $2.9 \mathrm{bcm}$ (103 bcf) at the end of 2018. Since reservoir pressure declines as the cushion gas is extracted, the future rate of production is not expected to match the rate in 2018. Centrica expects production in 2019 will be $0.6-0.8 \mathrm{bcm}$. Rough production will continue for several more years until the remaining reserves are no longer economically recoverable.

As the OGA indicated in 2017, gas output from the SNS may decline to less than $3 \mathrm{bcm}$ in 2030 unless some of the potential it has identified is realised. ${ }^{53}$ For the OGA, the SNS represents a particular challenge in pursuing MER UK and in ensuring that the expected decommissioning of gas infrastructure minimises the stranding of discovered resources and does not leave prospective areas or horizons unexplored. The start-up of Tolmount in 2021 and the prospect of further additions from Vulcan/Blythe and other fields, will briefly arrest the long-established decline in SNS production in 2021-22. SNS dry gas production will remain more vulnerable than other parts of the UKCS to a protracted period of low gas prices in the 2020s. From $14.4 \mathrm{bcm}$ in 2017 , SNS gross gas production is projected to fall to about $10 \mathrm{bcm}$ in 2024.

\footnotetext{
53 'Maximising recovery from the SNS', OGA presentation to SNS Conference 2017
} 

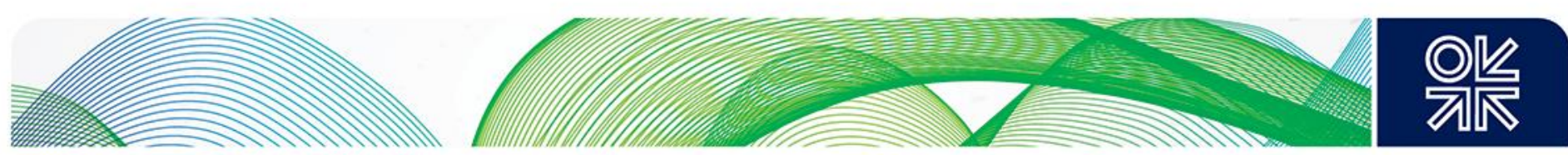

\section{Irish Sea}

The first discovery of gas in the Irish Sea was made by British Gas in 1974 and the first production from the South Morecambe field was brought ashore in 1985. The smaller North Morecambe field was developed in 1994 through a second onshore terminal at Morecambe and smaller discoveries of dry gas were later tied into this infrastructure. Further south in Liverpool Bay, a series of discoveries in the early 1990s of both oil and gas fields led to the construction of the Point of Ayr terminal which handled both dry and associated gas flows. At its peak, gas production from the Irish Sea fields via the three onshore terminals exceeded $15 \mathrm{bcm}$ in 2000. Since then, it has followed an almost uninterrupted decline to about $1.5 \mathrm{bcm}$ in 2018 . No discovery of economically recoverable oil or gas has been made in the basin since 2009 and drilling has effectively ceased.

The economic life of offshore operations and onshore infrastructure is gradually drawing to a close but there remains a concern that such infrastructure should not be closed prematurely. The main operator, Spirit Energy (formerly Centrica), has decommissioned offshore unmanned platforms and onshore facilities in recent years to reduce the operating costs borne by declining production volumes. The South Morecambe onshore gas terminal was closed in 2016. As in the SNS, there is a risk that some gas reserves will be left stranded if the two principal operators in Morecambe Bay, Spirit Energy and ConocoPhillips, pursue only their own individual interests under their legacy commercial contracts. The OGA is promoting an Area Plan to find a solution which creates an optimal outcome for the area as a whole and extends the operating life of existing assets. This may entail its intervention to re-allocate economic value between existing operators. Even if the OGA succeeds, we expect that gas output from the Irish Sea will cease by the mid-2020s.

\section{Central North Sea (CNS)}

The CNS is the largest gas-producing region of the UKCS, accounting for about $40 \%$ of total gross production each year since 2004. In 2017, estimated gross output from the CNS was $17 \mathrm{bcm}$, most of which was produced as associated gas from oil fields and gas condensate fields. Gas from CNS fields is delivered ashore through the CATS pipeline to Teesside, through the SAGE and Fulmar pipelines to St Fergus or, in the case of the Elgin-Franklin and Shearwater gas condensate fields, via the SEAL line to Bacton. The Forties liquids pipeline system, now owned and operated by Ineos, is also an essential piece of infrastructure since most gas production in the central CNS is dependent on liquids export via the Forties system. In February 2019, Ineos committed itself to a $£ 500$ million modernisation programme on the ageing Forties system to extend its operating life by at least 20 years. ${ }^{54}$ This is expected to facilitate and underpin oil and gas production by CNS resource holders into the 2030s.

The main producing fields in the CNS are currently Elgin and Franklin, operated by Total, Shearwater (Shell), Everest and Lomond (Shell) and the Britannia and J-Block fields (formerly ConocoPhillips, now Chrysaor). All these fields serve as major offshore infrastructure hubs for adjacent fields. ElginFranklin and Shearwater, located in the Central Graben, were among the first HPHT fields to be developed in the CNS. Output from Elgin-Franklin was severely curtailed after a very serious gas leak at the Elgin field in 2012 and it was not until 2018 that approval was given for a full restoration of production after completion of an extensive three-year redevelopment project. ${ }^{55}$

The largest gas project currently under development on the UKCS, the Culzean HPHT gas condensate field, also lies in the Central Graben area of the CNS. The operator Total estimates recoverable resources at Culzean are 250-300 million boe. Discovered by Maersk in 2008 and approved for development in 2015 after the introduction of the Cluster Area Allowance, this high-cost field is expected to produce $60-90,000$ boe/d, of which about $80 \%$ will be gas. At plateau in $2020-21$, Culzean is expected to produce about $4 \mathrm{bcm}$ per year, making it the largest gas-producing field on the UKCS. The first production from Culzean began in June 2019.

\footnotetext{
54 'INEOS to invest $£ 500$ million in the Forties Pipeline System', INEOS press release 27 February 2019.

${ }^{55}$ Total E\&P UK Limited Elgin Field Increase in Production: Environmental Statement Summary, OPRED, 2017.
} 

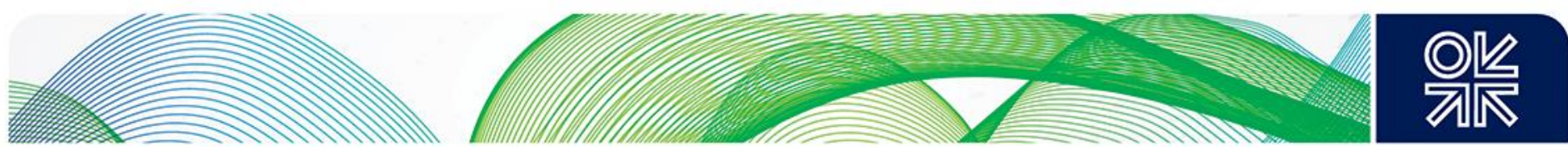

Figure 21: Central North Sea Gross Gas Production 2010-2024

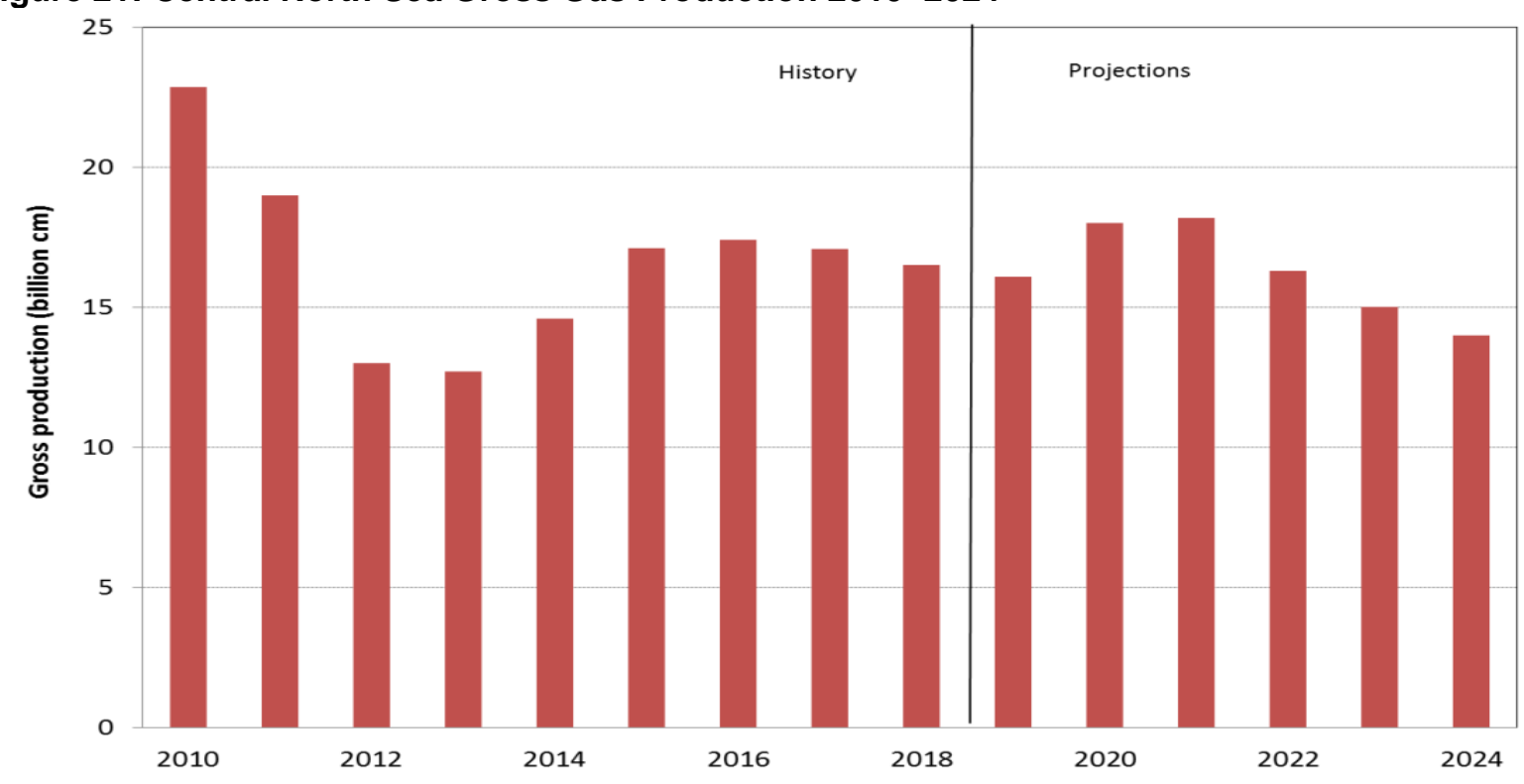

Source: UK DUKES, BEIS 2010-18 and author's projections

Shell is undertaking a major project in the Central Graben area to tie in three adjacent gas condensate fields (Fram, Arran and Columbus) to the Shearwater hub in 2020. It will also 're-plumb' gas flows from the Shearwater hub by connecting the Fulmar gas line (FGL) to Shearwater so that in future liquids-rich gas from Shearwater will flow east via the SEGAL system to St Fergus rather than south through the SEAL to Bacton. This will allow the value of wet gas from fields connected to Shearwater to be fully realised through the extraction of NGLs at St Fergus. Shell has confirmed that if it decides to develop the ultra-HPHT Jackdaw field, it will also be tied back to the Shearwater hub. The project is currently at the pre-FEED stage.

In January 2019, CNOOC announced the Glengorm discovery in the Central Graben area. Resources at this gas condensate discovery were initially estimated to be 'close to 250 million mboe', a figure which will have to be confirmed by further appraisal drilling before the partners explore the wide range of development options using adjacent infrastructure. ${ }^{56}$ Neither Jackdaw nor Glengorm is expected to be on stream before 2023-24. The scale of the projects currently under development in the CNS is expected to ensure that gas output will increase between 2018 and 2021, more than offsetting the natural decline at existing producing fields, before beginning to decline once again thereafter (see figure 21).

\section{Northern North Sea (NNS)}

Gross gas output from this highly mature, mainly oil-producing region stabilised between 2012 and 2018 at 5-6 bcm per year, having peaked in 2002 at $24 \mathrm{bcm}$. The main gas-producing fields in 2017 and 2018 were Rhum, Bruce, Jura and the late-life Statfjord field which straddles the UK/Norwegian median line. Production from the once-prolific Brent field had dwindled to negligible volumes by 2018 in anticipation of decommissioning. Gas produced and not used as fuel or re-injected locally is transported via the FUKA, FLAGS or Frigg UK pipelines to St Fergus.

In recent years, the main concern over gas for NNS operators has been its availability for use as a fuel at local oil field facilities as associated gas output declined. In 2014-15, offshore operators in the 

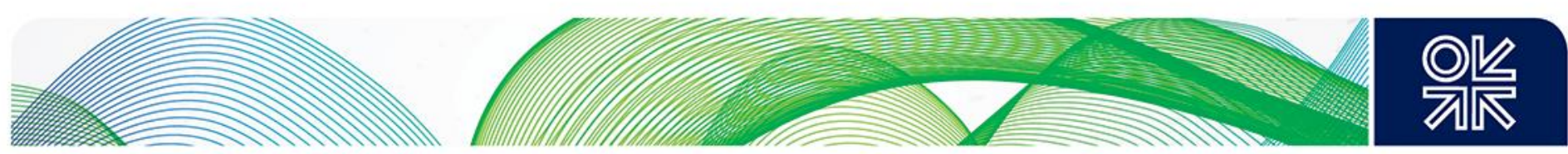

NNS formed the NNS Operational Gas Group to share fuel gas and to contract for new supply from adjacent Norwegian fields. Drilling and new project activity had been minimal in the NNS for several years but in 2018, Shell and ExxonMobil sanctioned the redevelopment of the Penguins oil and gas field which is expected to extend the life of this remote northerly field. The project entails the installation of a new FPSO and the re-routing of gas flows which previously passed through the Brent processing facilities.

The acquisition by Serica Energy of operating and non-operating interests in Bruce, Keith and Rhum fields in 2018 also offers the prospect of future investment and co-ordinated late-life management of the three fields. Rhum is co-owned by the National Iranian Oil Company (NIOC) and has been forced to shut for extended periods in recent years due to US sanctions against Iran. In 2017, unrestricted by US sanctions, Rhum produced $1.3 \mathrm{bcm}$ of gas, making it one of the largest gas-producing fields on the UKCS. Another area of the NNS where there is potential to increase gas production and to extend the life of producing fields is in the Greater Harding area incorporating the Harding, Morrone, Gryphon and Tullich oil fields. This has been designated by the OGA as the Quad 9 Area Plan to co-ordinate the recovery of the sizeable gas cap at these fields. Progress on the cross-licence issues has apparently so far has been limited but the prize of a co-ordinated blowdown of the accumulated gas resources remains. Barring further restrictions on Rhum output, we expect total NNS gas production will resume its gradual decline and to fall below 4 bcm in 2024 .

\section{West of Shetland (WoS)}

The area west of Shetland is the least mature area of the UKCS and its remoteness, water depth, severe winter weather and complex geology have provided economic barriers to development since the first exploration wells were drilled in the 1970s. Most resource discoveries and field development projects in the region so far have been of higher value oil, not of gas. Unlike much of the North Sea, this remains a core region for the oil majors, notably BP, Shell and Total, because of its exploration and growth potential. ${ }^{57}$

Gross gas production in 2018, largely from the Greater Laggan Area gas condensate fields, was an estimated $5 \mathrm{bcm}$, about $12 \%$ of total UKCS output. Yet the region offers perhaps the greatest potential for future gas discoveries and growth in commercial gas production in the 2020s from development of both discovered and undiscovered resources. The OGA estimates that just $8 \%$ of existing UKCS gas reserves lie west of Shetland but more than a third of undiscovered gas resources.

The first oil fields developed by BP and Shell west of Shetland, Foinavon (1997), Schiehallion (1998) and Clair (2005) used associated gas as fuel in offshore operations or reinjected it into the reservoir. Only after the construction of the West of Shetland Pipeline (WOSP), approved in 2000, was gas transported first to Shetland and then to the Magnus oil field in the NNS as part of the Magnus EOR project. The prospects for large-scale gas exports to the mainland were transformed by Total's decision in 2010 to develop the Laggan and Tormore gas condensate fields. The Shetland Gas Plant (SGP) was constructed to process up to $6 \mathrm{bcm}$ per year of gas which is then transported via the Shetland Island Regional Gas Export (SIRGE) pipeline to St Fergus. Production from Laggan and Tormore began in 2016, to which Total added ouput from two smaller fields, Edradour and Glenlivet, in 2017. The adjacent Glendronach discovery in 2018 is estimated to hold 170 mboe (1 tcf) of recoverable gas. After further appraisal, Total is expected to confirm development of Glendronach, possibly as early as 2020 , and will drill an exploration well on the nearby Ballechin prospect in 2019.58

\footnotetext{
57 'Why is West of Shetland the UK's final frontier for oil and gas growth?' Wood Mackenzie, SPE Aberdeen conference, December 2018.

58 'Total eyes more wells in wake of Glendronach', Upstream 26 September 2018.
} 

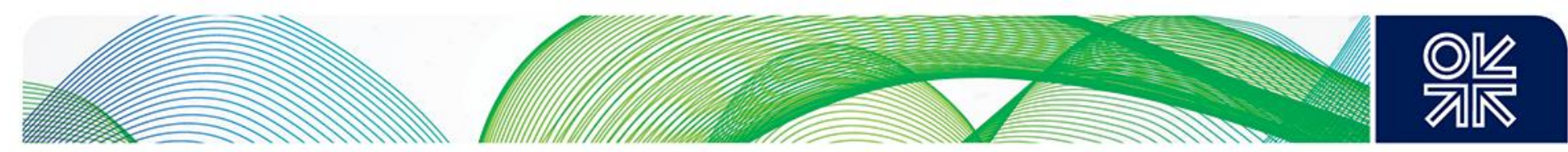

Figure 22: West of Shetland Oil and Gas Resources

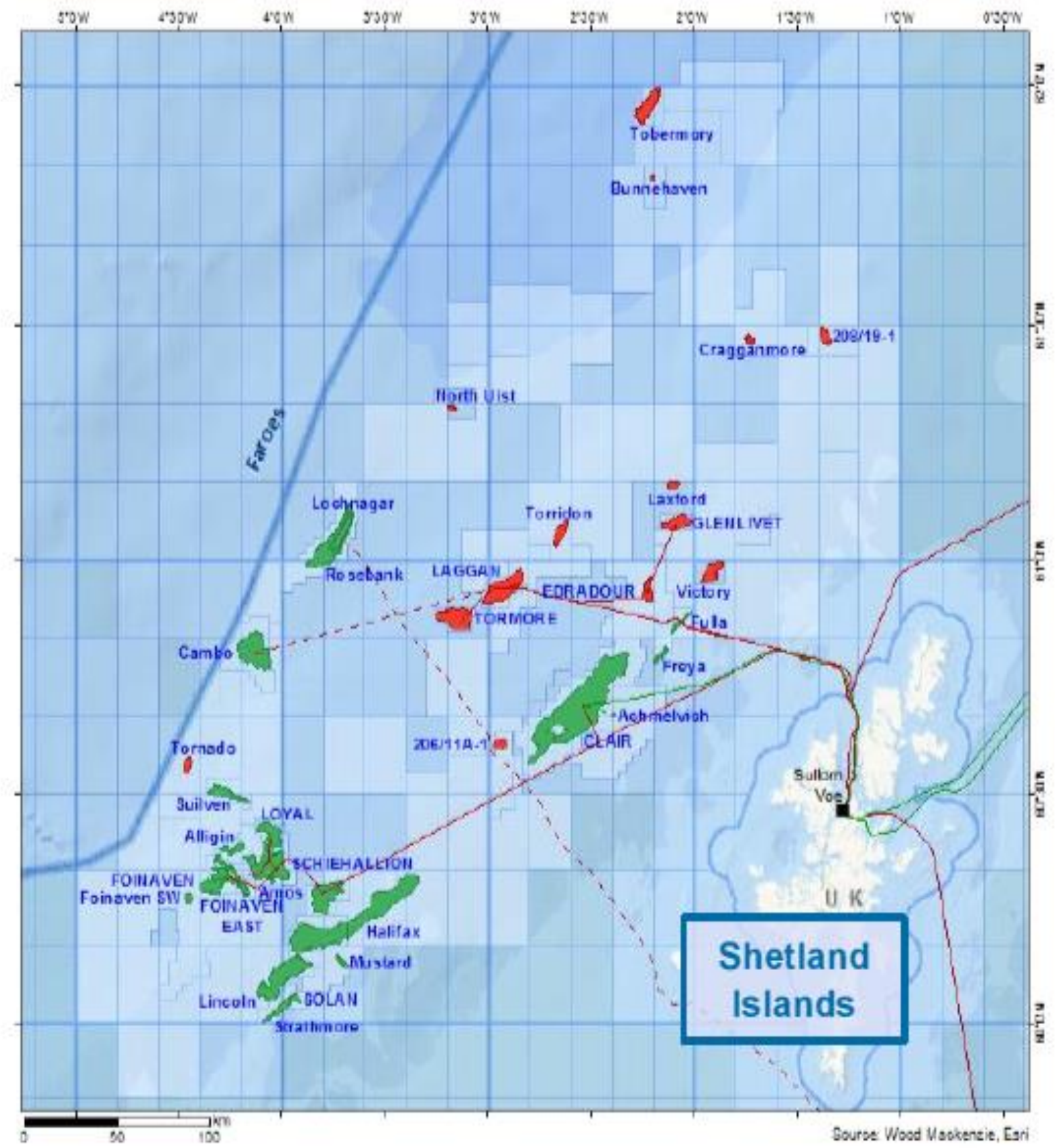

Source: Wood Mackenzie

Beyond the Greater Laggan area, the most likely prospect of new gas development west of Shetland currently lies in the Cambo field, discovered in 2002 and now operated by Siccar Point Energy. If the project proceeds, oil would be produced through an FPSO in a first phase and the associated gas would be exported through a separate export pipeline tied into existing infrastructure in a later phase. It was once expected that Cambo would be developed in conjunction with the Rosebank field to the north-east, which remains the largest undeveloped discovery on the UKCS (300 mboe of oil and gas). In its original plans, the Rosebank operator Chevron planned a new gas export pipeline to tie directly into the SIRGE line to St Fergus without landing the gas in Shetland. The decision by Chevron in 2014 to halt the project and the subsequent sale in 2018 of its $40 \%$ operating interest to Equinor (formerly Statoil) has set the project back several years. After securing a three-year extension to the 

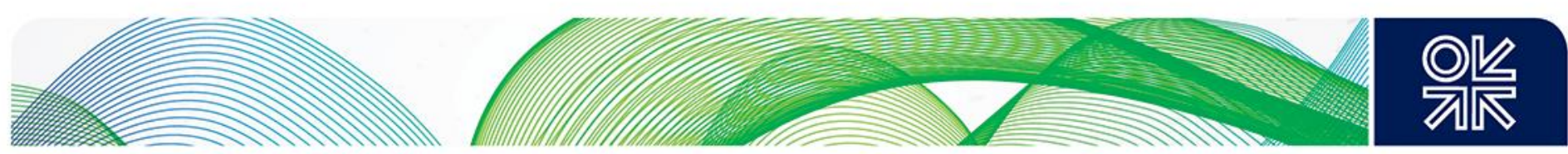

Rosebank licences from the OGA, Equinor announced in June 2019 that a final investment decision (FID) is not expected before 2022 as it seeks to reduce development costs. This means that first gas production from Rosebank is not likely before 2025-26. ${ }^{59}$

Further to the north, four existing gas discoveries (Tobermory, Bunnehaven, Cragganmore and Lyon) form what has become the Northern Gas Area of the WoS. The key to future development will be the addition of further resources and shared gas infrastructure investment to bring transport gas to Shetland. The drilling of the geologically promising Lyon prospect in 2019 may, if successful, unlock these discoveries and bring them closer to development.

Gas resource development west of Shetland is currently restricted by existing infrastructure. The OGA has a potentially important role to play in promoting the optimal use or expansion of existing infrastructure (WOSP, the Laggan-Tormore pipeline, SGP and SIRGE) and in encouraging licence consolidation and joint investment in new infrastructure. ${ }^{60}$ It initiated the WoS Gas Area Plan and has urged licence operators to collaborate more closely, particularly over infrastructure where it envisages greater integration of gas export systems east and west of Shetland. ${ }^{61}$ Such cooperation makes economic sense in the context of MER UK but may be difficult to achieve while operators' assessments of the resource base are still being modified through exploration and project redesign. It may also be complicated by the potential demand for fuel gas for the large existing and planned oil projects west of Shetland such as Quad 204 (Schiehallion/Loyal) and Clair Ridge/Clair South from the late 2020s. West of Shetland gas will indeed provide a demanding test of the OGA's ability to achieve MER UK in this least mature region of the UKCS.

\section{Conclusions}

The UKCS has undergone a period of rapid change between 2015 and 2019, the effects of which are expected to be seen in the next few years. The bold fiscal reforms in 2016, the introduction of MER UK and the creation of the OGA are directly attributable to reforms by government but the industry too has played its part by reducing its cost base, improving the reliability of its offshore operations and successfully commissioning major new oil and gas projects. The outlook for UKCS investment, resource recovery and future production has improved significantly but, as a relatively high-cost producing province, it will remain highly sensitive to oil and gas prices and the ability of the UKCS to attract new capital investment in a competitive international upstream market.

Barring a major resource discovery of 1-2 billion barrels, it is difficult to envisage even a temporary reversal of the expected long-term decline in UKCS oil and gas production from an extended peak of $1.8 \mathrm{mboe} / \mathrm{d}$ in 2018-20. Gas production is expected to continue at about $40 \mathrm{bcm}$ per year until 2021 as production from new fields such as Culzean and Tolmount and the development of recent gas discoveries largely offset the progressive decline from existing fields in the mature areas of CNS and SNS. Thereafter, we expect the decline in gas production will resume, falling to $33 \mathrm{bcm}$ in 2024 . At present, only west of Shetland is there a realistic prospect of higher gas production in the mid-2020s but further discoveries may of course revise this picture.

The introduction of MER UK into UK statute law and the creation of the OGA with new legal powers marked a fundamental change from the previous 'light touch' regulatory regime. The objective of improved economic recovery from UKCS resources is sensible and well-intentioned but the reforms come late in the life of the UKCS. The contribution of more active regulation to greater resource recovery will be limited by the maturity of much of the North Sea and the constraints imposed by commercial development decisions taken long ago with no regard for MER UK.

\footnotetext{
59 'Equinor looking to make the most out of Rosebank', Upstream 6 June 2019

60 'UKCS and NCS towards 2030 - a world of opportunities', OGA presentation, February 2019

61 'UK operators urged to look at bigger gas picture', Upstream, 11 September 2018
} 

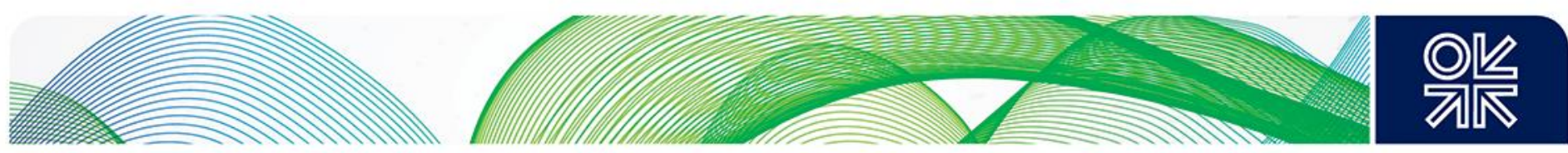

Ultimately, the success or failure of MER UK will depend on the ability of the UKCS to attract new capital investment into the sector, particularly for exploration, and to prevent the premature withdrawal of invested capital through decommissioning of infrastructure that undermines future exploration or production. The risk will remain that investors, particularly a new generation of private equity investors with different financial priorities and opportunities than the major oil companies, will find better opportunities elsewhere. Averting 'premature' decommissioning of infrastructure in mature parts of the UKCS is likely to present a particular difficulty for the OGA, particularly where lower-value gas production is concerned. In less mature areas, such as west of Shetland, the potential influence of the OGA on value maximisation and resource recovery, particularly on new gas infrastructure investment, is much greater.

Both future investment in exploration and infrastructure decommissioning will depend in part on the prevailing tax rates and the particular tax treatment of such expenditure. On tax matters, the OGA is an advisor to government and in the UK political system tax rates will always be subject to revision by successive governments. Realising MER UK will require not only fine judgment by the OGA on regulatory issues but the willingness of future governments to maintain a stable and competitive upstream tax regime.

The impact of MER UK on resource development and production will be gradual, cumulative and perhaps visible only in the 2020s. The 'hard economics' of the UKCS (costs, prices and taxes) will remain the primary motors of company investment activity and economic value creation. MER UK alone will not be sufficient to 'transform' investment and resource recovery on the UKCS; such a transformation could be realised only by an extended period of fiscal stability and continuous rigorous control of operating costs by industry operators. It is essential that the industry averts another damaging cycle of escalating costs and declining profitability if the UKCS is to remain internationally competitive. For the time being, the signs are favourable but the rate at which late-life fields become uneconomic will not diminish and upward pressure on unit operating costs may re-emerge in the 2020s. The real test will come if oil and gas prices fall again and stay low for a protracted period.

The OGA came into existence at an opportune time, during a severe downturn which forced the UKCS industry into a bout of self-examination and urgent cost reduction. In its first four years, it has generally adopted a sensible, pragmatic approach in laying the foundations of the new regime and in setting industry expectations. It has rightly focused on improving data reporting, transparency and access, on promoting better asset stewardship and on providing guidance on how it intends to interpret its obligations under MER UK. It deserves credit for its reforms to licensing and in improving data availability, and its initiative to ensure decommissioning costs are minimised should be welcomed by industry and taxpayers alike. In seeking to exercise its influence, rather than its formal legal powers, the OGA has so far acted as a behavioural regulator, seeking to change operators' commercial behaviour and, more ambitiously, to promote a new, more co-operative 'culture'. Its array of sanctions to ensure compliance with MER UK remains largely untested.

There are now signs that the OGA will introduce a new phase of more assertive regulation in order to address identified 'examples of behaviour which threaten MER UK' and to overcome commercial delays and obstacles which frustrate its efforts. ${ }^{62}$ In March 2019, the Government appointed Tim Eggar as the new Chairman of the OGA. It remains to be seen how the new chairman, a strong defender of the liberal upstream regime as energy minister in the 1990s, will guide the strategy of the OGA. Whatever the approach adopted, the OGA will have to reconcile competing pressures on it and to strike a proper balance between using its formal powers and avoiding possible damaging effects on future investment through its intervention.

Exploration is the life-blood of any hydrocarbon producing province. Revitalising exploration and appraisal activity before offshore infrastructure is decommissioned is perhaps the most difficult and urgent task facing the OGA. The UK tax regime offers no particular fiscal incentive for exploration of

\footnotetext{
${ }^{62}$ Open letter from OGA to licensees and infrastructure owners, OGA website, 4 June 2019
} 

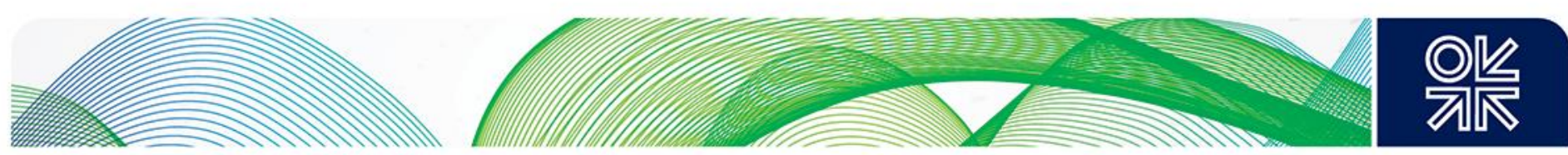

the kind which exists in Norway and there is no 'quick fix' to counter the industry's low propensity to invest in exploration. Recent discoveries, reforms to licensing, lower tax rates and better data availability appear to have stimulated some new interest but only exploration success is likely to sustain a recovery into the 2020 s.

It is far too early to say with confidence what impact MER UK and the OGA might have on ultimate resource recovery from the UKCS. The regulatory reforms were introduced after about $65-80 \%$ of the estimated ultimate recoverable resources of the UKCS (54-66 bn boe) had already been produced and only 10-20 bn boe remained to be recovered. The 'rules of the game' have been changed rather late in the game but perhaps not too late for the OGA to effect some beneficial changes. In the last four years, OGA estimates of cumulative production in the period 2016-50 have been revised up from $8 \mathrm{bn}$ boe to 12 bn boe and the most optimistic of projections currently stand at 15 bn boe. However, the baseline projections made in March 2015 marked a particularly pessimistic view of the outlook for the UKCS and should not be used as a reliable basis for measuring the contribution of the recent reforms.

There are good reasons for greater optimism today than in 2015 but these projections are highly sensitive to assumptions about commodity prices, costs, taxation and future investment behaviour. At present, there appears to be a willingness to anticipate success and to attribute the improved outlook since 2015 to the introduction of MER UK when in fact the improvement is rooted in the industry response to lower prices and the reduction in tax rates. Measuring the contribution of MER UK will always be a difficult and contentious exercise since there is no reliable way to isolate the contribution of regulation and no clearly defined counter-factual; we cannot know what would have happened in its absence. It is perhaps more useful to view MER UK in conjunction with the fiscal reforms of 2015-16 and the accompanying, more gradual changes in the ownership and business models of industry operators.

As the UK government recognises, MER UK is entirely consistent with the progressive decarbonisation of the UK economy towards the new 'net zero emissions' target in 2050. The energyintensive UK upstream industry currently accounts for about 3\% of UK GHG emissions and its total emissions are expected to decline broadly in line with production. Only Norwegian supply to the UK has a consistently lower upstream emissions intensity than domestic UKCS production. As the Committee on Climate Change acknowledges, decarbonisation of the UK economy is consistent with the continued use of natural gas if carbon capture and storage (CCS) is deployed to capture $\mathrm{CO}_{2}$ emissions from industry, power generation or hydrogen production.

The remit of the OGA includes a role supporting the UK's transition to a low-carbon economy. ${ }^{63}$ It is the designated licensor of $\mathrm{CO}_{2}$ storage at offshore locations on the UKCS and is responsible for ensuring that its flaring and venting regime is consistent with government policy on GHG emissions. As the energy transition proceeds, there is a risk for both UKCS resource holders and for the delivery of MER UK that the competitive position of the UKCS is undermined by unilateral policy measures which impose emission costs on operators which are not faced by imported sources. The OGA has a part to play in the 'global energy transition' but it is essential that it is not distracted from its statutory focus on MER UK by political concerns which portray the UKCS merely as source of GHG emissions or by decarbonisation policies which encourage carbon leakage and greater dependence on imported sources of oil and gas with higher upstream GHG emissions. 

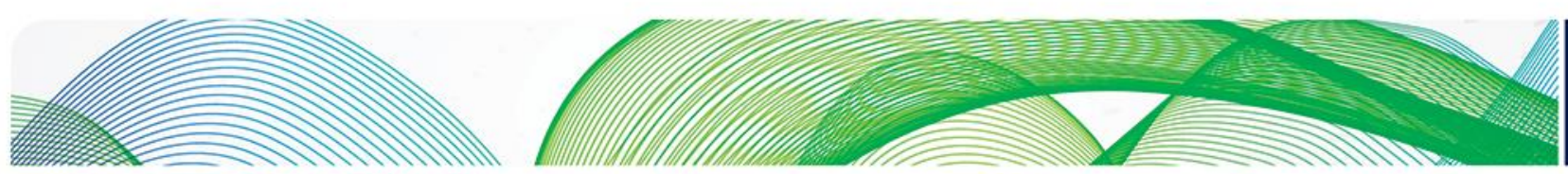

\section{잊조}

\section{Sources and Bibliography}

The Official History of North Sea Oil and Gas, Volumes 1 and 2, Alex Kemp (2012)

The Resurgence of UK Gas Production, Michael Stoppard, OIES paper (1994)

Digest of UK Energy Statistics 2018 (DUKES), Department of Business, Energy and Industrial Strategy (BEIS)

An Economic Assessment of the Long Term Prospects for the UKCS: Can Vision 2035 Become a Reality? Alex Kemp and Linda Stephen, North Sea occasional paper no 143, Aberdeen Centre for Research in Energy Economics and Finance (ACREEF), October 2018

Can Long Term Activity in the UKCS Really be Transformed? A Kemp and L Stephen, North Sea occasional paper no. 139, ACREEF, April 2017.

Driving Investment: A Plan to Reform the Oil and Gas Fiscal Regime, HM Treasury, December 2014

Statistics of Government Revenues from Oil and Gas Production, HMRC, 2018 and 2019 